\section{Pacific Northwest}

National Laboratory

Operated by Battelle for the

U.S. Department of Energy

\title{
Assessment of Tank 241-S-112 \\ Liquid Waste Mixing in Tank 241-SY-101
}

\author{
Y. Onishi \\ D. S. Trent \\ B. E. Wells \\ L. A. Mahoney
}

September 2003

Prepared for the U.S. Department of Energy under Contract DE-AC06-76RL01830 


\section{DISCLAIMER}

This report was prepared as an account of work sponsored by an agency of the United States Government. Neither the United States Government nor any agency thereof, nor Battelle Memorial Institute nor any of their employees makes any warranty, express or implied, or assumes any legal liability or responsibility for the accuracy, completeness, or usefulness of any information, apparatus, product, or process disclosed or represents that its use would not infringe privately owned rights. Reference herein to any specific commercial product, process, or service by trade name, trademark, manufacturer, or otherwise does not necessarily constitute or imply its endorsement, recommendation, or favoring by the United States Government or any agency thereof, or Battelle Memorial Institute. The views and opinions of authors expressed herein do not necessarily state or reflect those of the United States Government or any agency thereof.

\section{PACIFIC NORTHWEST NATIONAL LABORATORY \\ operated by \\ BATTELLE \\ for the}

\section{UNITED STATES DEPARTMENT OF ENERGY under Contract DE-AC06-76RL01830}

Printed in the United States of America

Available to DOE and DOE contractors from the Office of Scientific and Technical Information,

P.O. Box 62, Oak Ridge, TN 37831-0062;

ph: (865) 576-8401

fax: (865) 576-5728

email: reports@adonis.osti.gov

Available to the public from the National Technical Information Service,

U.S. Department of Commerce, 5285 Port Royal Rd., Springfield, VA 22161

ph: (800) 553-6847

fax: (703) 605-6900

email: orders@ntis.fedworld.gov

online ordering: http://www.ntis.gov/ordering.htm

This document was printed on recycled paper.

$(8 / 00)$ 


\section{Assessment of Tank 241-S-112 \\ Liquid Waste Mixing in Tank 241-SY-101}

Y. Onishi

D. S. Trent

B. E. Wells

L. A. Mahoney

September 2003

Prepared for

the U.S. Department of Energy

under Contract DE-AC06-76RL01830

Pacific Northwest National Laboratory

Richland, WA 99352 


\section{Summary}

The objectives of this study were to evaluate mixing of liquid waste from Tank 241-S-112 (S-112) with supernatant liquid waste in Tank 241-SY-101 (SY-101) and to determine the properties of the resulting mixed supernatant waste. The assessment was performed to assess potential double-shell tank corrosion and pipeline plugging during cross-site transfer. We applied the time-varying, three-dimensional computer code, TEMPEST, to Tank SY-101 to model the injection and mixing of the S-112 liquid waste.

Predicted three-dimensional temperature distributions in Tank SY-101 before S-112 waste addition indicate that the coolest temperature occurs along the tank wall and the hottest around the mid-depth of the solids layers, away from the tank wall. The predicted maximum temperature of the SY-101 sludge is $80.4^{\circ} \mathrm{F}$; the liquid waste layer has a nearly uniform temperature, varying within a fraction of $1^{\circ} \mathrm{F}$. These values are close to those measured in July 2003 , even though there is considerable scatter and uncertainty in the measured temperatures.

The modeling predicts that temperature variations within Tank SY-101 generate a natural convection flow. This flow is very slow, varying from about $7 \times 10^{-5}$ to $1 \times 10^{-3} \mathrm{ft} / \mathrm{sec}(0.3 \sim 4 \mathrm{ft} / \mathrm{hr})$ in most areas. Thus, the natural convection flow would eventually mix the liquid waste in Tank SY-101 but it would take a long time to achieve nearly complete mixing.

The velocity induced by combined S-112 waste injection and natural convection is still very small in most areas, of the order of $1 \times 10^{-4} \mathrm{ft} / \mathrm{sec}(0.4 \mathrm{ft} / \mathrm{hr})$ to $2 \times 10^{-3} \mathrm{ft} / \mathrm{sec}(7 \mathrm{ft} / \mathrm{hr})$, so mixing of S-112 and SY-101 liquid wastes is slow even with the S-112 waste being injected into the tank. After the transfer into Tank SY-101 of 115,200 gallons (one day of waste transfer at $80 \mathrm{gpm}$ ) of S-112 waste with a density of $1.35 \mathrm{~g} / \mathrm{mL}$, the resulting liquid waste in SY-101 is expected to have 11 to $12 \% \mathrm{~S}-112$ liquid and the rest SY-101 supernatant. This corresponds to $\mathrm{NO}_{2}{ }^{-}, \mathrm{NO}_{3}{ }^{-}$, and $\mathrm{OH}^{-}$concentrations of 46,700 47,000, 143,000 144,000, and 16,400 16,500 $\mu \mathrm{g} / \mathrm{mL}$, respectively. The waste withdrawn by the SY-101 transfer pump, whose inlet is 102 inches from the bottom of the tank, contains $20 \sim 22 \%$ S-112 waste after one day. This waste would have $\mathrm{NO}_{2}{ }^{-}, \mathrm{NO}_{3}{ }^{-}$, and $\mathrm{OH}^{-}$concentrations of 43,400 44,000, 151,000 153,000, and 16,000 $\sim 16,100 \mu \mathrm{g} / \mathrm{mL}$, respectively.

When lighter S-112 waste with a density of $1.25 \mathrm{~g} / \mathrm{mL}$ was injected into SY-101, the S-112 jet hardly penetrated the SY-101 waste but spread horizontally around the SY-101 liquid waste surface. The strongly nonuniform distribution of S-112 waste did not change much even after one day of waste transfer operations. The minimum S-112 concentration in the tank and in the waste withdrawn by the pump after one day of waste transfer are 2.9 and $3.3 \%$, respectively. The mixture contains $\mathrm{NO}_{2}^{-}, \mathrm{NO}_{3}^{-}$, and $\mathrm{OH}^{-}$concentrations of 47,700, 140,000, and $22,300 \mu \mathrm{g} / \mathrm{mL}$, respectively. 
These simulations indicate that the mixing of S-112 and SY-101 liquid wastes in Tank SY-101 is a very slow process and that the density difference between the two wastes further limits waste mixing. 


\section{Contents}

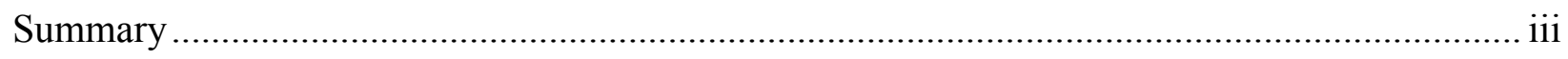

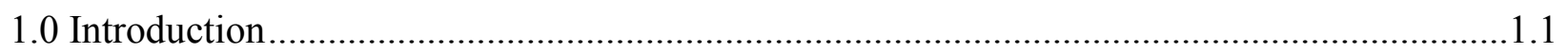

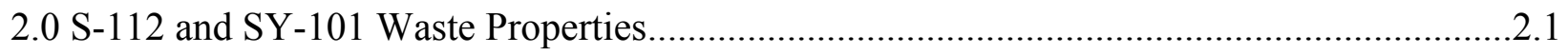

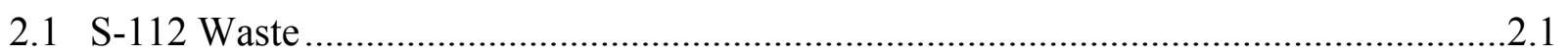

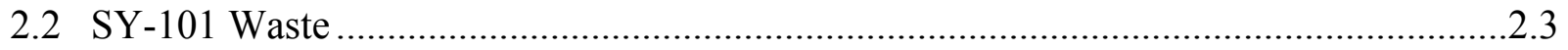

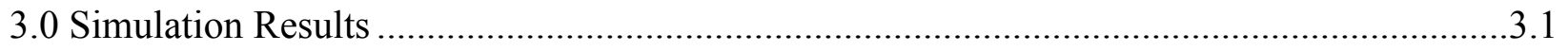

3.1 Modeling Approach ...............................................................................................

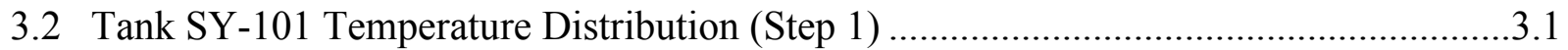

3.3 Natural Convection in Tank SY-101 (Step 2)...........................................................

3.4 Mixing of Equal-Density S-112 and SY-101 Wastes (Step 3) .....................................

3.5 Mixing S-112 and SY-101 Wastes of Unequal-Densities (Step 4).............................3.23

3.5.1 Slightly Warmer S-112 Waste .........................................................................23

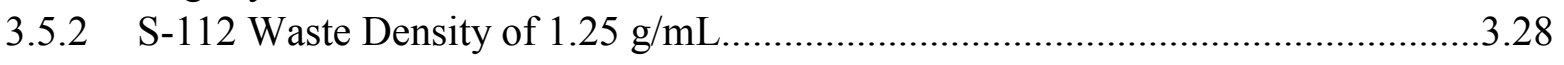

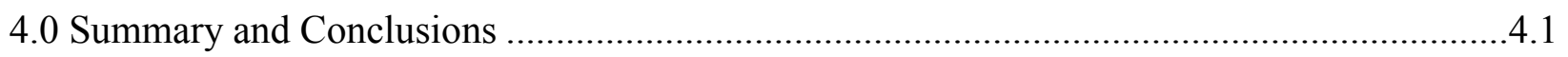

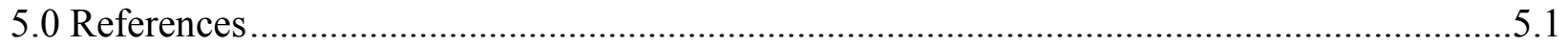




\section{Figures}

2.1 Measured/Predicted Aqueous Species of Interstitial Solution of S-112 Saltcake ...........2.2

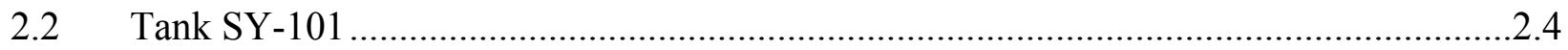

2.3 Identified Post-Mitigation SY-101 Solid Phases ......................................................2.5

2.4 Gamma Count Profile of SY-101 Waste ..................................................................2.6

2.5 Temperature Profile History of SY-101 Waste in Riser 17C .....................................2.7

3.1 Predicted Temperature Distributions in SY-101 and Surrounding Area ........................3.3

3.2 Predicted Temperature Distributions of SY-101 Solid and Liquid Waste Layers............3.3

3.3 SY-101 Waste Temperature Distribution Along Riser 17B on July 1, 2003.................3.4

3.4 SY-101 Waste Temperature Distribution Along Riser 17C on July 1, 2003...................5

3.5 Predicted Temperature Distributions of SY-101 Solid and Liquid Layers

Along 3 O'Clock Azimuthal Position.....................................................................

3.6 Predicted Temperature Distributions of SY-101 Solid and Liquid Layers

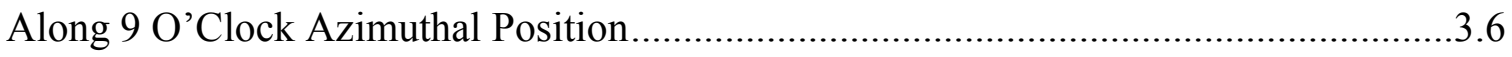

3.7 Predicted SY-101 Natural Convection Flow and Temperature Distribution

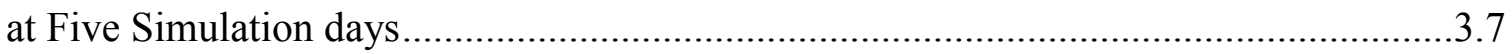

3.8 Predicted SY-101 Natural Convection Flow and Temperature Distribution

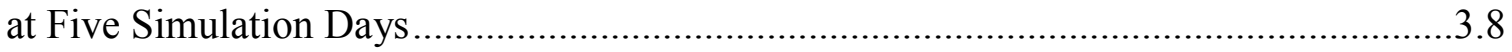

Estimated S-112 Waste Jet Spread in Air ................................................................. 3.9

3.10 Predicted Vertical Distributions of Flow and Temperature along 3 O'clock Position at 12 Simulation $\mathrm{hr}$ for Injection of $1.35-\mathrm{g} / \mathrm{mL} \mathrm{S}-112$ Waste ..........................10

3.11 Predicted Vertical Distributions of Flow and Temperature along 12 O'clock Position at 12 Simulation hr for Injection of $1.35-\mathrm{g} / \mathrm{mL} \mathrm{S}-112$ Waste

3.12 Predicted Vertical Distributions of Flow and Temperature Along 9 O'clock Position at 12 Simulation hr for Injection of $1.35-\mathrm{g} / \mathrm{mL} \mathrm{S}-112$ Waste

3.13 Predicted Vertical Distributions of Flow and Concentration Along 3 O'clock Position at 12 Simulation $\mathrm{hr}$ for Injection of $1.35-\mathrm{g} / \mathrm{mL} \mathrm{S}-112$ Waste

3.14 Predicted Horizontal Distributions of Flow and Concentration on SY-101

Sludge Surface at 12 Simulation hr for Injection of $1.35-\mathrm{g} / \mathrm{mL}$ S-112 Waste.

3.15 Predicted Vertical Distributions of Flow and Concentration Immediately Next to 3 O'clock Position at 12 Simulation hr for Injection of $1.35-\mathrm{g} / \mathrm{mL}$ S-112 Waste ...........3.14

3.16 Predicted Vertical Distributions of Flow and Concentration Along 12 O'clock Position at 12 Simulation $\mathrm{hr}$ for Injection of $1.35-\mathrm{g} / \mathrm{mL} \mathrm{S}-112$ Waste.

3.17 Predicted Vertical Distributions of Flow and Concentration Immediately Next to 9 O'clock Position at12 Simulation hr for Injection of $1.35-\mathrm{g} / \mathrm{mL} \mathrm{S}-112$ Waste.

3.18 Predicted Vertical Distributions of Flow and Concentration Along 9 O'clock Position at 12 Simulation hr for Injection of $1.35-\mathrm{g} / \mathrm{mL} \mathrm{S}-112$ Waste

3.19 Predicted Horizontal Distribution of Flow and Concentration at Transfer Pump Inlet Elevation at 12 Simulation hr for Injection of $1.35-\mathrm{g} / \mathrm{mL} \mathrm{S-112} \mathrm{Waste}$

3.20 Predicted Horizontal Distribution of Flow and Concentration at Mid-Depth of SY-101 Liquid at 12 Simulation hr for Injection of $1.35-\mathrm{g} / \mathrm{mL} \mathrm{S}-112$ Waste. 
3.21 Predicted Horizontal Distributions of Flow and Concentration Just Below

Liquid Surface at 12 Simulation $\mathrm{hr}$ for Injection of $1.35-\mathrm{g} / \mathrm{mL} \mathrm{S}-112$ Waste

3.22 Predicted Vertical Distributions of Flow and Concentration Along 3 O'clock

Position at One Simulation Day for Injection of $1.35-\mathrm{g} / \mathrm{mL} \mathrm{S}-112$ Waste

3.23 Predicted Horizontal Distributions of Flow and Concentration on SY-101

Sludge Surface at One Simulation Day for Injection of $1.35-\mathrm{g} / \mathrm{mL}$ S-112 Waste..........3.19

3.24 Predicted Vertical Distributions of Flow and Concentration Immediately Next to

3 O'clock Position at One Simulation Day for Injection of 1.35-g/mL S-112 Waste....3.19

3.25 Predicted Vertical Distributions of Flow and Concentration Along 12 O'clock

Position at One Simulation Day for Injection of $1.35-\mathrm{g} / \mathrm{mL} \mathrm{S}-112$ Waste

3.26 Predicted Vertical Distributions of Flow and Concentration Immediately Next to

9 O'clock Position at One Simulation Day for Injection of 1.35-g/mL S-112 Waste....3.20

3.27 Predicted Vertical Distributions of Flow and Concentration Along 9 O'clock

Position at One Simulation Day for Injection of $1.35-\mathrm{g} / \mathrm{mL} \mathrm{S}-112$ Waste.

3.28 Predicted Horizontal Distributions of Flow and Concentration at Transfer Pump

Inlet Elevation at One Simulation Day for Injection of $1.35-\mathrm{g} / \mathrm{mL} \mathrm{S}-112$ Waste

3.29 Predicted Horizontal Distributions of Flow and Concentration at Mid-Depth of

SY-101 Liquid at One Simulation Day for Injection of 1.35-g/mL S-112 Waste

3.30 Predicted Horizontal Distributions of Flow and Concentration Just Below Liquid

Waste Surface at One Simulation Day for Injection of $1.35-\mathrm{g} / \mathrm{mL} \mathrm{S}-112$ Waste............3.22

3.31 Predicted Vertical Distributions of Flow and Concentration Along 3 O'clock

Position at 12 Simulation hr for Slightly Lighter S-112 Waste Injection

3.32 Predicted Vertical Distributions of Flow and Concentration Along the 12 O'clock

Position at 12 Simulation hr for Slightly Lighter S-112 Waste Injection.......................3.24

3.33 Predicted Vertical Distributions of Flow and Concentration Along the 9 O'clock Position at 12 Simulation hr for Slightly Lighter S-112 Waste Injection..........................25

3.34 Predicted Horizontal Distributions of Flow and Concentration at the Mid-Depth of SY-101 Liquid Waste at 12 Simulation hr for Slightly Lighter S-112 Waste

3.35 Predicted Vertical Distributions of Flow and Concentration Along 3 O'clock

Position at One Simulation Day for Slightly Lighter S-112 Waste Injection.

3.36 Predicted Vertical Distributions of Flow and Concentration Along 12 O'clock Position at One Simulation Day for Slightly Lighter S-112 Waste Injection.

3.37 Predicted Vertical Distributions of Flow and Concentration Along 9 O'clock

Position at One Simulation Day for Slightly Lighter S-112 Waste Injection.

3.38 Predicted Horizontal Distributions of Flow and Concentration at Mid-Depth of SY-101 Liquid Waste at One Simulation Day for Slightly Lighter S-112 Waste...........3.28

3.39 Predicted Vertical Distributions of Flow and Concentration Along 3 O'clock Position at 12 Simulation hr for Injection of $1.25-\mathrm{g} / \mathrm{mL} \mathrm{S}-112$ Waste

3.40 Predicted Vertical Distributions of Flow and Concentration Along 12 O'clock Position at 12 Simulation hr for Injection of $1.25-\mathrm{g} / \mathrm{mL} \mathrm{S}-112$ Waste

3.41 Predicted Vertical Distributions of Flow and Concentration Along 9 O'clock Position at 12 Simulation hr for Injection of $1.25-\mathrm{g} / \mathrm{mL} \mathrm{S}-112$ Waste. 
3.42 Predicted Vertical Distributions of Flow and Concentration Along 3 O'clock Position at One Simulation Day for Injection of $1.25-\mathrm{g} / \mathrm{mL} \mathrm{S}-112$ Waste

3.43 Predicted Vertical Distributions of Flow and Concentration Along 12 O'clock Position at One Simulation Day for Injection of $1.25-\mathrm{g} / \mathrm{mL} \mathrm{S}-112$ Waste

3.44 Predicted Vertical Distributions of Flow and Concentration Along 9 O'clock Position at One Simulation Day for Injection of $1.25-\mathrm{g} / \mathrm{mL} \mathrm{S}-112$ Waste

\section{Tables}

2.1 Chemical Compositions and Their Concentrations for S-112 Supernatant Liquid .2 .1

3.1 S-112 and SY-101 Waste Properties for Case 1 3.8

3.2 Conversion of S-112 Waste Fraction to $\mathrm{NO}_{2}{ }^{-}, \mathrm{NO}_{3}{ }^{-}$, and $\mathrm{OH}^{-}$Concentrations, Case 1.3.12

$3.4 \quad$ S-112 and SY-101 Waste Properties for Case 2 …………..........................................28

3.5 Conversion of S-112 Waste Fraction to $\mathrm{NO}_{2}{ }^{-}, \mathrm{NO}_{3}{ }^{-}$, and $\mathrm{OH}^{-}$Concentrations ................3.29

4.1 S-112 and SY-101 Liquid Waste Characteristics ............................................................ 


\subsection{Introduction}

Waste dissolution with water and saltwell pumping is used to retrieve the radioactive waste stored in single-shell tank (SST) 241-S-112 (S-112) in the 200 West Area of the Hanford Site in southeastern Washington State. This retrieval method adds water to Tank S-112 to dissolve the saltcake and pumps the resulting liquid out of the tank (Herting and Bechtold 2002). The retrieved liquid waste is planned to be transferred to double-shell tank (DST) 241-SY-101 (SY101) also located in the 200 West Area. The mixture of S-112 and SY-101 wastes will then be transferred to the 200 East Area of the Hanford Site through a 6.2-mile, 3-inch-diameter, stainless steel cross-site transfer pipeline for subsequent waste treatment. To avoid corrosion of the DST tank walls and plugging of the cross-site transfer pipeline, the wastes must meet specific requirements (e.g., $\mathrm{NO}_{2}^{-}, \mathrm{NO}_{3}^{-}$, and $\mathrm{OH}^{-}$concentrations in the DSTs and density and solid weight percent) for using the cross-site supernatant pipeline).

The following four main factors are expected to affect flow in the supernatant liquid layer of Tank SY-101:

- density difference (due to temperature difference) existing in SY-101 before the injection of S-112 waste

- S-112 waste injection (at the expected rate of $80 \mathrm{gpm}$ )

- waste withdrawal from SY-101 (at the expected rate of $60 \mathrm{gpm}$ )

- possible density difference between SY-101 waste and S-112 wastes (because the S-112 waste enters at the top of the SY-101 supernatant layer, mixing would be suppressed by the lower-density S-112 liquid.

The objectives of this study were to assess the mixing of S-112 liquid waste in SY-101 and to determine the waste properties of the resulting liquid waste to assess flow for cross-site transfer. We applied the time-varying, three-dimensional computer code, TEMPEST (Onishi and Trent 1999) to model Tank SY-101 receiving the S-112 liquid waste. We conducted this assessment in the following modeling sequence:

- Predict current SY-101 temperature distributions, mainly affected by heat generation in convective and nonconvective wastes, ventilation air in annular and dome spaces, and heat loss/gain through the surrounding soil.

- Predict a natural convection flow in SY-101 without S-112 waste.

- Predict the mixing of S-112 and SY-101 wastes in Tank SY-101.

Section 2 presents S-112 and SY-101 waste characteristics. Section 3 discusses the SY-101 model and its simulation results. The summary and conclusions are presented in Section 4, and cited references are listed in Section 5. 


\subsection{S-112 and SY-101 Waste Properties}

\section{$2.1 \quad$ S-112 Waste}

The S-112 tank waste is mostly saltcake, consisting of solids and interstitial solution. The waste mostly contains Al, Cl, F, Cr, K, Na, P, S, Si, inorganic carbon, and organic carbon, based on the Hanford Tank Waste Information System (TWINS) database. Thus the liquid waste probably contains $\mathrm{Al}(\mathrm{OH})_{4}^{-}, \mathrm{Cl}^{-}, \mathrm{F}^{-}, \mathrm{OH}^{-}, \mathrm{NO}_{3}{ }^{-}, \mathrm{NO}_{2}{ }^{-}, \mathrm{PO}_{4}{ }^{3-}$, and $\mathrm{SO}_{4}{ }^{2-}$. $\mathrm{S}-112$ 's interstitial solution in the saltcake is expected to be in an equilibrium condition with solids in the saltcake. The elements in the S-112 interstitial solution within the saltcake are shown in Table 2.1 (Onishi 2002). Herting and Bechtold (2002) identified S-112 solids in approximate relative order of abundance: $\mathrm{NaNO}_{3}(\mathrm{~s})>>\mathrm{Na}_{2} \mathrm{CO}_{3} \cdot \mathrm{H}_{2} \mathrm{O}(\mathrm{s})>$ anhydrous $\mathrm{Na}_{2} \mathrm{CO}_{3} \cdot \mathrm{H}_{2} \mathrm{O}(\mathrm{s})>\mathrm{Na}_{6} \mathrm{CO}_{3}\left(\mathrm{SO}_{4}\right)_{2}$ (burkeite) $>>\mathrm{Na}_{3} \mathrm{PO}_{4} \cdot 12 \mathrm{H}_{2} \mathrm{O}(\mathrm{s})$ and unidentified phases of Na-S-rich phase, an Al-rich phase with no association with $\mathrm{Si}$ or $\mathrm{Cr}$, and a trace phase containing $\mathrm{U}-\mathrm{Cr}-\mathrm{Mn}-\mathrm{Fe}$.

Figure 2.1 presents predicted aqueous chemical species of S-112's interstitial solution, which is in equilibrium with $\mathrm{NaNO}_{3}(\mathrm{~s}), \mathrm{Na}_{2} \mathrm{CO}_{3} \cdot \mathrm{H}_{2} \mathrm{O}(\mathrm{s}), \mathrm{Na}_{3} \mathrm{PO}_{4} \cdot 12 \mathrm{H}_{2} \mathrm{O}(\mathrm{s})$, and $\mathrm{NaF}(\mathrm{s})$ solids (Onishi 2002), together with measured or estimated concentrations. This prediction was obtained by applying the equilibrium chemistry chemical model GMIN (Felmy 1995) to Tank S-112. The GMIN code minimizes the Gibbs free energy and uses the Pitzer equations (Harvie et al. 1987) in the aqueous phase modeling to handle tank waste under high ionic-strength conditions.

Table 2.1. Chemical Compositions and Their Concentrations for S-112 Supernatant Liquid (estimated from the TWINS database) (Onishi 2002)

\begin{tabular}{|c|c|c|c|}
\hline Compound & $\begin{array}{c}\text { Measured Concentration } \\
\mu \mathrm{g} / \mathrm{g}\end{array}$ & $\begin{array}{c}\text { Expected } \\
\text { Aqueous Species }\end{array}$ & $\begin{array}{c}\text { Measured or Estimated } \\
\text { Concentration } \\
\text { m }\end{array}$ \\
\hline $\mathrm{Al}$ & 36,867 & $\mathrm{Al}(\mathrm{OH})_{4}^{-}$ & 1.795 \\
\hline $\mathrm{Cr}$ & 13,800 & $\mathrm{Cr}(\mathrm{OH})_{4}{ }^{-}$ & 0.349 \\
\hline $\mathrm{K}$ & 5,280 & $\mathrm{~K}^{+}$ & 0.061 \\
\hline $\mathrm{Na}$ & 238,000 & $\mathrm{Na}^{+}$ & $11.953^{(a)}$ \\
\hline TIC (as $\mathrm{CO}^{3}$ ) & 5,993 & $\mathrm{CO}_{3}{ }^{2-}$ & 0.263 \\
\hline $\mathrm{Si}$ & 1,877 & $\mathrm{H}_{2} \mathrm{SiO}_{4}{ }^{2-}$ & 0.002 \\
\hline \multirow[t]{6}{*}{$\mathrm{Cl}$} & 7,057 & $\mathrm{Cl}^{-}$ & 0.261 \\
\hline & & $\mathrm{NO}_{2}^{-}$ & 1.174 \\
\hline & & $\mathrm{NO}_{3}^{-}$ & 3.570 \\
\hline & & $\mathrm{SO}_{4}{ }^{2-}$ & 0.125 \\
\hline & & $\mathrm{PO}_{4}{ }^{3-}$ & 0.104 \\
\hline & & $\mathrm{OH}^{-}$ & 3.767 \\
\hline
\end{tabular}




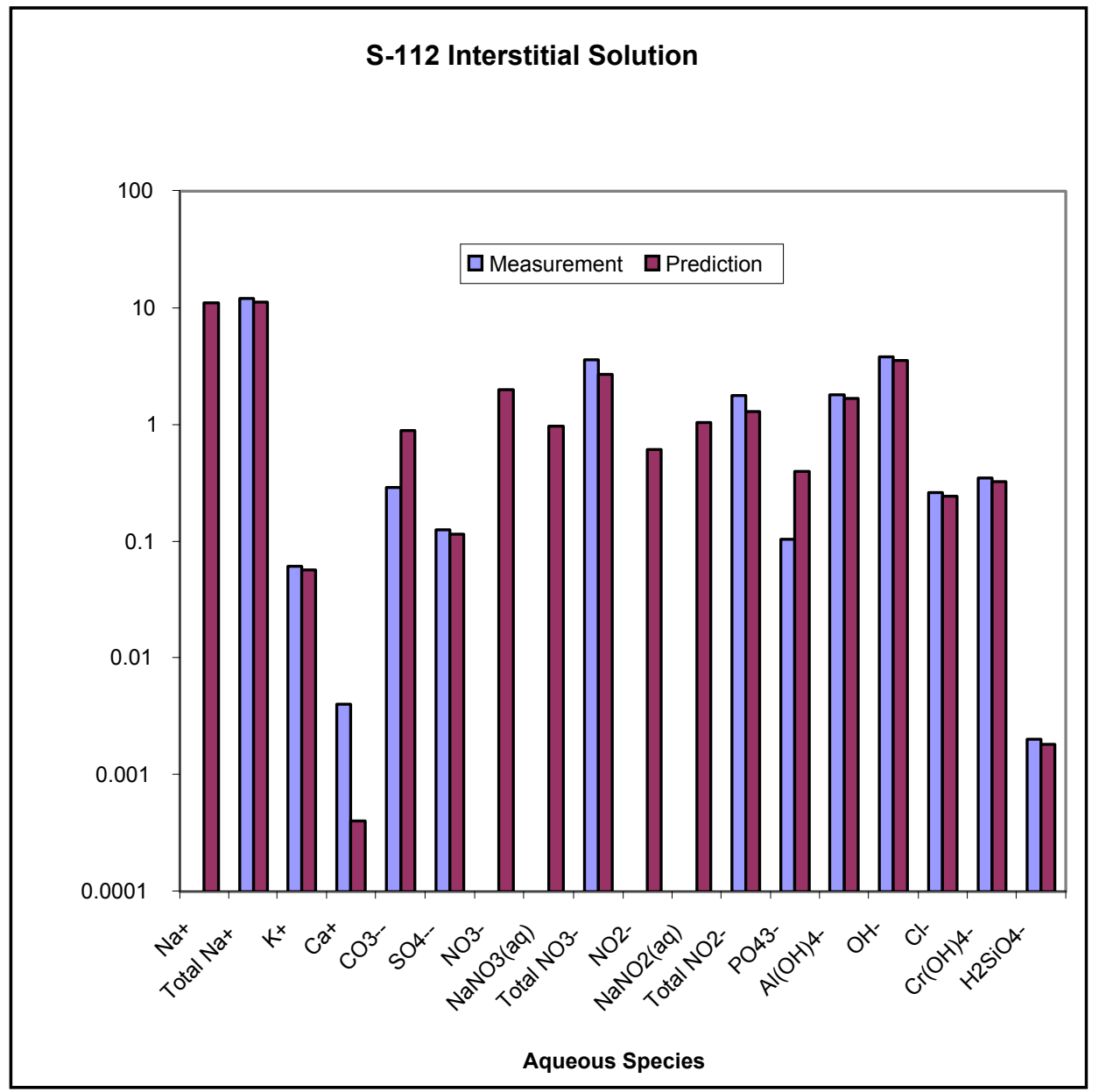

Figure 2.1. Measured (or estimated) and Predicted Aqueous Species of an Interstitial Solution of S-112 Saltcake (Onishi 2002)

The saltwell pumping process dissolves a large amount of saltcake with water, and the resulting solution will be transferred to Tank SY-101. Although the solution chemistry varies during saltwell pumping, the following three $\mathrm{NO}_{2}{ }^{-}, \mathrm{NO}_{3}{ }^{-}$, and $\mathrm{OH}^{-}$concentration levels and corresponding solution densities are possible based on the Hanford Site's compatibility spreadsheets:

- Case 1: S-112 liquid waste

$$
\begin{array}{ll}
\mathrm{NO}^{-} & =17,400 \mu \mathrm{g} / \mathrm{mL} \\
\mathrm{NO}^{-} & =218,000 \mu \mathrm{g} / \mathrm{mL} \\
\mathrm{OH}^{-} & =12,800 \mu \mathrm{g} / \mathrm{mL} \\
\text { Density } & =1.35
\end{array}
$$


- Case 2: S-112 liquid waste

$$
\begin{array}{ll}
\mathrm{NO}^{-} & =5,520 \mu \mathrm{g} / \mathrm{mL} \\
\mathrm{NO}^{-} & =174,000 \mu \mathrm{g} / \mathrm{mL} \\
\mathrm{OH}^{-} & =3,790 \mu \mathrm{g} / \mathrm{mL} \\
\text { Density } & =1.25
\end{array}
$$

- Case 3: S-112 liquid waste

$$
\begin{array}{ll}
\mathrm{NO}^{-} & =360 \mu \mathrm{g} / \mathrm{mL} \\
\mathrm{NO}^{-} & =116,000 \mu \mathrm{g} / \mathrm{mL} \\
\mathrm{OH}^{-} & =350 \mu \mathrm{g} / \mathrm{mL} \\
\text { Density } & =1.10
\end{array}
$$

One of the main concerns about this solution is that $\mathrm{NO}_{2}{ }^{-}, \mathrm{NO}_{3}{ }^{-}$, and $\mathrm{OH}^{-}$concentrations may cause corrosion in Tank SY-101.

\subsection{SY-101 Waste}

Tank SY-101 is an underground DST containing both liquid and solid waste, as shown in Figure 2.2. The tank diameter is $75 \mathrm{ft}(23 \mathrm{~m})$, and the operational tank depth is $35 \mathrm{ft}(10.7 \mathrm{~m})$; thus the tank can contain a little over 1 million gallons $\left(4,000 \mathrm{~m}^{3}\right)$ of waste. As shown in this figure, outdoor air is used to ventilate the tank. One ventilation system runs in the tank dome space at a ventilation rate of $555 \mathrm{cfm}$. The second system is for the annular space between the primary and secondary steel liners of the tank, and it runs at a rate of $275 \mathrm{cfm}$. S-112 liquid waste will be released to the tank though a two-inch-diameter pipe in a riser that is $22 \mathrm{ft}$ from the center of the tank. The mixture of the S-112 and SY-101 wastes will be withdrawn by a waste transfer pump in SY-101 with a 2-inch-diameter inlet located 102 inches above the tank bottom. This configuration is also shown in Figure 2.2.

The amount and composition of the supernatant liquid waste changes as the tank receives new liquid wastes and existing waste is removed. Based on compatibility spreadsheets, the expected concentrations of $\mathrm{NO}_{2}^{-}, \mathrm{NO}_{3}^{-}$, and $\mathrm{OH}^{-}$in the receiving SY-101 liquid wastes, corresponding to the three S-112 cases listed above, are the following:

- Case 1: SY-101 liquid waste

$$
\begin{array}{ll}
\mathrm{NO}_{2}^{-} & =50,700 \mu \mathrm{g} / \mathrm{mL} \\
\mathrm{NO}_{3}{ }^{-} & =134,000 \mu \mathrm{g} / \mathrm{mL} \\
\mathrm{OH}^{-} & =16,900 \mu \mathrm{g} / \mathrm{mL} \\
\text { Density } & =1.35
\end{array}
$$




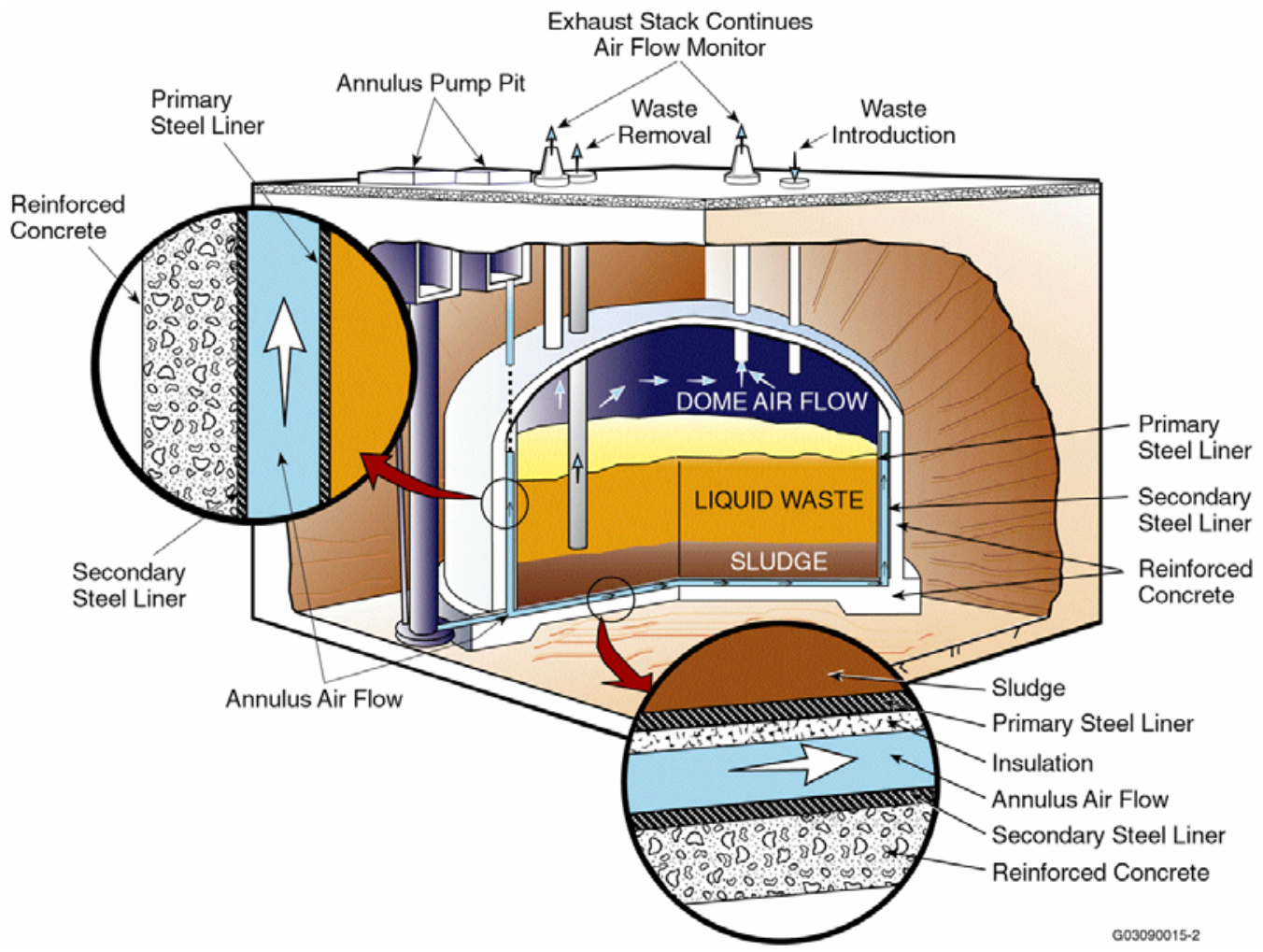

Figure 2.2. Tank SY-101

- Case 2: SY-101 liquid waste

$$
\begin{array}{ll}
\mathrm{NO}_{2}^{-} & =49,000 \mu \mathrm{g} / \mathrm{mL} \\
\mathrm{NO}_{3}{ }^{-} & =138,500 \mu \mathrm{g} / \mathrm{mL} \\
\mathrm{OH}^{-} & =22,900 \mu \mathrm{g} / \mathrm{mL} \\
\text { Density } & =1.35
\end{array}
$$

- Case 3: SY-101 liquid waste

$$
\begin{array}{ll}
\mathrm{NO}_{2}^{-} & =50,500 \mu \mathrm{g} / \mathrm{mL} \\
\mathrm{NO}_{3}{ }^{-} & =123,000 \mu \mathrm{g} / \mathrm{mL} \\
\mathrm{OH}^{-} & =22,000 \mu \mathrm{g} / \mathrm{mL} \\
\text { Density } & =1.35
\end{array}
$$

The liquid viscosity was selected to be $5 \mathrm{cP}$ for this study based on 1991 (Reynolds 1992) and 1998-1999 samples, ${ }^{(a)}$ as suggested in Onishi et al. (2002). Based on the June 2000 grab samples, the liquid density is $1.35 \mathrm{~g} / \mathrm{mL}$ (Johnson et al. 2000). Because natural convection is the

(a) DL Herting. August 21, 2000. Fluor Hanford Inc. Interoffice Memo 8D500-DLH-00-045 to RA Esch. Subject: Microscopy Analysis of SY-101 Grab Samples. 
main flow driver for the SY-101 liquid waste, the SY-101 liquid density must be expressed as a function of the liquid temperature. But we did not find enough accurate data to obtain a densitytemperature relationship based on data. Because $\mathrm{NaNO}_{3}(\mathrm{aq})$ is a major aqueous chemical species of SY-101 waste, we estimated the SY-101 liquid density as a function of temperature, assuming that the variation of the SY-101 liquid density with temperature is the same as that of $\mathrm{NaNO}_{3}(\mathrm{aq})$ solution. We assigned the following correlation for the SY-101 liquid waste in this assessment:

$$
\rho_{\mathrm{L}}=0.0278 \mathrm{~T}+86.4153
$$

where

$\mathrm{T}=$ waste temperature $\left({ }^{\circ} \mathrm{F}\right)$

$\rho_{\mathrm{L}}=\mathrm{SY}-101$ liquid waste density $\left(\mathrm{lb}_{\mathrm{m}} / \mathrm{ft}^{3}\right)$.

The centrifuged solids from the April 2000 grab samples were analyzed by polarized light microscopy (PLM) and scanning electron microscopy with energy-dispersive x-ray spectroscopy (SEM/EDS), ${ }^{(a)}$ as discussed in Johnson et al. (2000). The SY-101 solids identified by PLM and EDS and those identified from the analytical results of the April 2000 grab samples are shown in Figure 2.3.

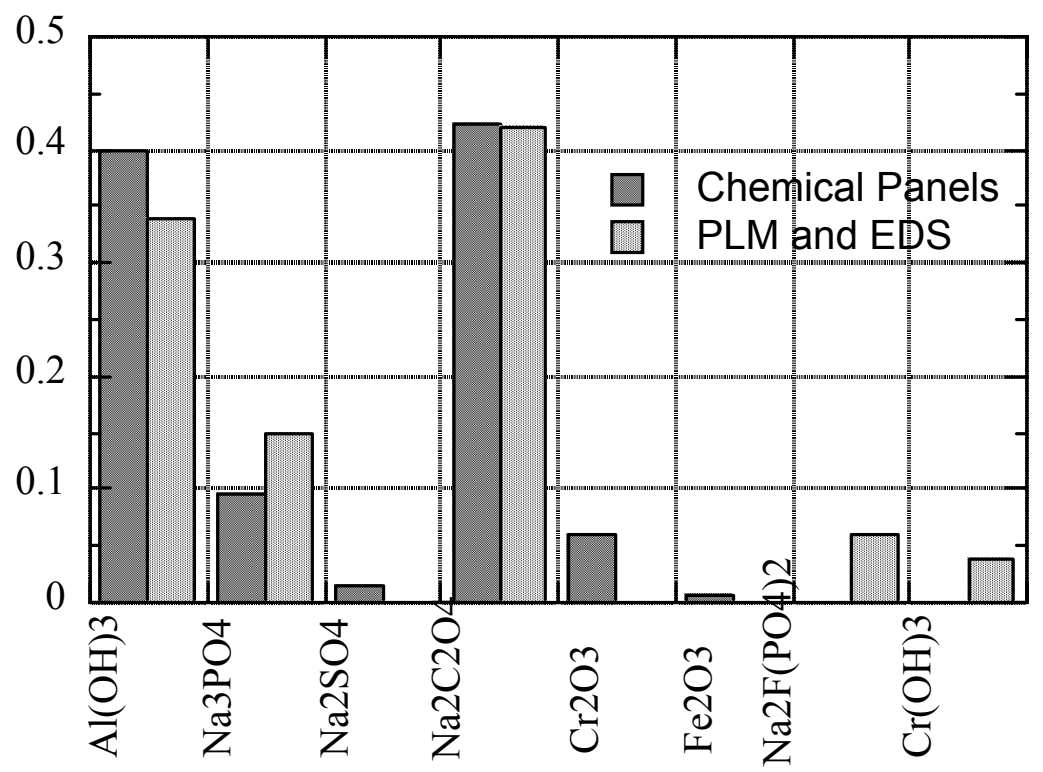

Figure 2.3. Identified Post-Mitigation SY-101 Solid Phases

(a) Fluor Hanford Inc. Interoffice Memo 8D500-DLH-00-052, DL Herting to RA Esch, September 28, 2000. Subject: Microscopy Analysis of SY-101 Grab 2 Samples. 
The bulk dry solid density computed from the individual specie density is approximately $2.2 \mathrm{~g} / \mathrm{mL}$ based on the PLM and EDS analyses and $2.3 \mathrm{~g} / \mathrm{mL}$ from the analytical results on the April 2000 samples (Onishi et al. 2002). The bulk density of the sludge (consisting of these solids and interstitial solution) is $1.5 \mathrm{~g} / \mathrm{mL}$; thus, these solids occupy $17 \mathrm{vol} \%$ of the sludge (using the liquid density of $1.35 \mathrm{~g} / \mathrm{mL}$ ).

The height of the SY-101 settled solid layer is decreasing with time. By October 2000, the settled solids layer height had decreased to 100 inches, from which a bulk density of $1.50 \mathrm{~g} / \mathrm{mL}$ (corresponding to a solid volume fraction of 0.17) can be determined (Johnson et al. 2000). At that time the total waste depth was approximately 350 inches. Examples of gamma counts and thermocouple readings measured in riser 17 in 2001 are shown in Figures 2.4 and 2.5, as plotted by Onishi et al. (2002). These figures indicate that the settled solids layer depth is at or below 100 inches and above 76 inches. The transfer pump inlet height is 102 inches. Thus we selected the sludge thickness to be 88 inches (the average of 100 and 76 inches) for this study.

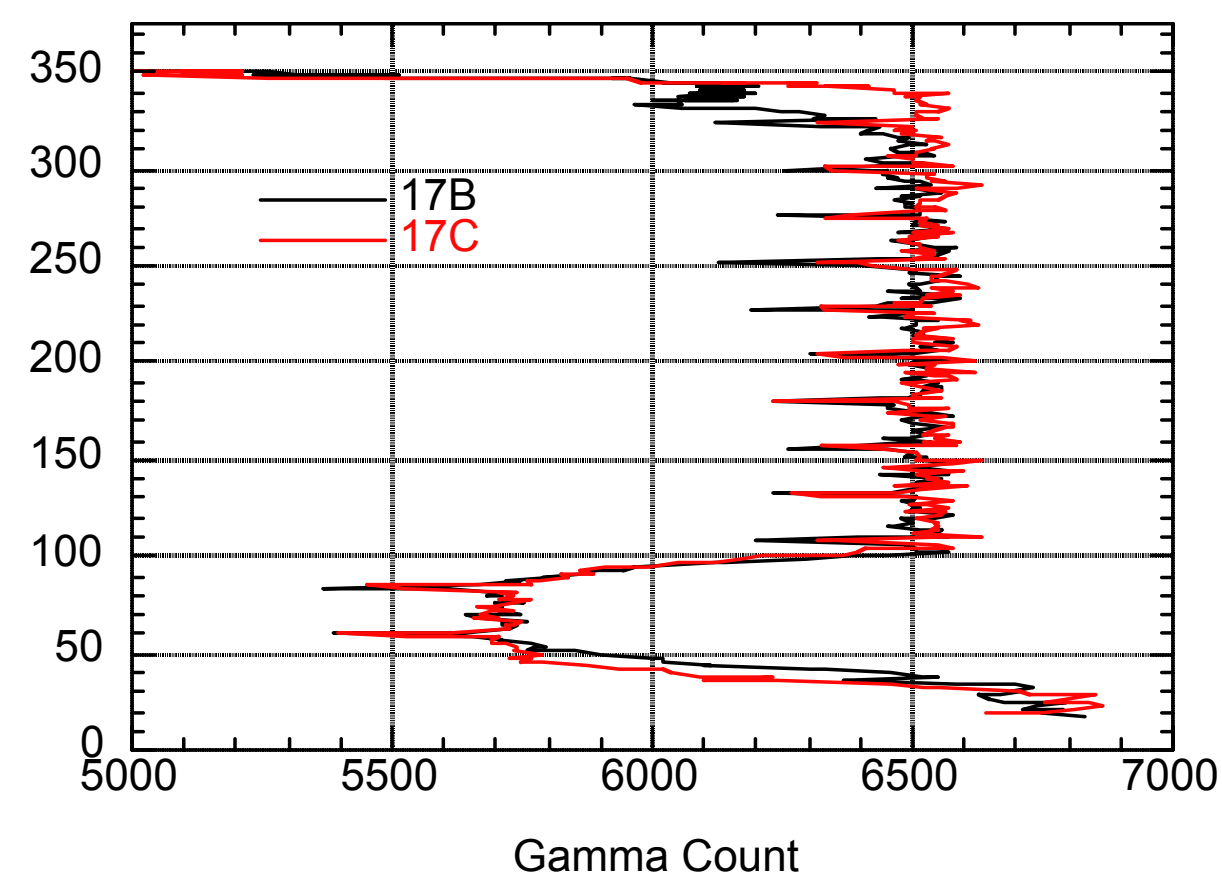

Figure 2.4. Gamma Count Profile of SY-101 Waste

The SY-101 waste generates heat, mostly as a result of the decay of radioactive ${ }^{137} \mathrm{Cs}$. Based on the Hanford compatibility spreadsheets, the waste generates approximately 11,000 Btu of heat when the total waste thickness is 213 inches. Because most of the ${ }^{137} \mathrm{Cs}$ is in a dissolved form, and solids constitute $17 \mathrm{vol} \%$ of the sludge, the supernatant liquid layer could produce $17 \%$ more heat than the same volume of sludge. Nonetheless, as indicated in Figure 2.5, the sludge layer temperature is higher than the supernatant liquid layer temperature because the sludge is less convective and provides self-insulation. 


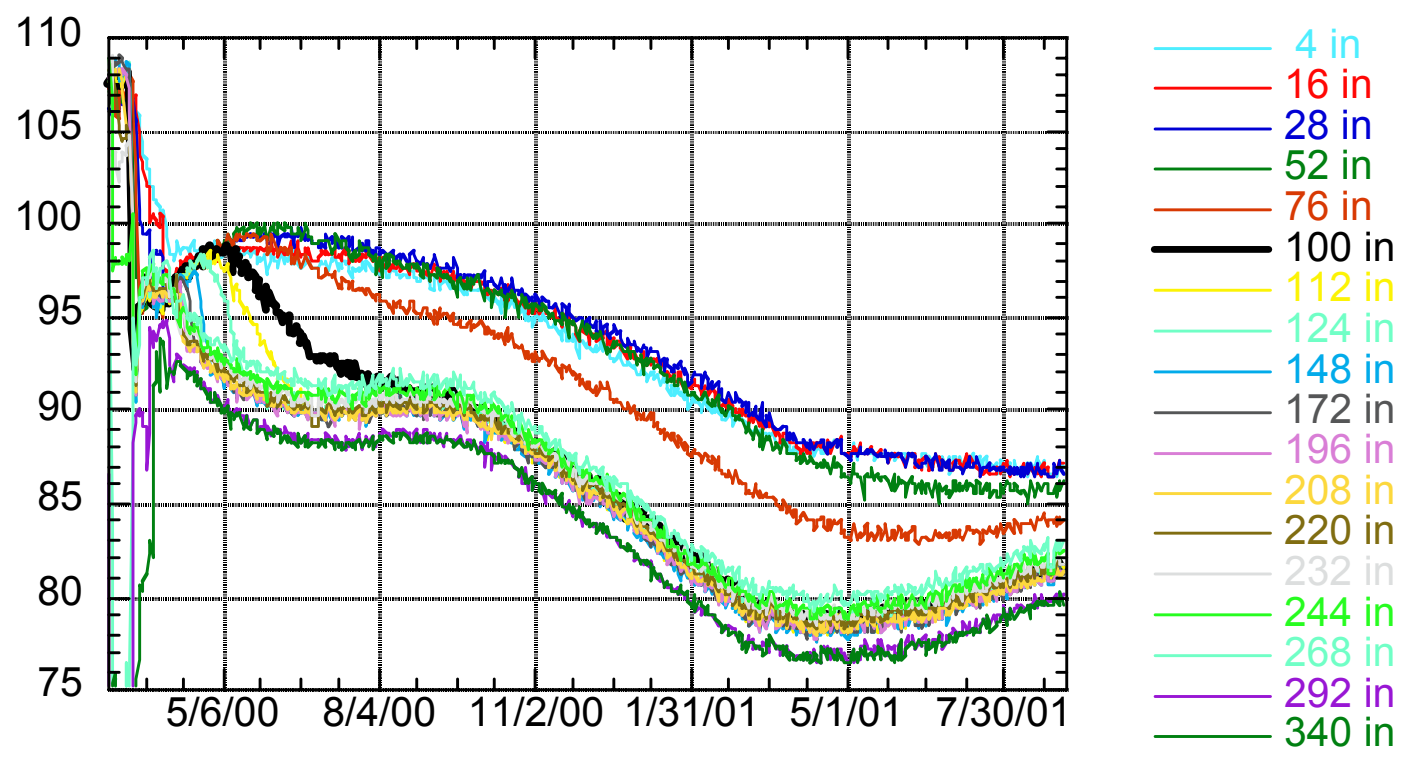

Figure 2.5. Temperature Profile History of SY-101 Waste in Riser 17C 


\subsection{Simulation Results}

\subsection{Modeling Approach}

Four main factors are expected to produce a flow in Tank SY-101, as indicated in Section 1:

- density difference (due to temperature difference) existing in the tank before the S-112 waste is injected

- S-112 waste injection (at the expected rate of $80 \mathrm{gpm}$ )

- waste withdrawal from Tank SY-101 (at expected rate of $60 \mathrm{gpm}$ )

- possible density difference between SY-101 waste and S-112 waste.

Thus we selected the following three-step modeling approach using the TEMPEST code:

- Step 1: Reproduce the temperature distributions exiting in Tank SY-101 before injecting the S-112 waste into the tank.

Step 1.1: Quasi-three dimensional modeling

Step 1.2: Three-dimensional modeling.

- Step 2: Compute expected natural convection of supernatant liquid in the tank.

- Step 3: Predict mixing of S-112 and SY-101 wastes caused by natural convection, S-112 liquid waste injection, and S-112/SY-101 liquid waste withdrawal when the densities of S-112 and SY-101 wastes are the same (Case 1 discussed in Sections 2.1 and 2.2).

- Step 4. Predict mixing of S-112 and SY-101 wastes caused by natural convection, S-112 liquid waste injection, and S-112/SY-101 liquid waste withdrawal when the S-112 waste density is less than that of SY-101 waste (e.g., Cases 2 and 3, discussed in Sections 2.1 and 2.2).

\subsection{Tank SY-101 Temperature Distribution (Step 1)}

The SY-101 waste temperature distributions are affected by decay heat generation, convective heat loss through ventilating air in the dome and annulus spaces, and conductive heat loss through the steel liners, air, insulation and concrete to the surrounding soil (see Figure 2.2). Thus, the SY-101 models to predict the temperature distributions included these SY-101 tank components and the surrounding soil.

The first step (Step 1.1) was to simulate the quasi three-dimensional SY-101 temperature distribution, which is independent of the azimuthal direction. We included only three slices of the tank in the azimuthal direction. 
We assigned the incoming ventilation air a temperature of $70^{\circ} \mathrm{F}$, reflecting the average outdoor air temperature of late August to early September at Hanford. The surrounding soil temperature not affected by the presence of Tank SY-101 was assigned as $60^{\circ} \mathrm{F}$, which is the average soil temperature at Hanford. Because temperature measurements of the liquid layers of most of the heat-generating Hanford wastes are nearly uniform vertically (thus a liquid layer is usually called a "convective" layer), we assigned a large heat conductivity coefficient instead of convecting heat through the moving liquid waste under Step 1. Under Step 2, we simulated the convective flow movement. Under Step 1, we simulated ventilation air movements and the temperature distributions of solids and liquid layers, headspace, primary steel liner, insulation layer, annulus space, secondary steel liner, concrete layer, and surrounding soil. We simulated the SY-101 model long enough to obtain the steady-state air temperature distributions.

Predicted temperature distributions of Tank SY-101 (one half of the tank) and the surrounding soil are shown in Figure 3.1. A colored temperature scale $\left({ }^{\circ} \mathrm{F}\right)$ is shown in the lower part of the figure. Figure 3.2 shows temperatures of only the SY-101 solid and liquid layers, together with the air flow distribution. These figures show the 88 -inch- (2.2-m-) thick sludge and 125-inch- (3.18-m-) thick supernatant liquid layer, totaling 213 inches $(5.41 \mathrm{~m})$ of waste in this tank.

The top of Figure 3.2 shows the time (8.481 simulation hours). Note that we ran this model under a combination of time-varying and steady-state conditions to reach the final steady-state temperature and ventilation air flows; thus the simulation time listed on the figure does not reflect the actual simulation time. The left side of the figure shows the ventilation air coming into the dome and annulus spaces. The right side of the figure describes which vertical plane is shown (in this case the $\mathrm{r}-\mathrm{z}$ plane at $\mathrm{I}=3$, which is the middle vertical slice in the azimuthal direction), and an area of plot coverage on this vertical plane (in this case, $\mathrm{J}=1$ to 24 , indicating the horizontal direction from the pump center to the tank wall, and $\mathrm{K}=8$ to 61 , indicating the vertical direction from the annulus ventilation air inlet to the tank top. Note that the right side of the lower plot also shows temperatures (expressed in ${ }^{\circ} \mathrm{F}$ ) represented by lines 1 through 15 . "Plane min and max" indicate the minimum and maximum values (temperature of $64.71^{\circ}$ and $79.65^{\circ} \mathrm{F}$, respectively, in this case within the plotted plane, while "array min and max" indicate the minimum and maximum temperatures, $60.10^{\circ}$ and $79.65^{\circ} \mathrm{F}$, respectively, encountered within the entire simulation area. At the bottom right, the maximum air velocity on this vertical plane is shown (in this case $0.0157 \mathrm{ft} / \mathrm{sec}$ with its corresponding scale length). All velocity magnitude in this plot is scaled to this magnitude.

As shown in Figures 3.1 and 3.2, the SY-101 model with 11,000 Btu/hr heat load predicted that the temperature of the solid (nonconvective) layer varies from $79.69^{\circ}$ to $77.03^{\circ} \mathrm{F}$, low at both the top and bottom of the solids layer, while the liquid (convective) layer temperature was predicted to be $76.44^{\circ} \mathrm{F}$ during late August —early September conditions. 


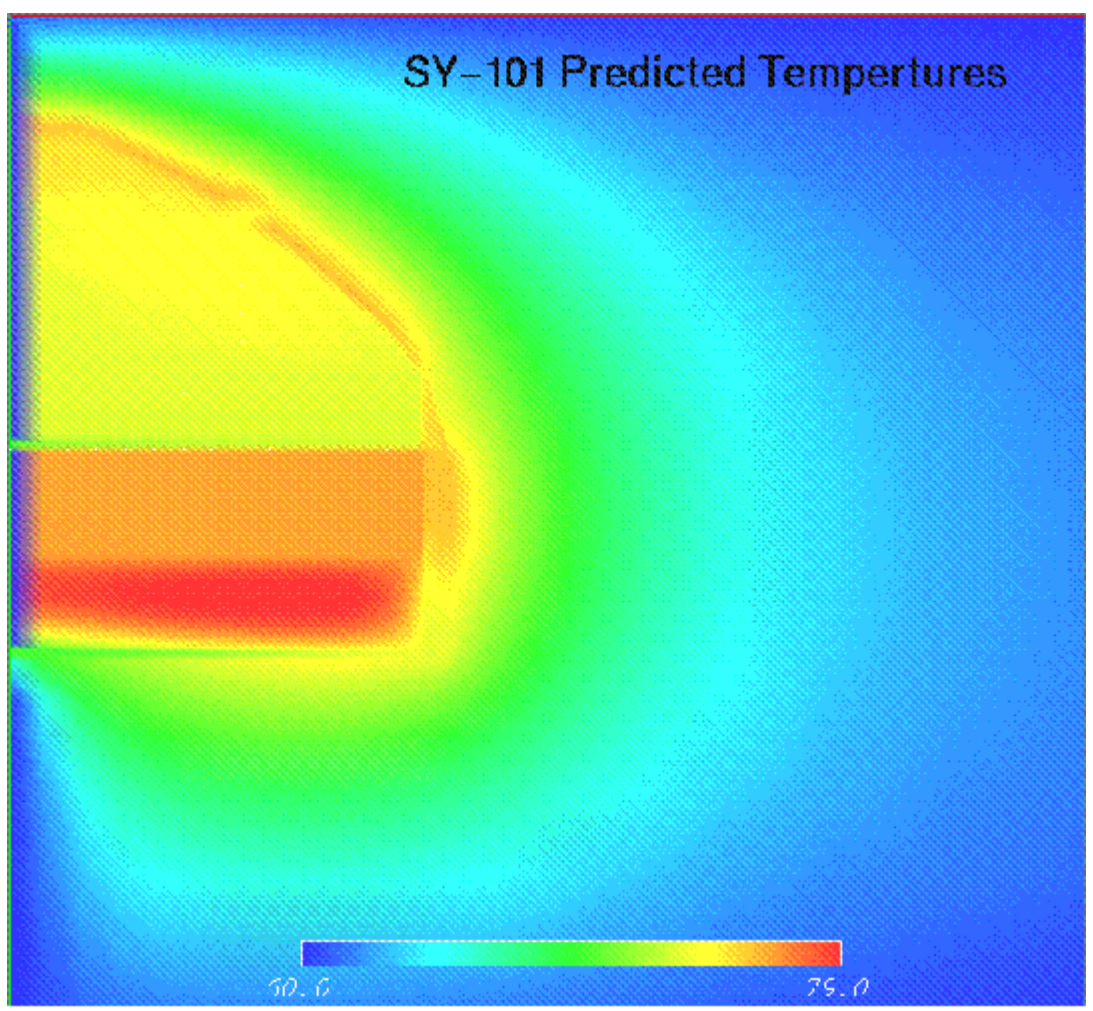

Figure 3.1. Predicted Temperature Distributions in SY-101 and Surrounding Area

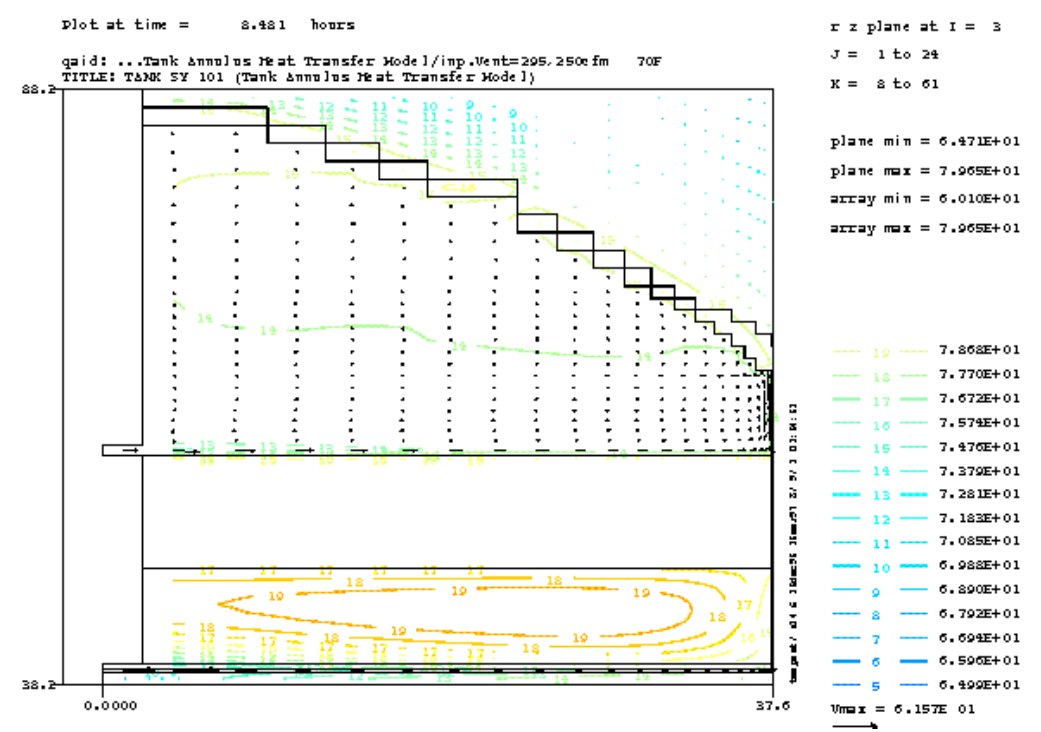

Figure 3.2. Predicted Temperature Distributions of SY-101 Solid and Liquid Waste Layers 
SY-101 temperature distributions measured on July 1, 2003 along risers 17B and 17C are shown in Figures 3.3 and 3.4. At that time, the waste level was about 400 inches above the tank bottom. The interface between the liquid (convective) and solid (nonconvective) layers was very roughly estimated at around 85 inches above the tank bottom. There is considerable scatter, especially in the convective layer readings, probably because there has been no recent thermocouple calibration. Nonetheless, it appears that the maximum temperature of the nonconvective layer is approximately $80^{\circ} \mathrm{F}$, while the temperature of the convective layer is about $76.5^{\circ} \mathrm{F}$. Thus the SY-101 model results agreed reasonably with recent SY-101 temperature data, although there is considerable uncertainty in these measured temperature values.

Because the S-112 injection and S-112/SY-101 waste withdrawal would produce threedimensional flow and temperature distributions (Steps 3 and 4), three-dimensional simulations were needed. Thus, under Step 1.2, we developed a three-dimensional SY-101 model to predict three-dimensional temperature distributions by assigning ventilation air temperatures based on the quasi three-dimensional model predictions obtained under Step 1.1. Similar to the quasi three-dimensional case, we used a combination of the time-varying and steady-state simulations to reach the steady-state temperature distributions in the solid and liquid layers.

The predicted three-dimensional temperature distribution is very similar to that shown in Figure 3.2, with small three-dimensional effects, as expected. Figures 3.5 and 3.6 show predicted temperature distributions along 180 degree opposite vertical planes of the tank. The figures show the coolest temperature occurring along the tank wall and the hottest temperatures

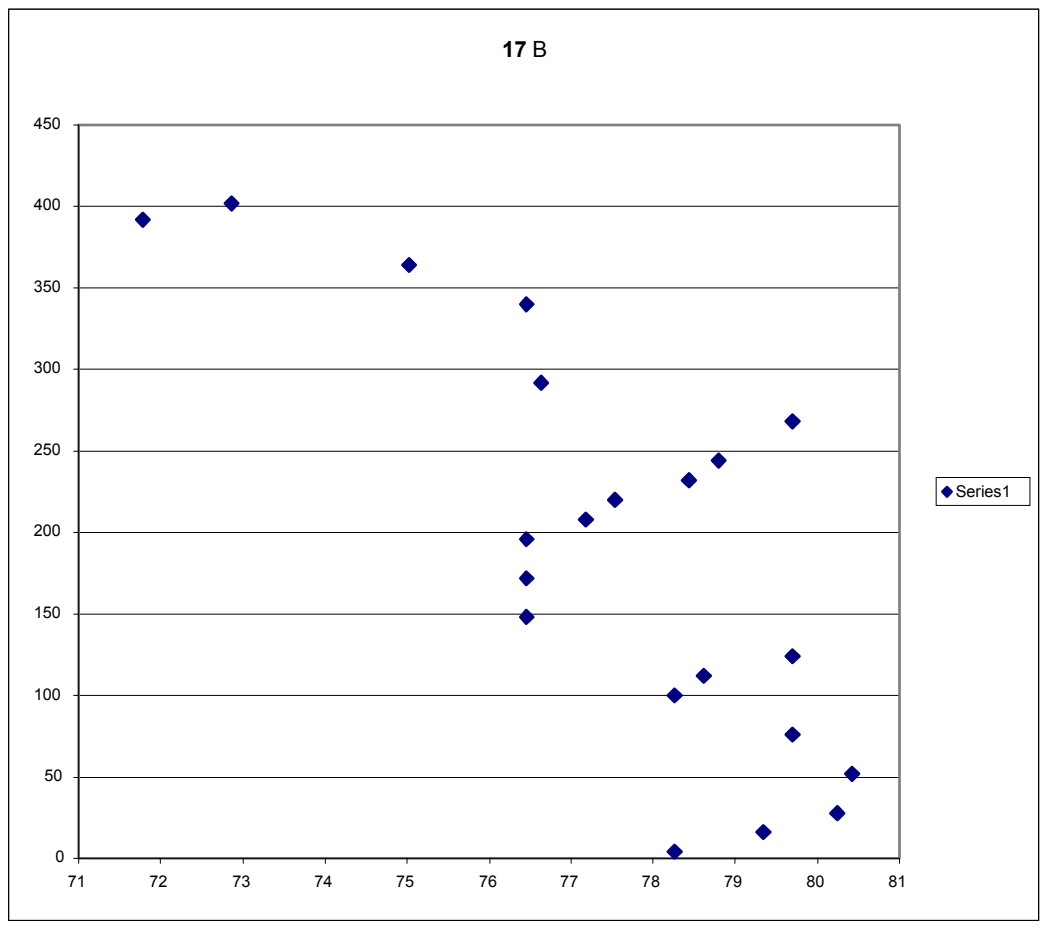

Figure 3.3. SY-101 Waste Temperature Distribution Along Riser 17B Measured on July 1, 2003 


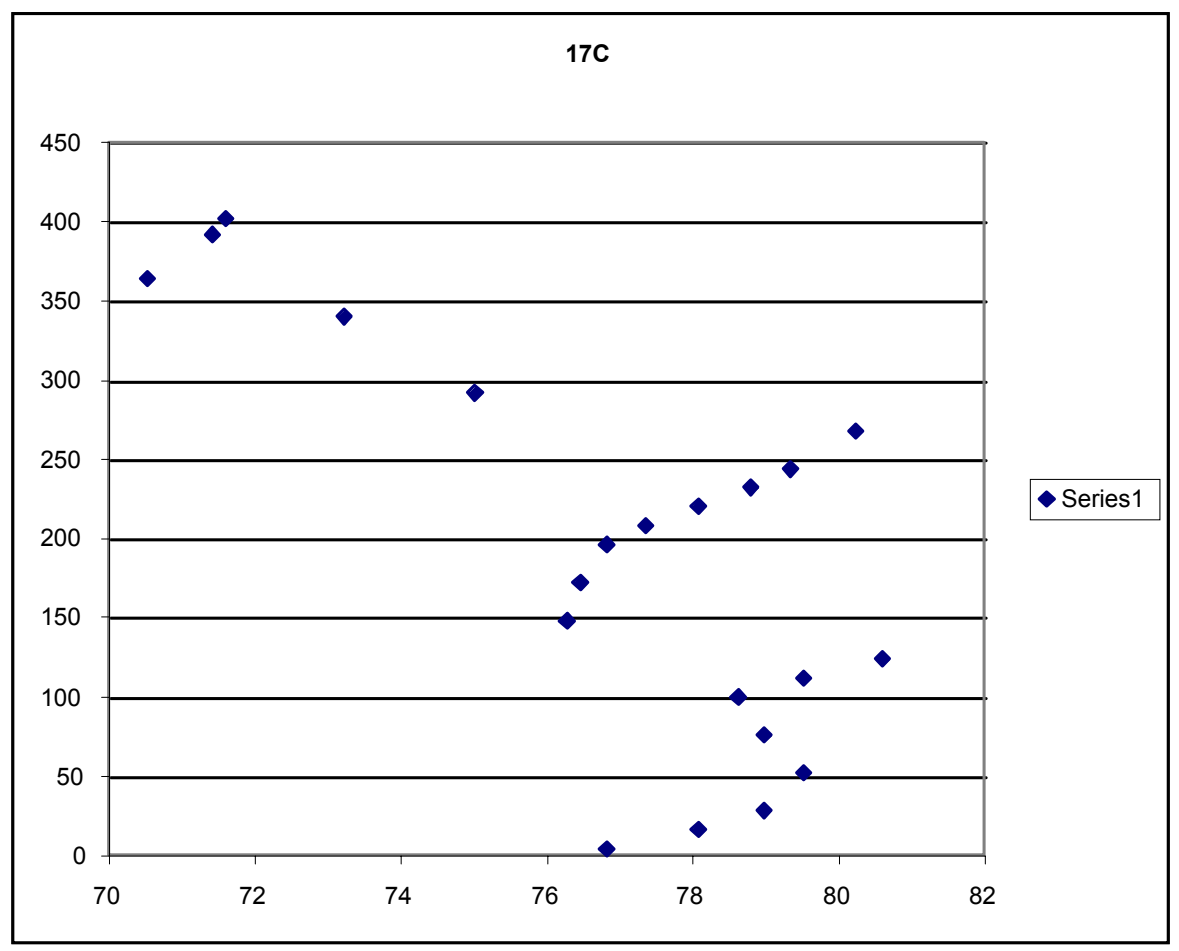

Figure 3.4. SY-101 Waste Temperature Distribution Along Riser 17C Measured on July 1, 2003

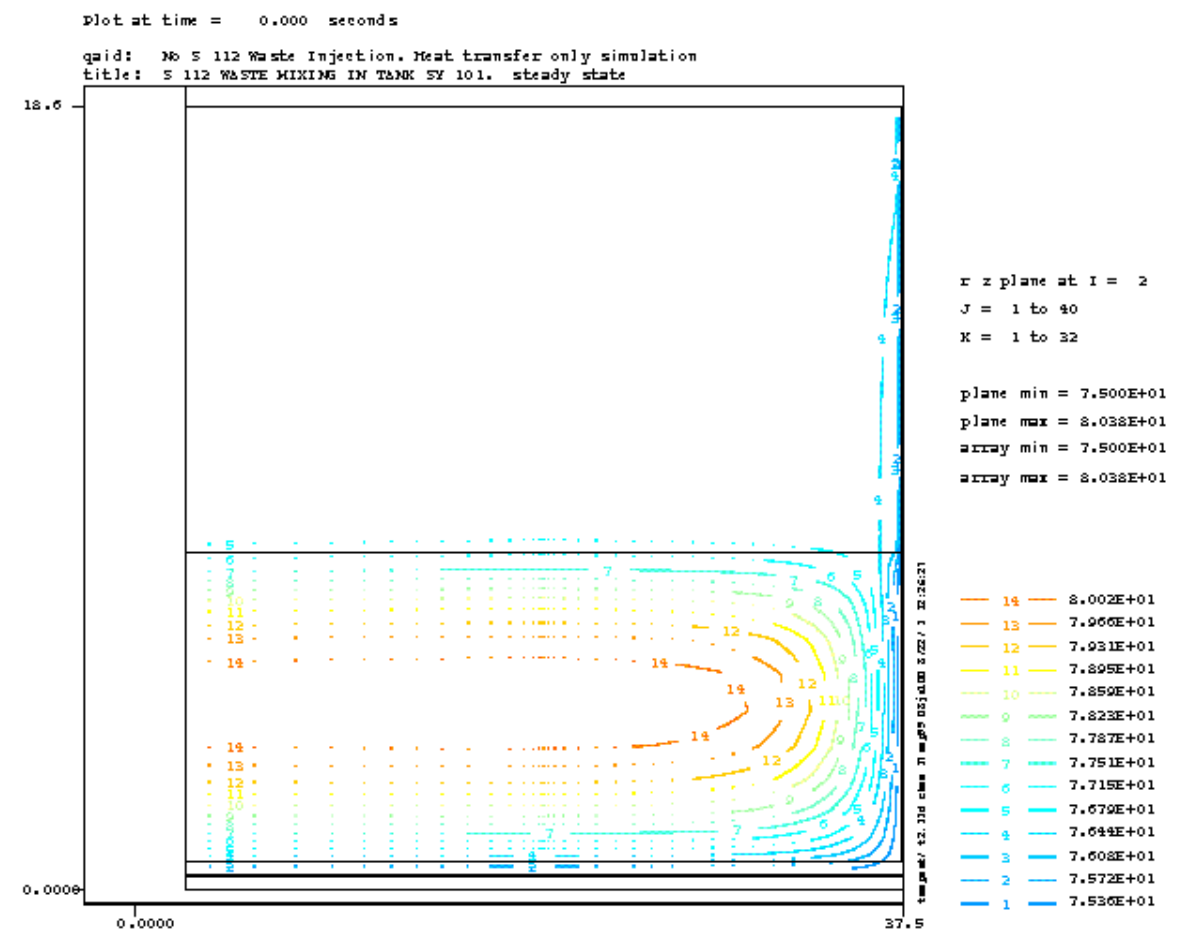

Figure 3.5. Predicted Temperature Distributions of SY-101 Solid and Liquid Layers Along 3 O’Clock Azimuthal Position 


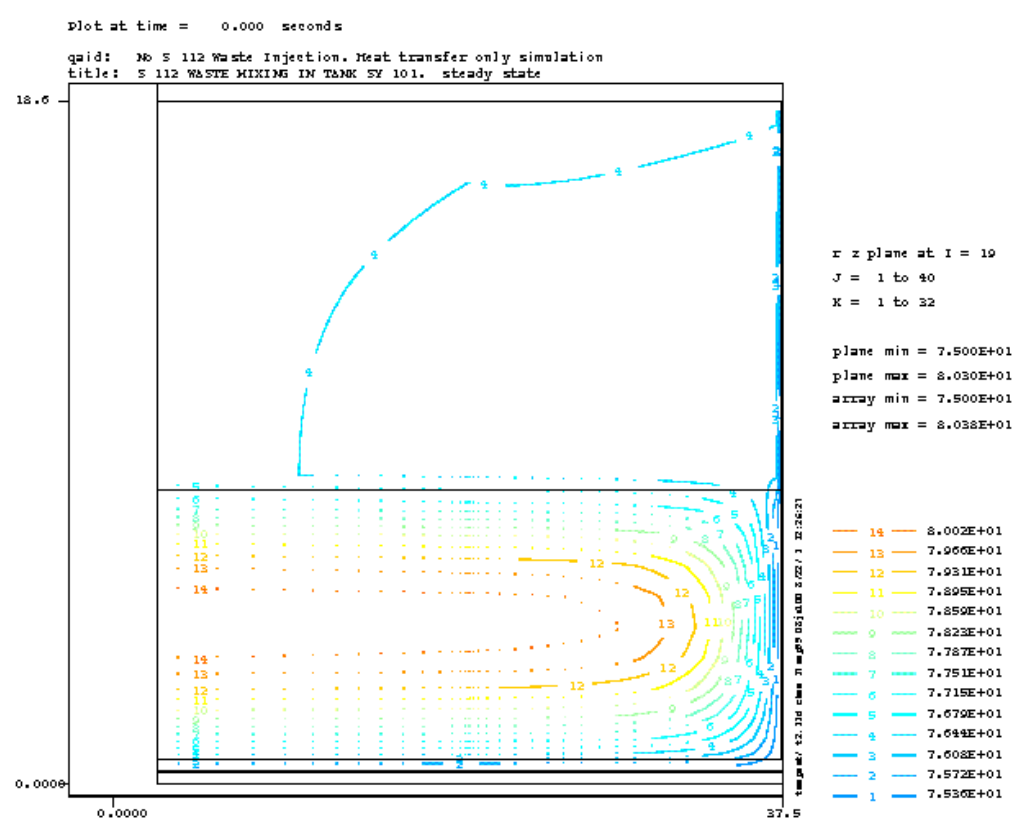

Figure 3.6. Predicted Temperature Distributions of SY-101 Solid and Liquid Layers Along 9 O’Clock Azimuthal Position

were predicted around the mid-depth of the solids layer, away from the tank wall. Predicted maximum temperature is $80.38^{\circ} \mathrm{F}$, while the liquid layer has an almost uniform temperature, varying from $76.1^{\circ}$ to $76.8^{\circ} \mathrm{F}$. Again, these predictions matched well with measured temperatures shown in Figures 2.5, 3.3, and 3.4.

\subsection{Natural Convection in Tank SY-101 (Step 2)}

Because there are some temperature variations within the SY-101 waste, natural convection is expected to occur in the liquid (convective) layer. For Step 2, we assigned realistic liquid waste properties such as density as a function of the temperature expressed in Equation 2.1. Except for including the natural convection mechanism in this case, all other mechanisms and conditions (e.g., waste heat generation, ventilation air) included under Step 1.2 were included in Step 2 analysis. The simulation did not include interstitial solution movements in the solids layer.

With predicted three-dimensional temperature distributions obtained under Step 2 as the initial condition, we ran the SY-101 three-dimensional model for five simulation days. By that time, the temperature and the predicted natural convection flow reached steady-state conditions. The results indicate that overall flow is

- moving from the tank center to tank wall near the liquid waste surface

- moving down along the steel tank wall 
- moving from the tank wall toward the tank center just above the solid waste surface

- moving upward near the tank center

- moving from the tank center toward the tank wall at about one-third of the liquid depth, producing circulation

- moving upward above this circulation area.

Because of this natural convection, the temperature in the liquid waste layer is almost uniform, around $76.5^{\circ} \mathrm{F}$, varying only by $0.05^{\circ} \mathrm{F}$ within the convective layer except along the tank wall. These predicted flow and temperature distributions are shown in Figures 3.7 and 3.8. These figures, at two 180-degree opposing planes, are the same vertical planes shown in Figures 3.5 and 3.6.

As the cooled liquid waste moves down along the tank wall toward the center of the tank and along the top surface of the sludge, its temperature increases from contact with the hotter sludge layer with internal decay heat generation. This now warmed-up liquid waste now rises until it reaches the waste surface or to an elevation at which its density is equal to that of the surrounding liquid. Once it reaches this "mixing" height, the rising liquid starts to move horizontally. Thus, Figures 3.7 and 3.8 show the horizontal flow about $1 / 3$ of the way up in the liquid. This flow pattern is common to nonhomogeneous flow mixing (e.g., thermal plumes and municipal waste discharged to rivers and coastal waters). As the waste moves horizontally it is heated further and starts moving upward again, as indicated in Figures 3.7 and 3.8.

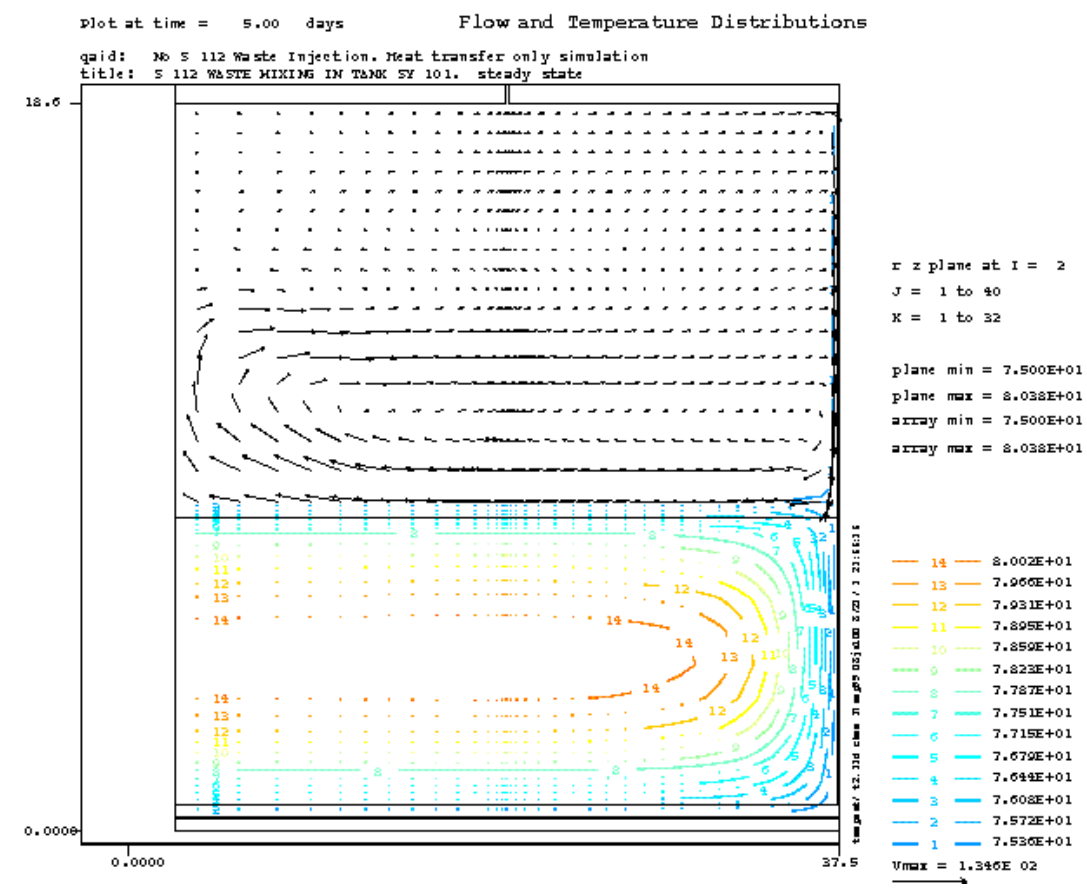

Figure 3.7. Predicted SY-101 Natural Convection Flow and Temperature Distribution at Five Simulation Days 


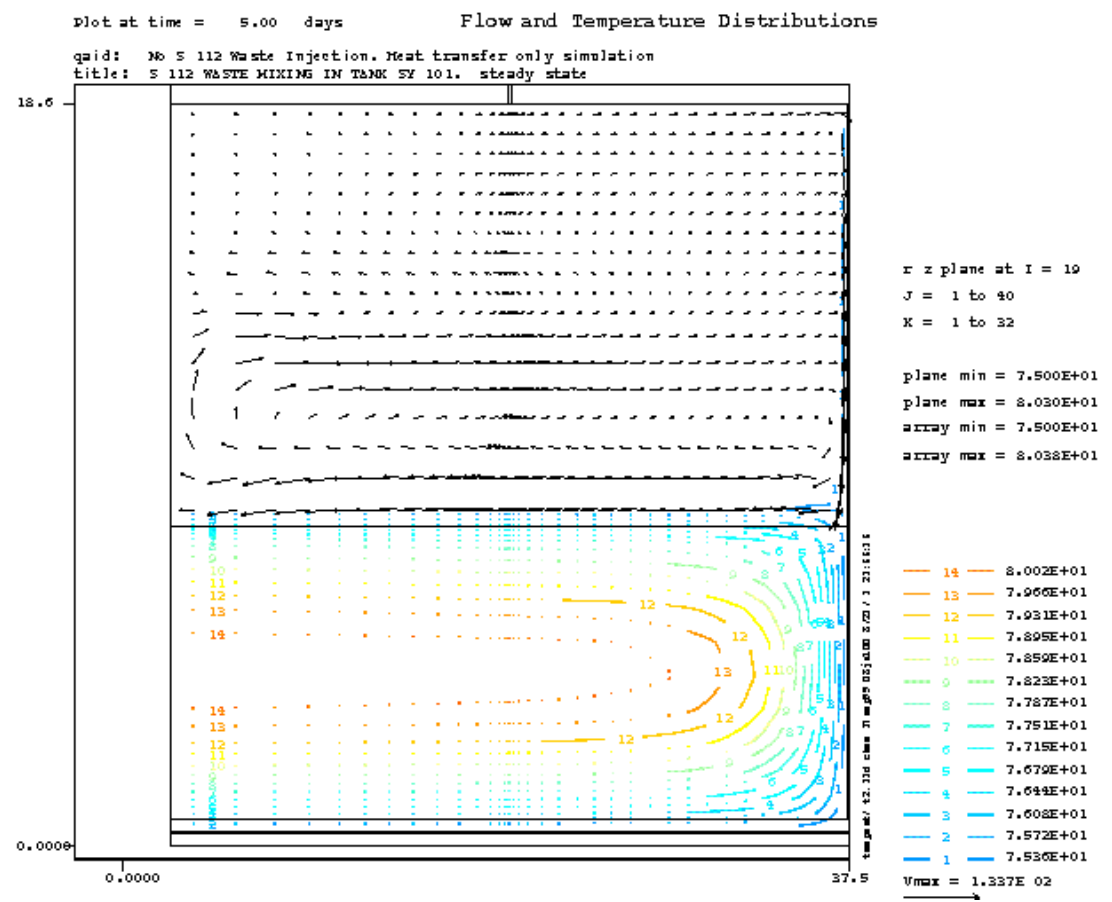

Figure 3.8. Predicted SY-101 Natural Convection Flow and Temperature Distribution at Five Simulation Days

The predicted natural convection flow is very slow; its maximum velocity is $0.013 \mathrm{ft} / \mathrm{sec}$ $(50 \mathrm{ft} / \mathrm{hr})$ downward along the tank wall. In most areas of the convective layer, the velocity varies from approximately $7 \times 10^{-5}$ to $1 \times 10^{-3} \mathrm{ft} / \mathrm{sec}(0.3 \sim 4 \mathrm{ft} / \mathrm{hr})$. Thus, though natural convection flow would eventually mix the liquid waste in SY-101, it would be a very slow process.

\subsection{Mixing of Equal-Density S-112 and SY-101 Wastes (Step 3)}

S-112 liquid waste will be transferred into Tank SY-101 at a rate of $80 \mathrm{gpm}$, and the resulting mixture of S-112 and SY-101 wastes will be retrieved through a waste transfer pump. The inlet of the transfer pump (withdrawal point from SY-101) is 102 inches above the tank bottom (see Figure 2.3). This section evaluates mixing under the Case 1 condition presented in Section 2. Under this condition, the two liquid wastes have the same density, as shown in Table 3.1. The temperature of the S-112 waste was assumed to be the same as that of the SY-101 liquid waste.

Table 3.1. S-112 and SY-101 Waste Properties for Case 1

\begin{tabular}{|c|c|c|}
\hline Waste Characteristic & S-112 Waste & SY-101 Waste \\
\hline $\mathrm{NO}_{2}^{-}, \mu \mathrm{g} / \mathrm{mL}$ & 17,400 & 50,700 \\
\hline $\mathrm{NO}_{3}^{-}, \mu \mathrm{g} / \mathrm{mL}$ & 218,000 & 134,000 \\
\hline $\mathrm{OH}^{-}, \mu \mathrm{g} / \mathrm{mL}$ & 12,800 & 16,900 \\
\hline Liquid Density, $\mathrm{g} / \mathrm{mL}$ & 1.35 & 1.35 \\
\hline
\end{tabular}


As shown in Figure 2.3, S-112 waste would be injected into SY-101 from a 2-inch pipe, probably through a 7-5/8-inch port that is $22 \mathrm{ft}$ from the tank center and about $26 \mathrm{ft}$ above the waste surface. The mixed waste would be withdrawn from Tank SY-101 at a point that is 102 inches above tank bottom, or 14 inches above the SY-101 sludge surface, which is assumed to be 88 inches above tank bottom. Both waste injection and withdrawal points are $22 \mathrm{ft}$ from the tank center and 180 degrees opposite one another. From the plan view point, the vertical plane containing the S-112 waste injection point is along the 3 o'clock azimuthal position, while the withdrawal point is in the vertical plane along the 9 o'clock position in the model. We covered half of the tank due to symmetry of flow and mass/heat transfer patterns.

Because there are no available data for the S-112 waste jet, we used an empirical formula for the water jet spread in air derived by horizontal jet experiments (Enderlin et al. 2002). With a waste density of 1.35 injected through a 2-inch-diameter pipe at $80 \mathrm{gpm}$, the jet-diameter spread and dynamic pressure drops estimated with this empirical formula are shown in Figure 3.9, which indicates the jet may increase to about 6 inches in diameter when it impacts the SY-101 waste surface. Enderlin's experimental condition is different from the S-112 waste release mode, and we selected 8 inches for the S-112 waste jet diameter (four times the 2-inch pipe diameter) at the SY-101 waste surface for this evaluation. With this jet diameter, the S-112 jet velocity is $0.5 \mathrm{ft} / \mathrm{sec}$ at the $\mathrm{SY}-101$ waste surface.

To simplify the mixing assessment, we assigned the waste withdrawal rate from Tank $\mathrm{SY}-101$ to be $80 \mathrm{gpm}$, the same as the S-112 waste transfer rate. We assigned the diameter of the transfer pump inlet (waste withdrawal inlet) to be 8 inches instead of the actual 2 inches to be

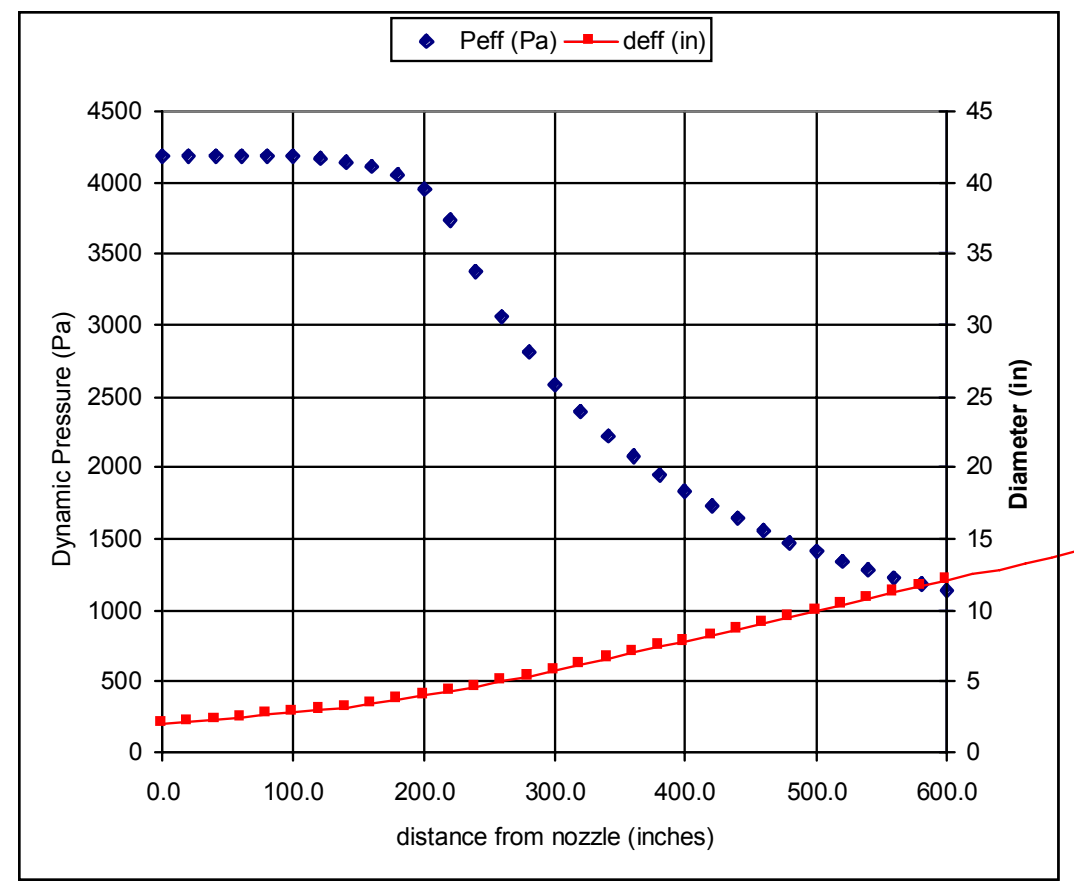

Figure 3.9. Estimated S-112 Waste Jet Spread in Air 
able to use a larger time step, around 1 millisecond, instead of a sub-millisecond time step. Unlike the jet injection, the 8-inch transfer inlet diameter should not affect the flow field except in the immediate vicinity of the transfer pump inlet. We did not simulate the potential movements of liquids and solids in the sludge layer.

Using the simulation results at the end of the fifth day of natural convection modeling (see Figures 3.7 and 3.8) as the starting condition, the S-112 waste was released to Tank SY-101 at $80 \mathrm{gpm}$ and at the same time the waste was withdrawn from SY-101 at the same rate. This model assigned the S-112 density to be the same as SY-101 liquid density. This homogeneous waste mixing simulation included all the fluid mechanic and heat transfer mechanisms included in natural convection modeling (Section 3.2).

Predicted flow and temperature distributions at 12 simulation hours (indicated as 5.5 days) are shown in Figures 3.10 through 3.12. As shown in Figure 3.10 depicting distributions in the vertical plane at the 3 o'clock position, the S-112 waste jet penetrates the SY-101 liquid waste and reaches the sludge surface. While there is a significant temperature variation within the sludge layer, the temperature in the liquid layer is uniform, as expected. The S-112 waste jet impact on the flow field is weak in areas away from the release point. For example, Figure 3. 11 presents the flow and temperature distributions along the 12 o'clock position, indicating almost the same flow pattern in the lower half of the liquid layer as that without the S-112 waste release to Tank SY-101 (see Figure 3.8). However, the upper-left half-tank area shown in Figure 3.11

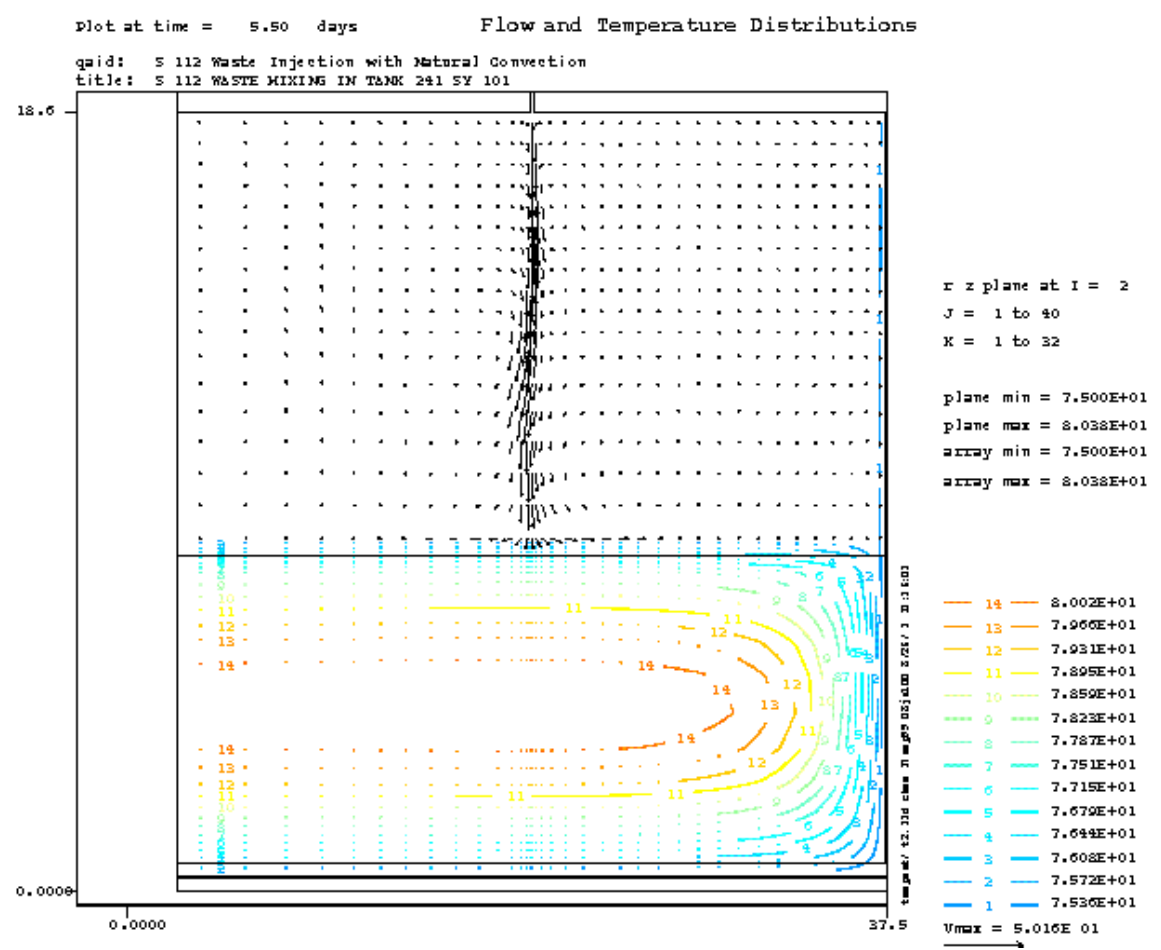

Figure 3.10. Predicted Vertical Distributions of Flow and Temperature Along 3 O'clock Position at 12 Simulation hr for Injection of $1.35-\mathrm{g} / \mathrm{mL} \mathrm{S}-112$ Waste 


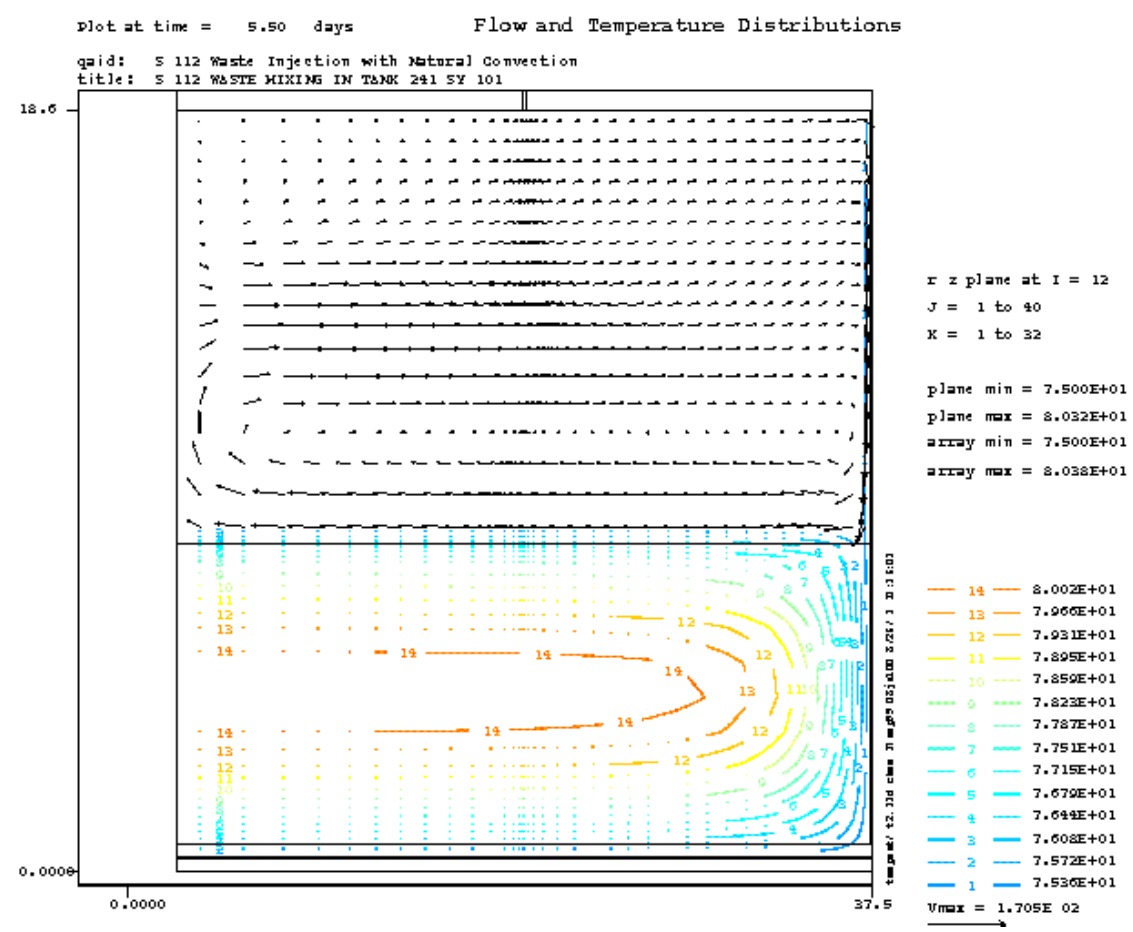

Figure 3.11. Predicted Vertical Distributions of Flow and Temperature Along 12 O'clock Position at 12 Simulation $\mathrm{hr}$ for Injection of $1.35-\mathrm{g} / \mathrm{mL} \mathrm{S}-112$ Waste

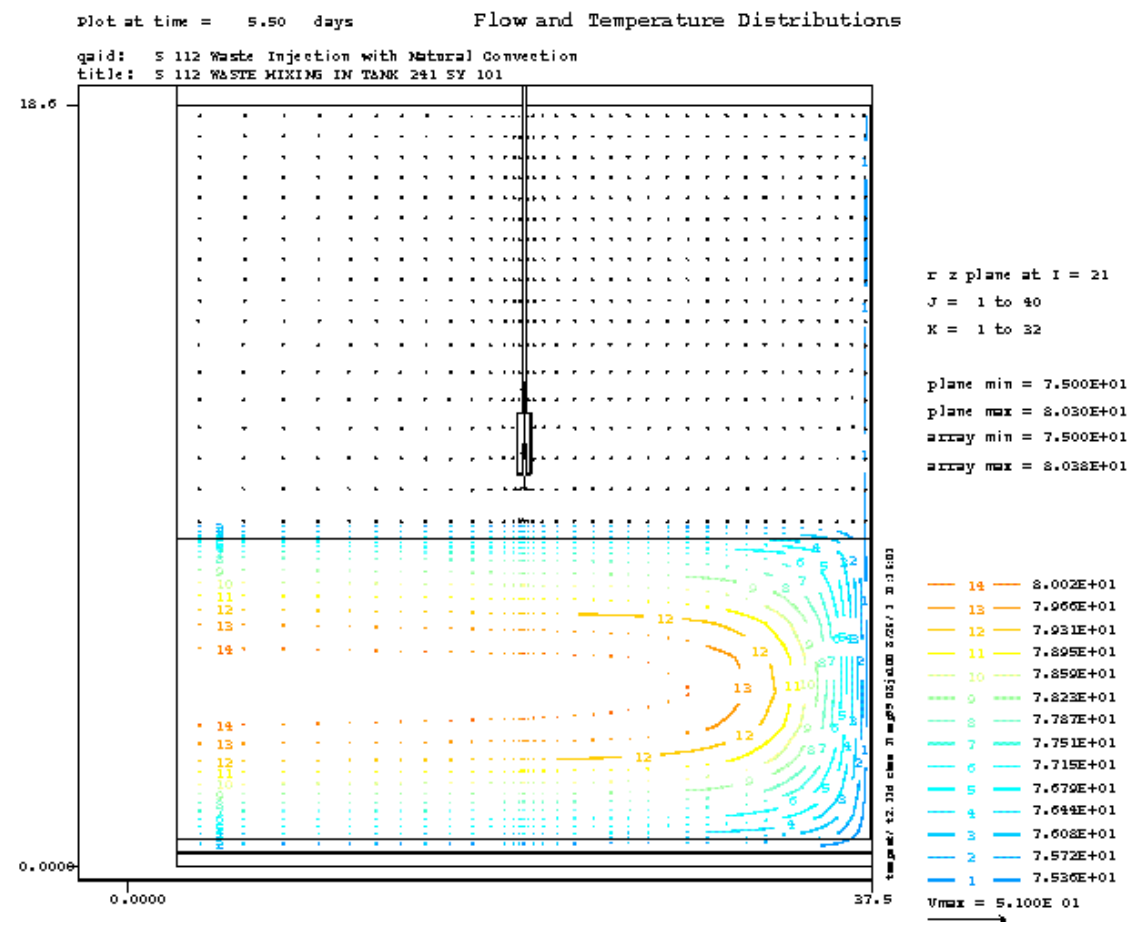

Figure 3.12. Predicted Vertical Distributions of Flow and Temperature Along 9 O'clock Position at 12 Simulation $\mathrm{hr}$ for Injection of $1.35-\mathrm{g} / \mathrm{mL} \mathrm{S}-112$ Waste 
has a slow counter-clockwise circulation that was not present in Figure 3.8. Figure 3.12 shows predicted velocity and temperature distributions in the vertical plane containing the transfer pump inlet (waste withdrawal nozzle), where the waste being is withdrawn into the transfer pump at a velocity of $0.5-\mathrm{ft} / \mathrm{sec}(80 \mathrm{gpm})$.

Predicted S-112 waste mixing with SY-101 waste at 12 simulation hours is shown in Figures 3.13 through 3.21 along with the velocity distributions. In these figures, the S-112 concentrations are shown as a fraction of the original concentration at the S-112 release point. Thus, for example, a waste concentration of 0.1 indicates that $\mathrm{S}-112$ waste concentration at that location is $10 \%$ of the original concentration, and SY-101 waste makes up the remaining $90 \%$. Table 3.2 presents a conversion of the waste concentrations to concentrations of $\mathrm{NO}_{2}{ }^{-}, \mathrm{NO}_{3}^{-}$, and $\mathrm{OH}^{-}$in the mixed waste in the tank.

Table 3.2. Conversion of $\mathrm{S}-112$ Waste Fraction to $\mathrm{NO}_{2}{ }^{-}, \mathrm{NO}_{3}{ }^{-}$, and $\mathrm{OH}^{-}$Concentrations, Case 1

\begin{tabular}{|c|c|c|c||}
\hline $\begin{array}{c}\text { Fraction of Predicted } \\
\text { S-112 Waste } \\
\text { Concentration }\end{array}$ & \multicolumn{3}{|c||}{ Concentration of Waste Mixture } \\
\cline { 2 - 4 } & $\mathbf{N O}_{\mathbf{2}}{ }^{-}$ & $\mathbf{N O}_{\mathbf{3}}{ }^{-}$ & $\mathbf{O H}^{-}$ \\
\hline 0 & 50,700 & 134,000 & 16,900 \\
\hline 0.1 & 47,400 & 142,000 & 16,500 \\
\hline 0.2 & 44,000 & 151,000 & 16,100 \\
\hline 0.3 & 40,700 & 159,000 & 15,700 \\
\hline 0.4 & 37,400 & 168,000 & 15,300 \\
\hline 0.5 & 34,100 & 176,000 & 14,900 \\
\hline 0.6 & 30,700 & 184,000 & 14,400 \\
\hline 0.7 & 27,400 & 193,000 & 14,000 \\
\hline 0.8 & 24,100 & 201,000 & 13,600 \\
\hline 0.9 & 20,700 & 210,000 & 13,200 \\
\hline 1.0 & 17,400 & 218,000 & 12,800 \\
\hline
\end{tabular}

Figure 3.13 shows the predicted S-112 waste vertical distribution along the 3 o'clock position. It shows the S-112 waste reaching the sludge surface. At that location, the S-112 waste is diluted by two times. Thus, from Table 3.2, for 0.5 fraction of S-112 waste concentration the predicted chemical concentration would be $\mathrm{NO}_{2}{ }^{-}, 34,100 \mu \mathrm{g} / \mathrm{mL} ; \mathrm{NO}_{3}{ }^{-}, 176,000 \mu \mathrm{g} / \mathrm{mL}$; and $\mathrm{OH}^{-}, 14,900 \mu \mathrm{g} / \mathrm{mL}$.

Once the S-112 waste jet hits the sludge it spreads on the sludge surface, as shown in Figure 3.14, which depicts the horizontal distributions of flow and concentration. The waste jet also reverses direction to move upward, as shown in Figure 3.15, which depicts the distributions along the vertical plane immediately next to that containing the S-112 waste injection point. 


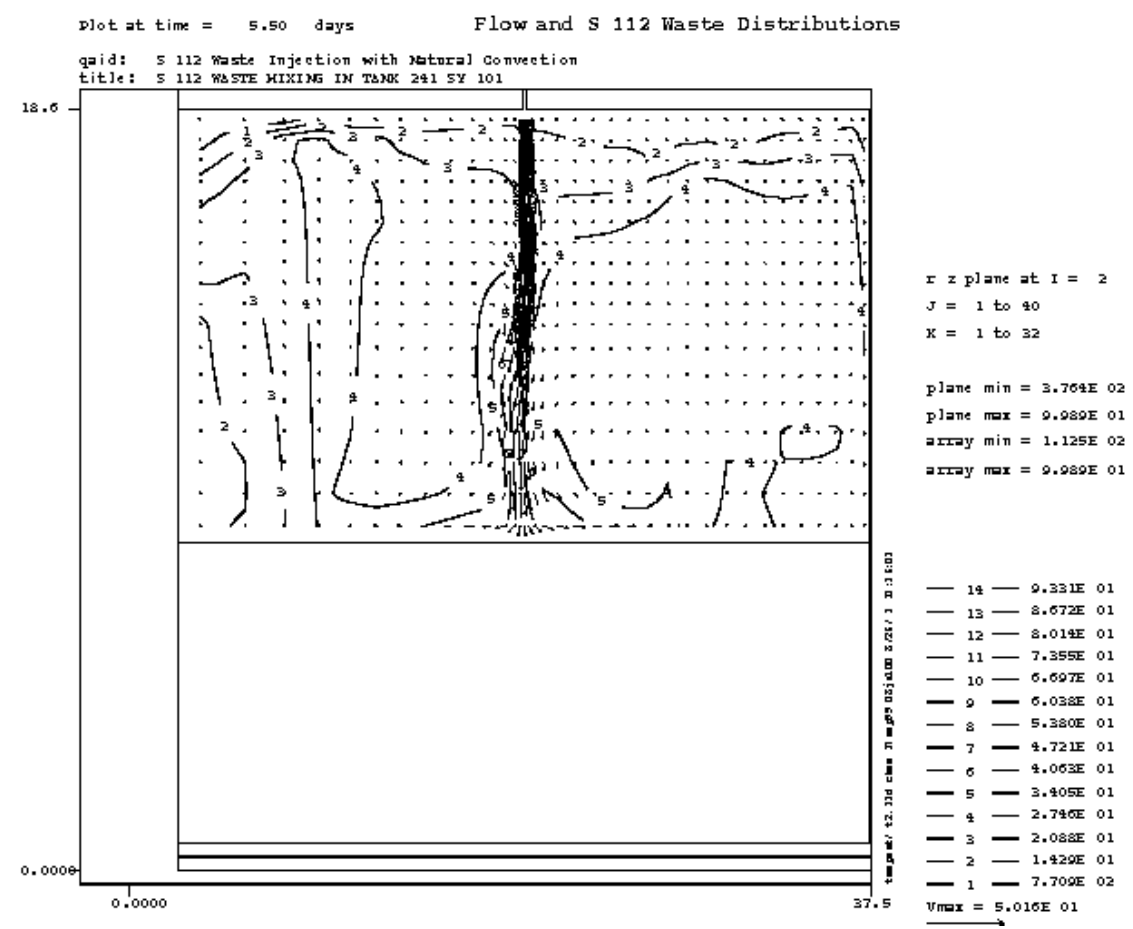

Figure 3.13. Predicted Vertical Distributions of Flow and Concentration Along 3 O'clock Position at 12 Simulation hr for Injection of $1.35-\mathrm{g} / \mathrm{mL} \mathrm{S}-112$ Waste

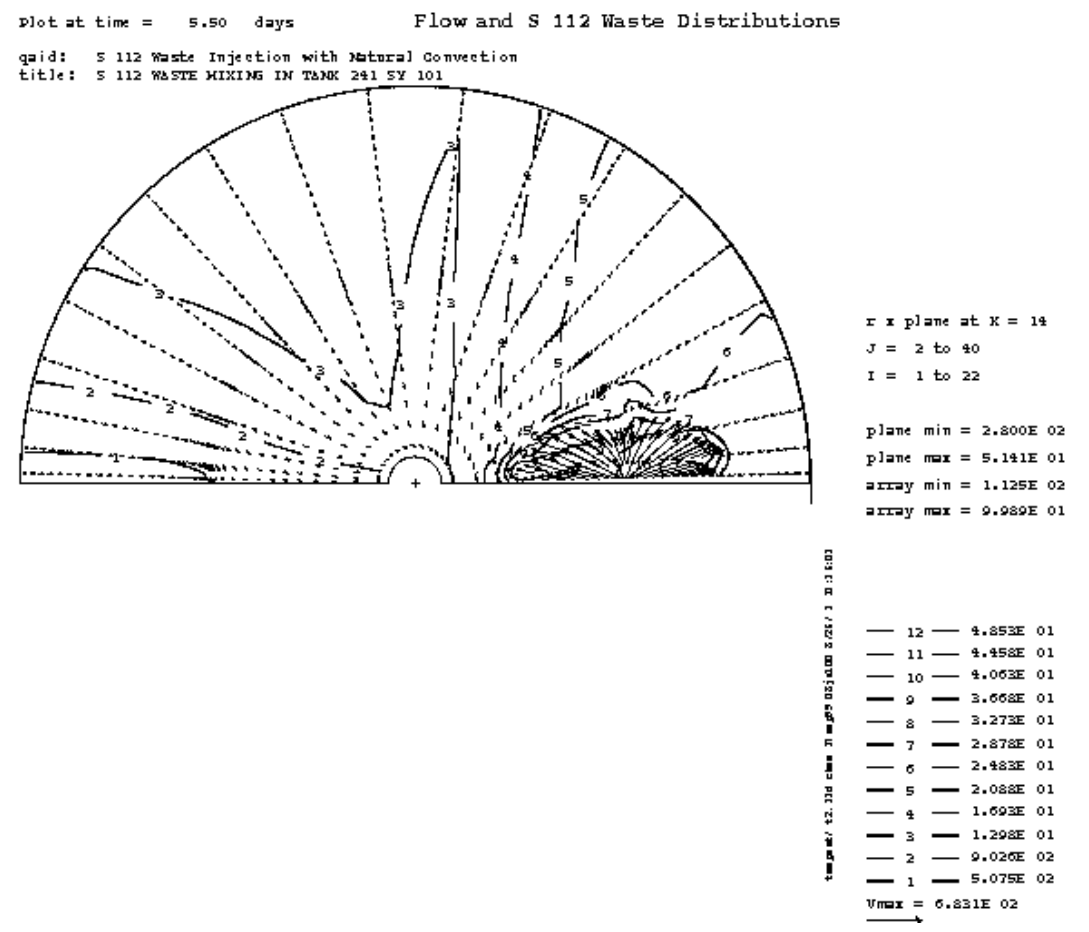

Figure 3.14. Predicted Horizontal Distributions of Flow and Concentration on the SY-101 Sludge Surface at 12 Simulation hr for Injection of $1.35-\mathrm{g} / \mathrm{mL} \mathrm{S-112} \mathrm{Waste}$ 


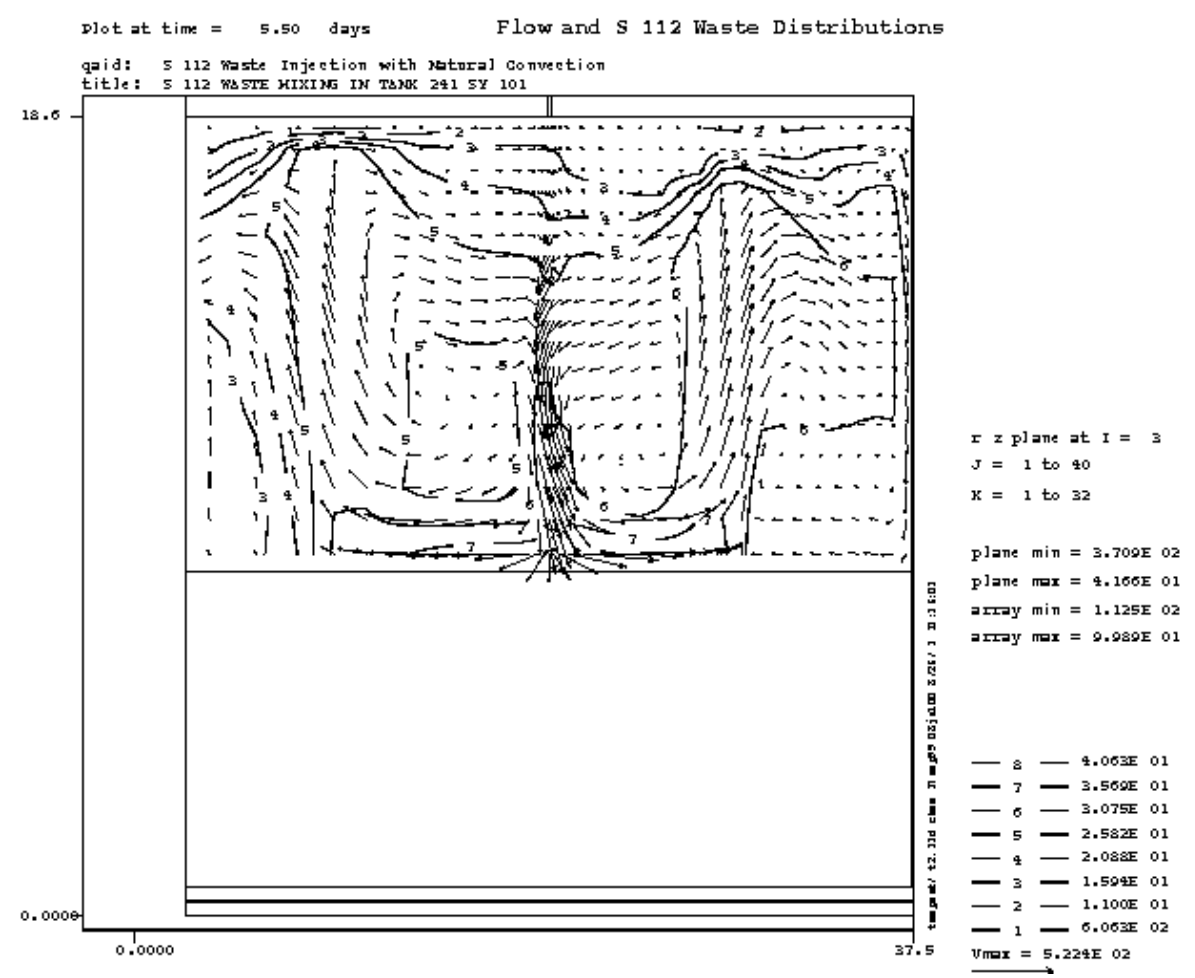

Figure 3.15. Predicted Vertical Distributions of Flow and Concentration Immediately Next to the 3 O'clock Position at 12 Simulation hr for Injection of $1.35-\mathrm{g} / \mathrm{mL}$ S-112 Waste

However, except in areas of the direct passage of the waste jet, the velocity induced by the waste injection and natural convection is very small in most areas, of the order of $1 \times 10^{-4} \mathrm{ft} / \mathrm{sec}$ $(0.4 \mathrm{ft} / \mathrm{hr})$ to $2 \times 10^{-3} \mathrm{ft} / \mathrm{sec}(7 \mathrm{ft} / \mathrm{hr})$. Thus the mixing of S-112 and SY-101 liquid wastes is slow.

Figures 3.16 through 3.18 present predicted vertical distributions of S-112 waste along the 12 o'clock plane, immediately next to the transfer pump, and the transfer pump position (9 o'clock). These figures indicate there is a considerable variation of S-112 waste concentrations within the tank after 12 hours of S-112 waste transfer, or 57,600 gallons. This nonuniformity is also revealed by predicted horizontal distributions at the SY-101 transfer pump inlet elevation (102 inches above tank bottom), mid-depth of the SY-101 liquid waste, and just below the waste surface, as shown in Figures 3.19 through 3.21, respectively. Figures 3.18 and 3.19 show that the waste being withdrawn by the transfer pump has a concentration of $6 \% \mathrm{~S}-112$ waste 12 hours after the waste transfer to Tank SY-101 began. Thus, $\mathrm{NO}_{2}^{-}, \mathrm{NO}_{3}{ }^{-}$, and $\mathrm{OH}^{-}$ concentrations in this mixed waste are $48,700,139,000$, and $16,700 \mu \mathrm{g} / \mathrm{mL}$, respectively. The minimum S-112 concentration in the tank occurs near the surface of the liquid waste on the opposite side (9 o'clock position) of the tank from the S-112 injection position (3 o'clock). Its S112 concentration after 12 hours of waste transfer is $1 \%$ of the original S-112 concentration. Thus, $\mathrm{NO}_{2}^{-}, \mathrm{NO}_{3}^{-}$, and $\mathrm{OH}^{-}$concentrations there are 50,400, 135,000, and 16,900 $\mu \mathrm{g} / \mathrm{mL}$, respectively. 


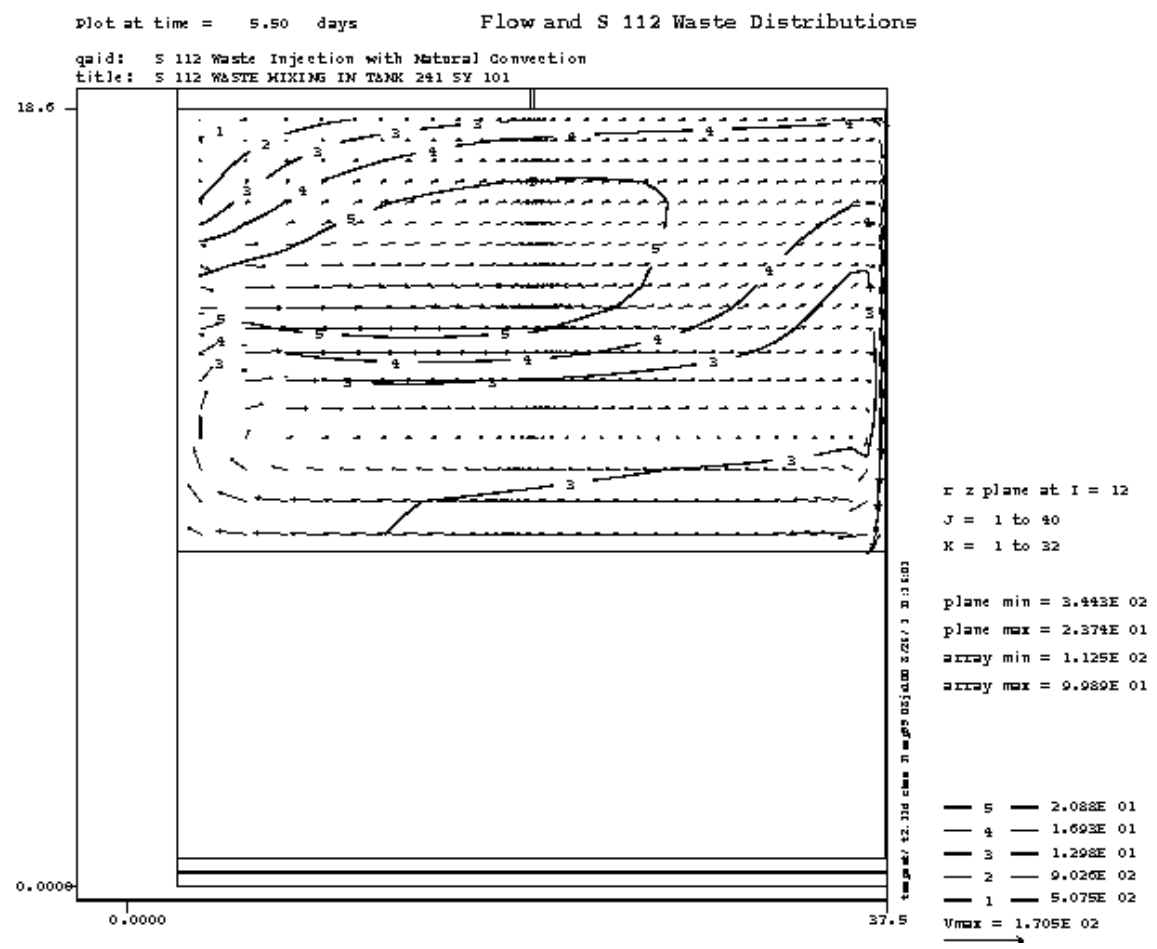

Figure 3.16. Predicted Vertical Distributions of Flow and Concentration Along the 12 O'clock Position at 12 Simulation hr for Injection of $1.35-\mathrm{g} / \mathrm{mL} \mathrm{S}-112$ Waste

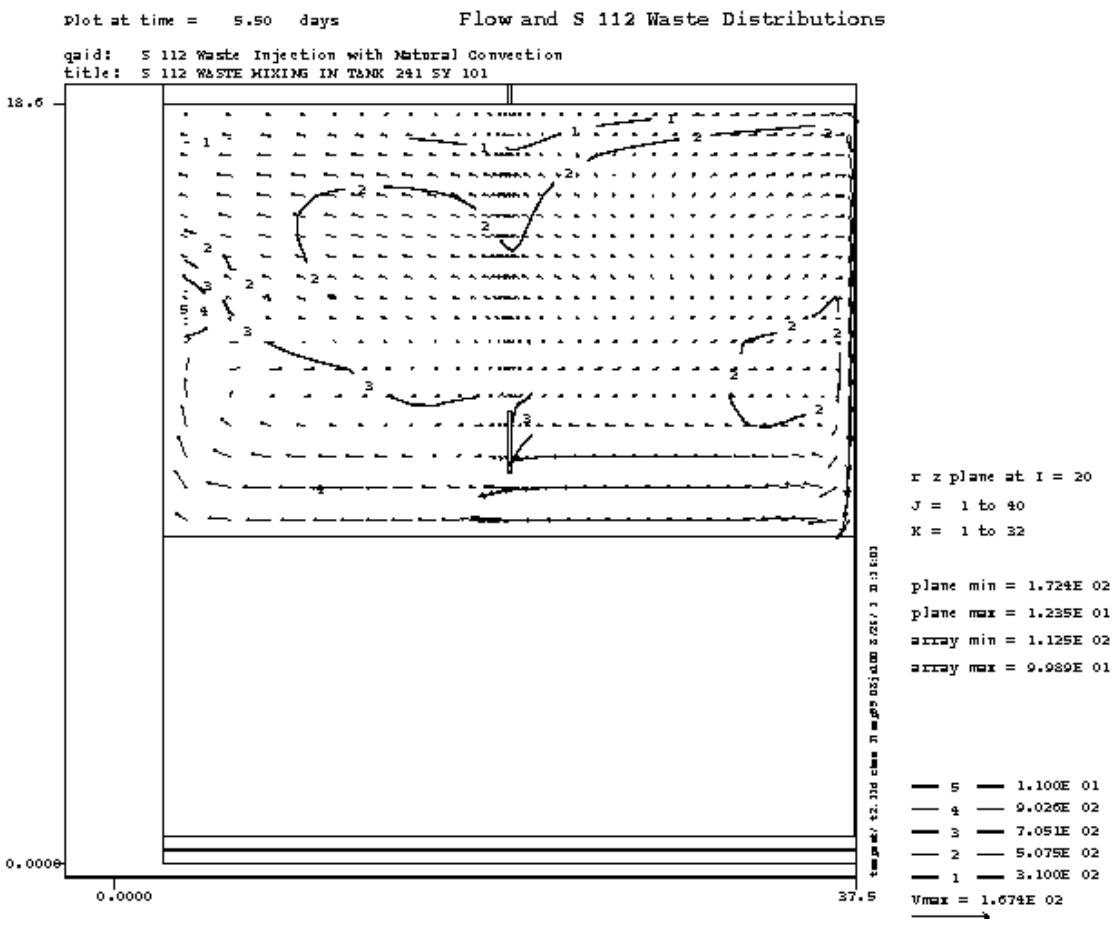

Figure 3.17. Predicted Vertical Distributions of Flow and Concentration Immediately Next to the 9 O'clock Position at 12 Simulation hr for Injection of $1.35-\mathrm{g} / \mathrm{mL} \mathrm{S}-112$ Waste 


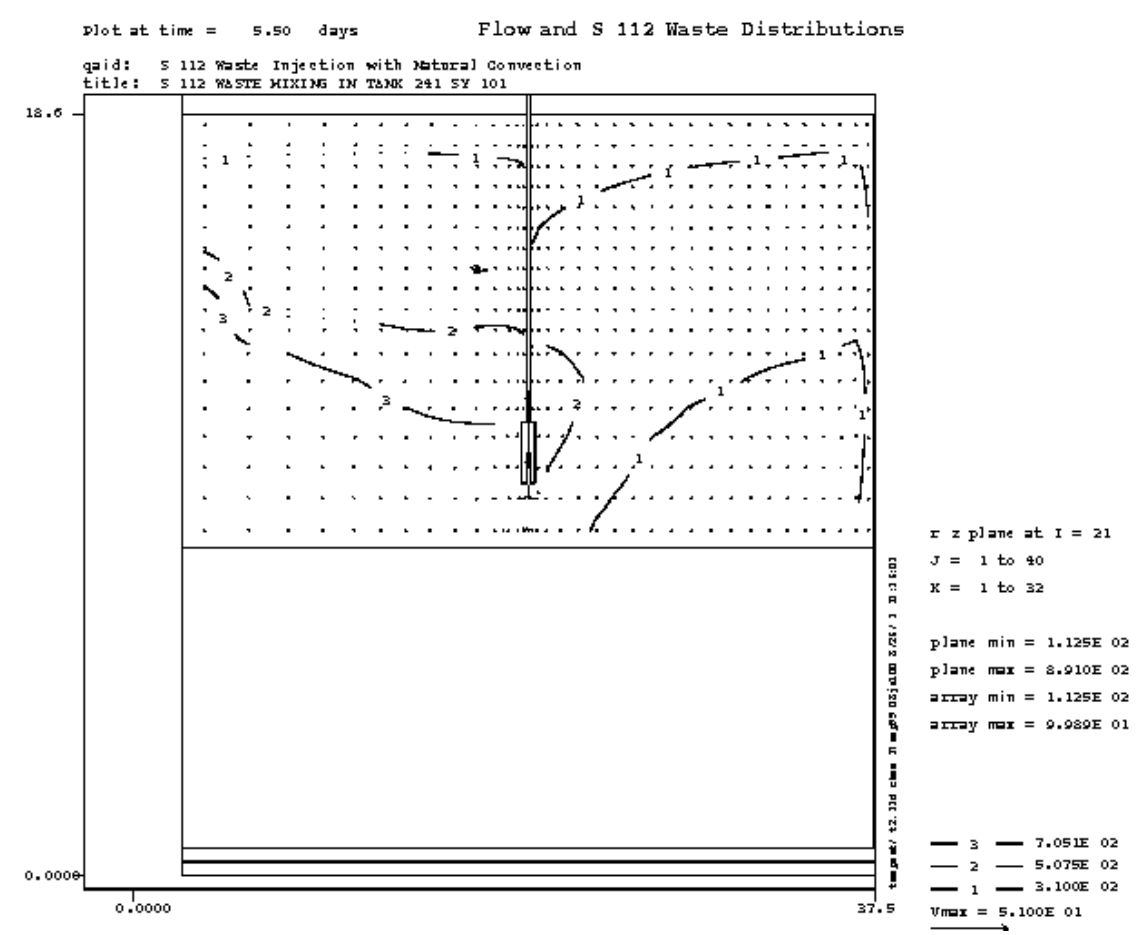

Figure 3.18. Predicted Vertical Distributions of Flow and Concentration Along the 9 O'clock Position at 12 Simulation hr for Injection of $1.35-\mathrm{g} / \mathrm{mL} \mathrm{S}-112$ Waste

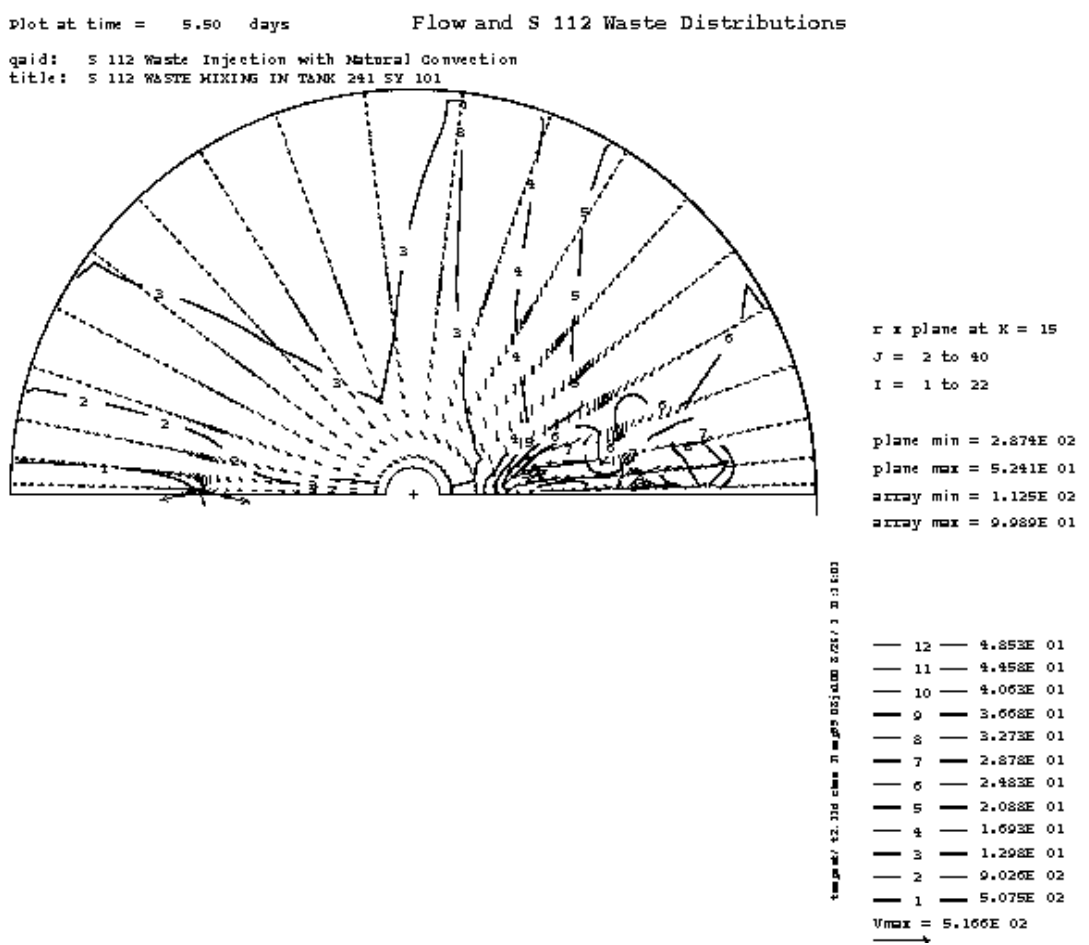

Figure 3.19. Predicted Horizontal Distributions of Flow and Concentration at SY-101 Transfer Pump Inlet Elevation (102 in. above tank bottom) at 12 Simulation hr for Injection of $1.35-\mathrm{g} / \mathrm{mL} \mathrm{S}-112$ Waste 


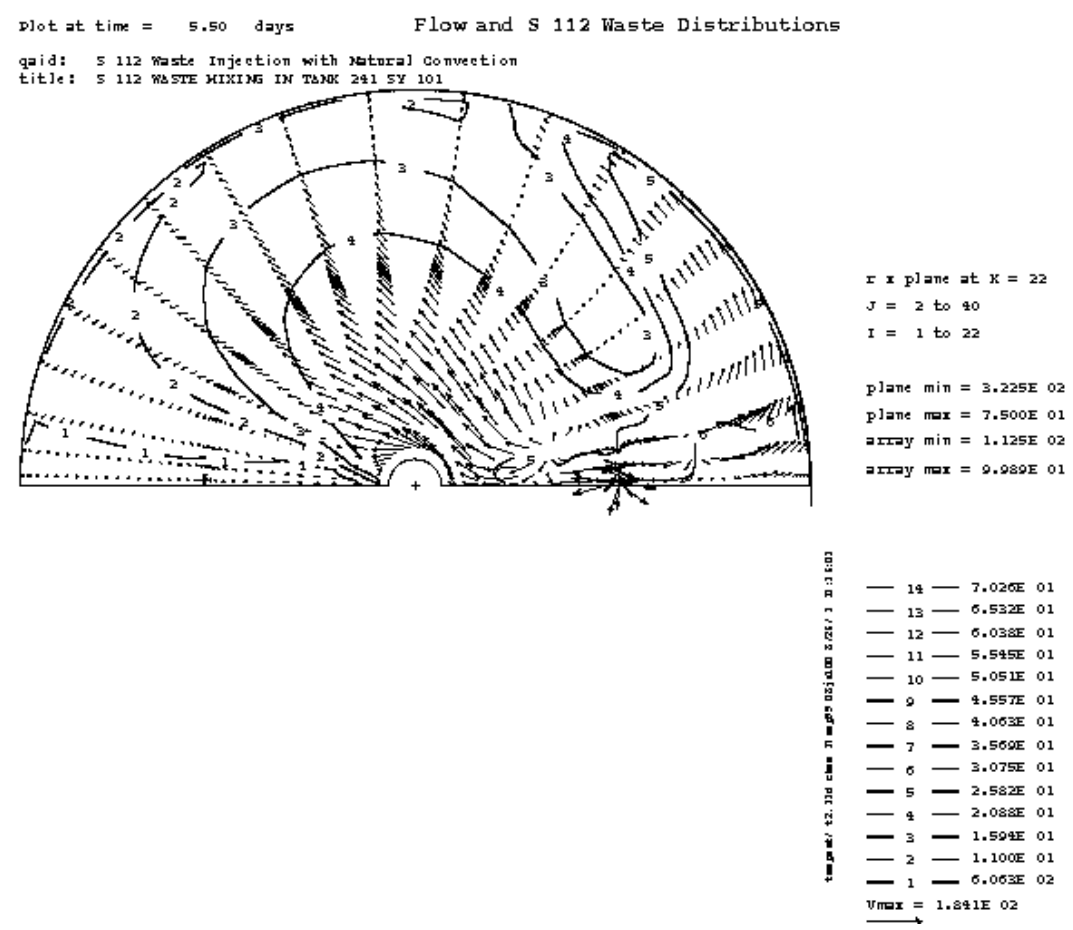

Figure 3.20. Predicted Horizontal Distributions of Flow and Concentration at the Mid-Depth of SY-101 Liquid Waste at 12 Simulation hr for Injection of $1.35-\mathrm{g} / \mathrm{mL} \mathrm{S}-112$ Waste

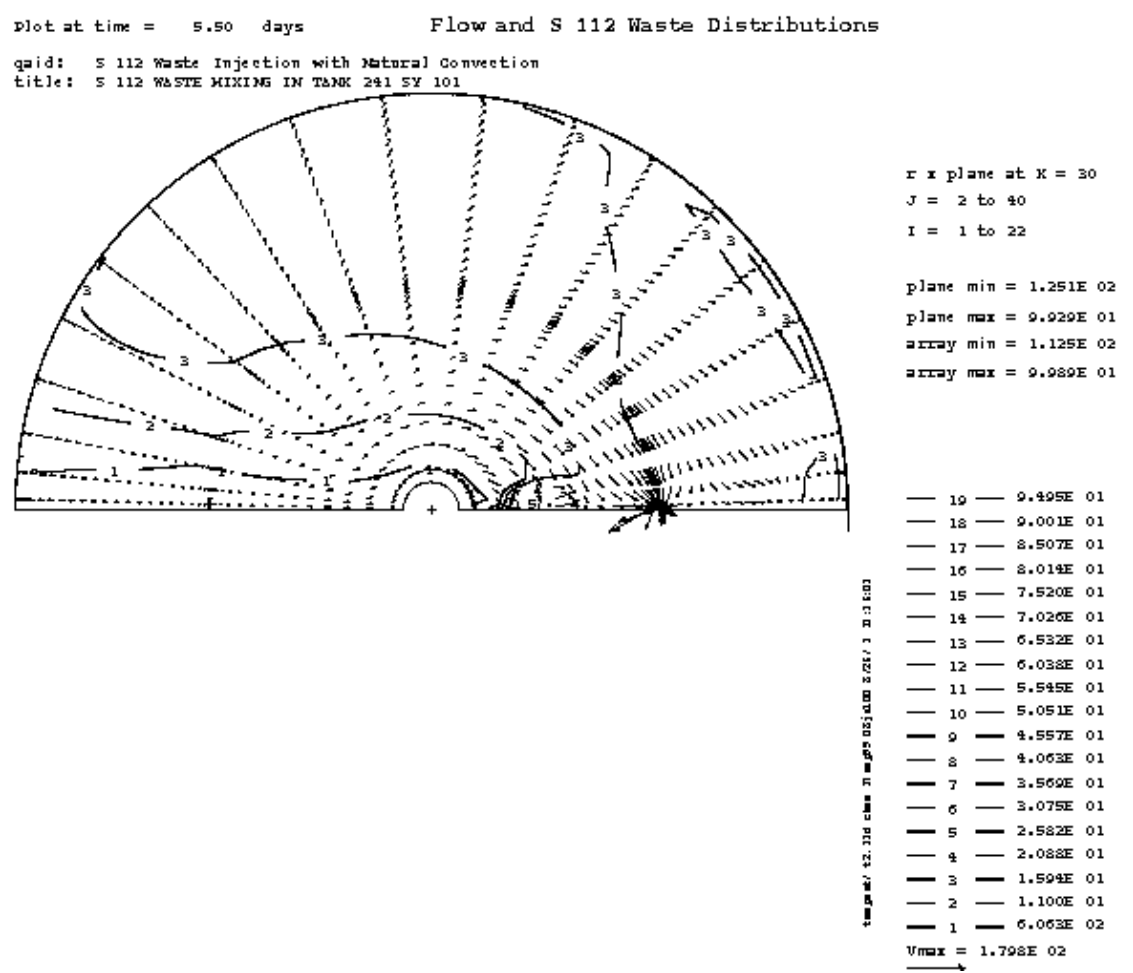

Figure 3.21. Predicted Horizontal Distributions of Flow and Concentration Just Below the Liquid Waste Surface at 12 Simulation hr for Injection of $1.35-\mathrm{g} / \mathrm{mL} \mathrm{S}-112$ Waste 
As S-112 waste injection and waste withdrawal continue, the S-112 and SY-101 wastes mixing continues. Predicted flow and S-112 waste distributions are shown in Figures 3.22 through 3.30 after one day of waste retrieval operations injecting 115,200 gallons of S-112 waste. These figures correspond to Figures 3.13 through 3.21 with 12 simulation hours. After one day of waste injection into and transfer out of the tank, the S-112 concentrations in the tank vary from $12 \%$ (Figure 3.26 ) to $100 \%$ (Figure 3.22 ). The minimum S-112 concentration of $12 \%$ corresponds to $\mathrm{NO}_{2}{ }^{-}, \mathrm{NO}_{3}{ }^{-}$, and $\mathrm{OH}^{-}$concentrations of 46,700, 144,000, and 16,400 $\mu \mathrm{g} / \mathrm{mL}$, respectively. The waste withdrawn by the transfer pump has $20 \% \mathrm{~S}-112$ waste; thus it contains $\mathrm{NO}_{2}{ }^{-}, \mathrm{NO}_{3}{ }^{-}$, and $\mathrm{OH}^{-}$concentrations of $44,000,151,000$, and $16,100 \mu \mathrm{g} / \mathrm{mL}$, respectively.

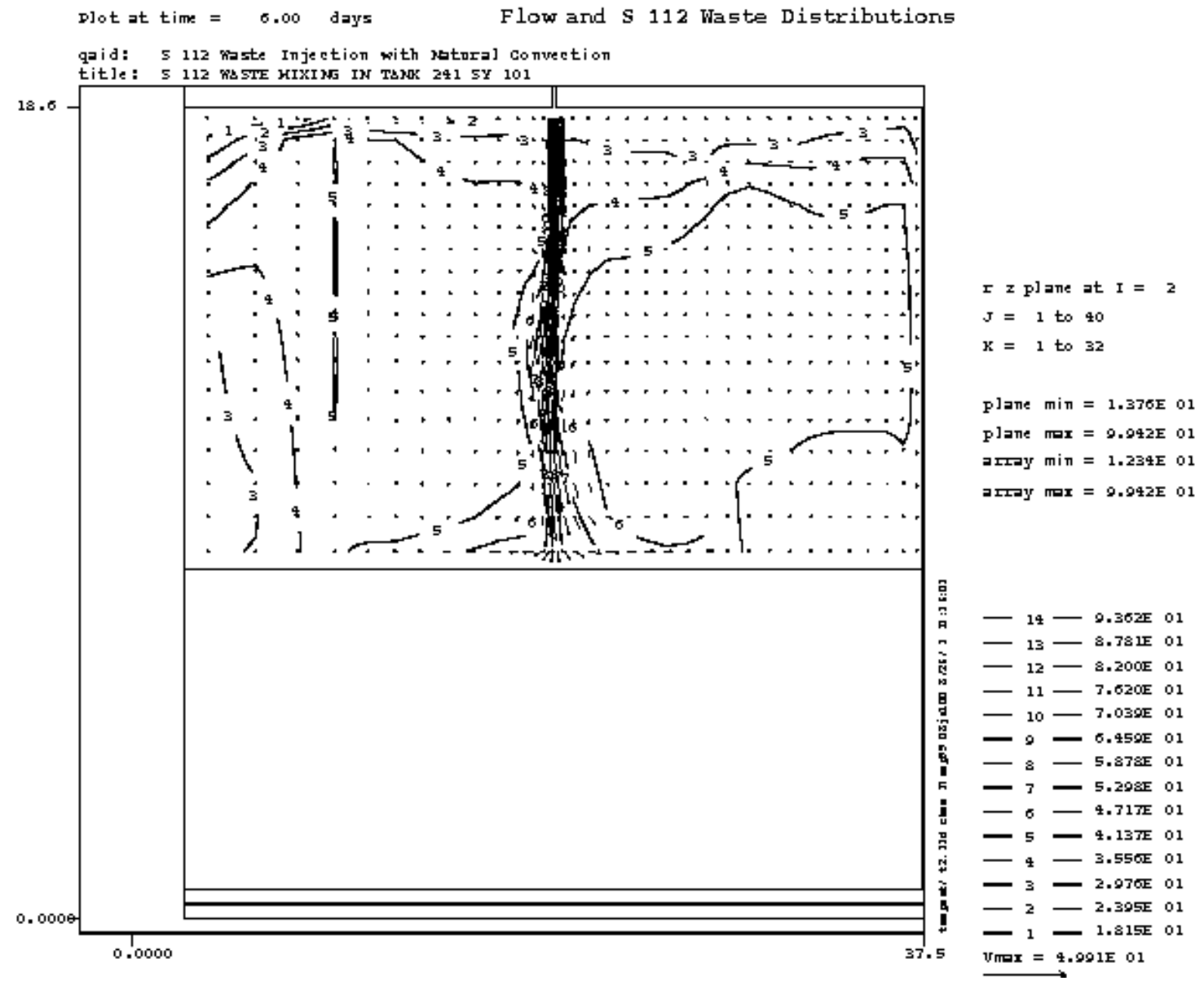

Figure 3.22. Predicted Vertical Distributions of Flow and Concentration Along 3 O'clock Position at One Simulation Day for Injection of $1.35-\mathrm{g} / \mathrm{mL} \mathrm{S}-112$ Waste 


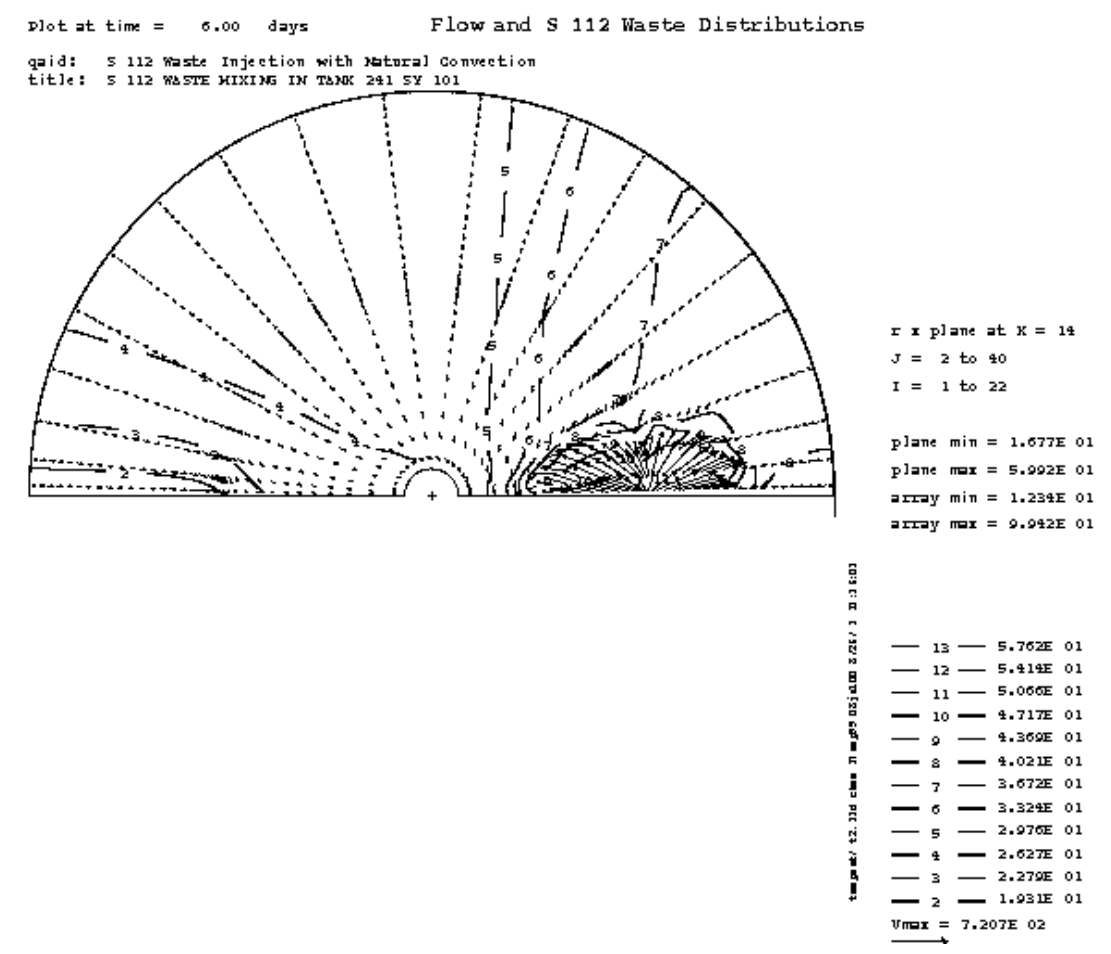

Figure 3.23. Predicted Horizontal Distributions of Flow and Concentration on the SY-101 Sludge Surface at One Simulation Day for Injection of $1.35-\mathrm{g} / \mathrm{mL}$ S-112 Waste

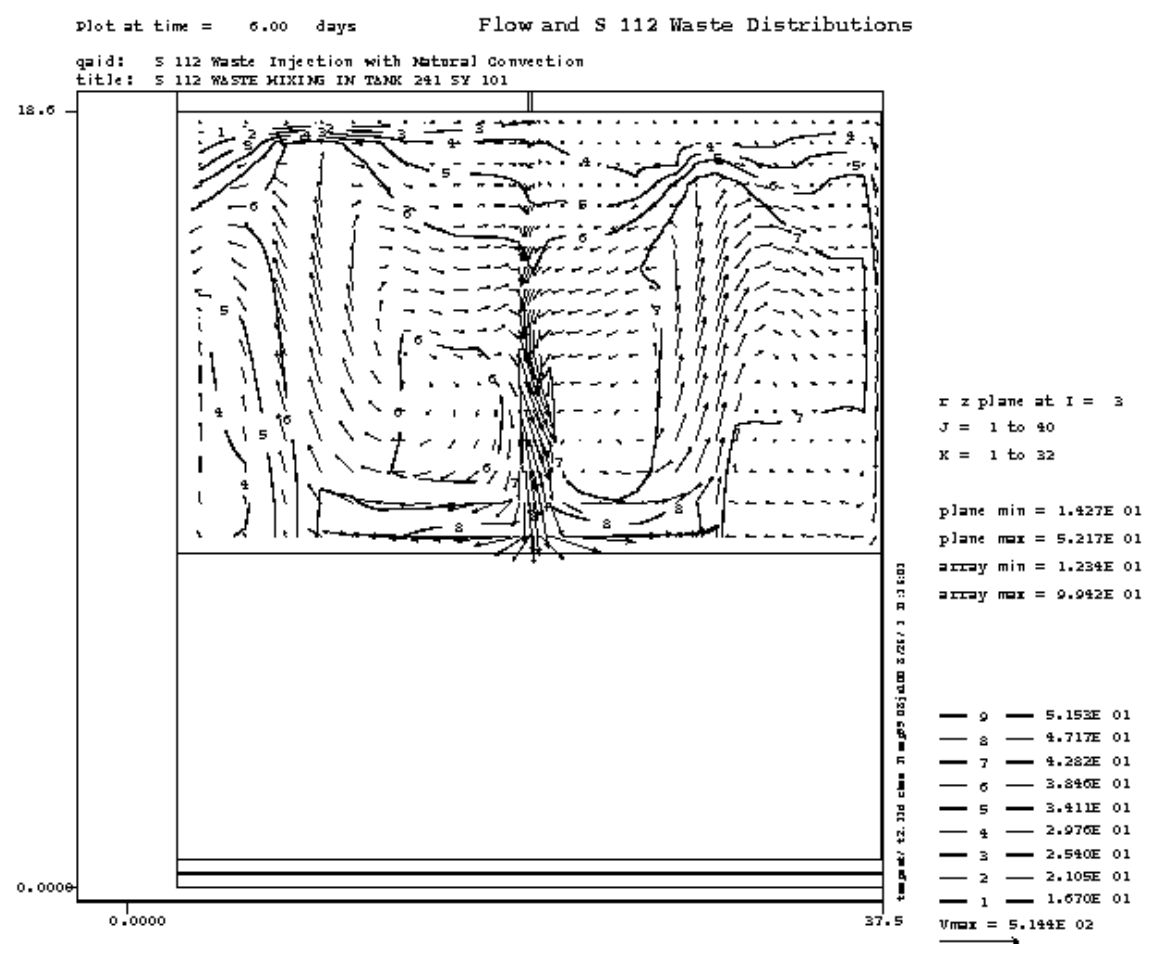

Figure 3.24. Predicted Vertical Distributions of Flow and Concentration Immediately Next to the 3 O'clock Position at One Simulation Day for Injection of 1.35-g/mL S-112 Waste 


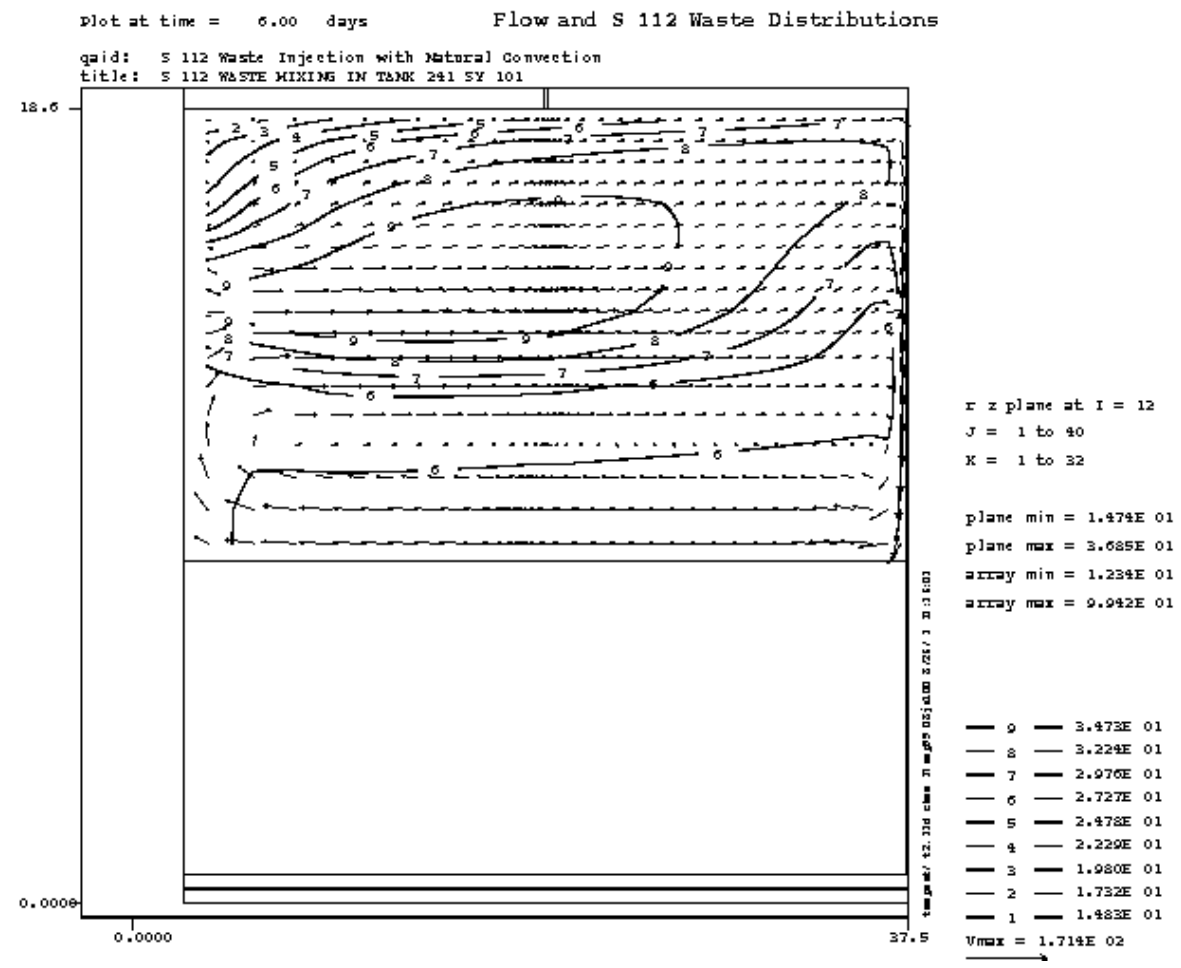

Figure 3.25. Predicted Vertical Distributions of Flow and Concentration Along the 12 O'clock Position at One Simulation Day for Injection of $1.35-\mathrm{g} / \mathrm{mL} \mathrm{S}-112$ Waste

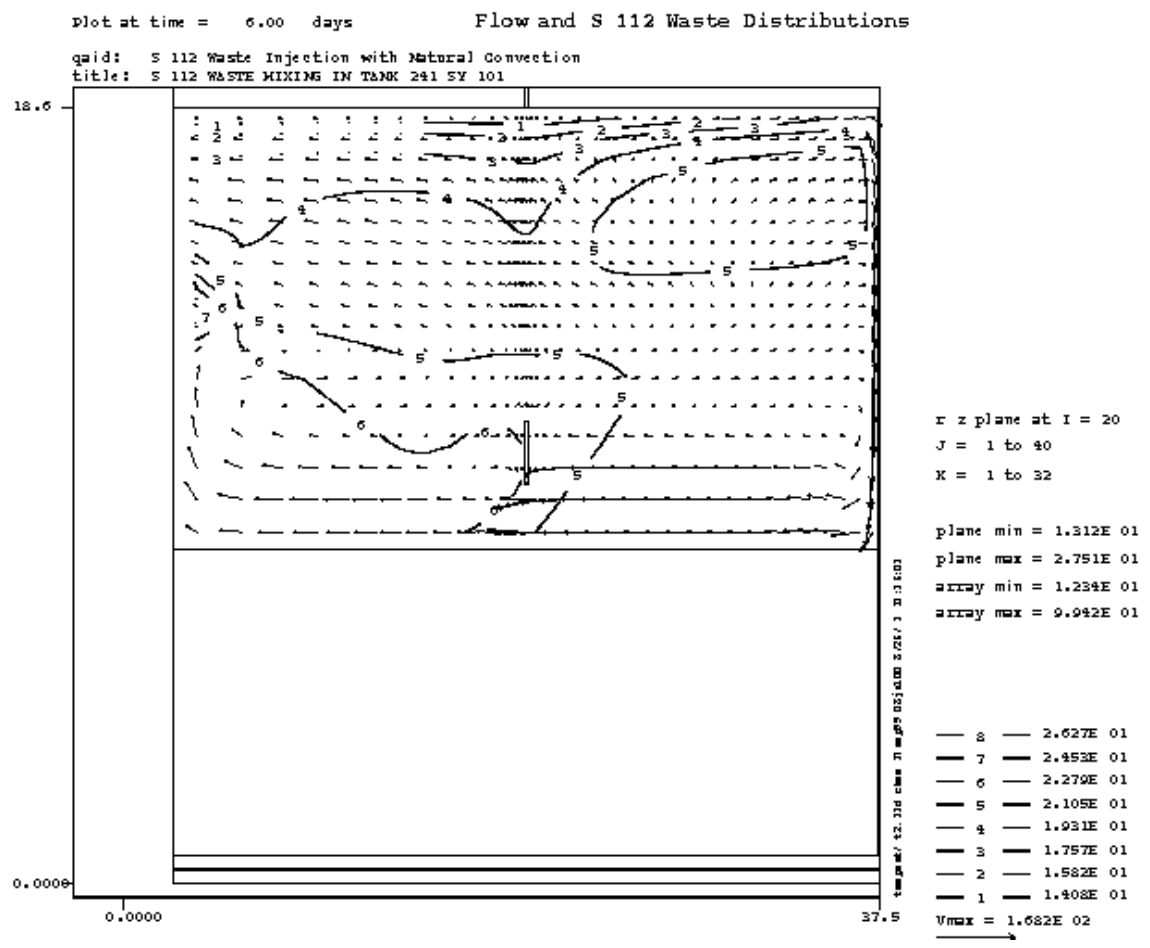

Figure 3.26. Predicted Vertical Distributions of Flow and Concentration Immediately Next to the 9 O'clock Position at One Simulation Day for Injection of 1.35-g/mL S-112 Waste 


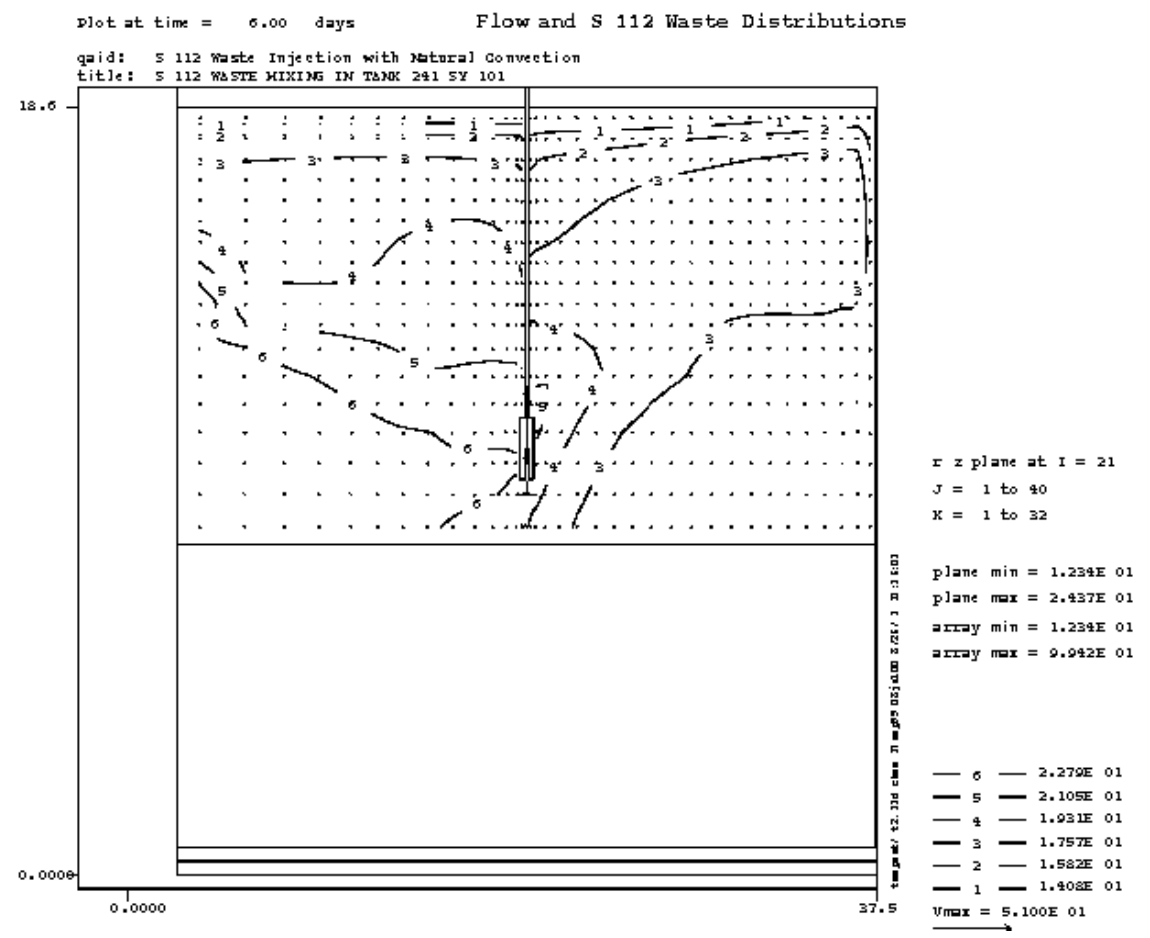

Figure 3.27. Predicted Vertical Distributions of Flow and Concentration Along the 9 O'clock Position at One Simulation Day for Injection of $1.35-\mathrm{g} / \mathrm{mL} \mathrm{S}-112$ Waste

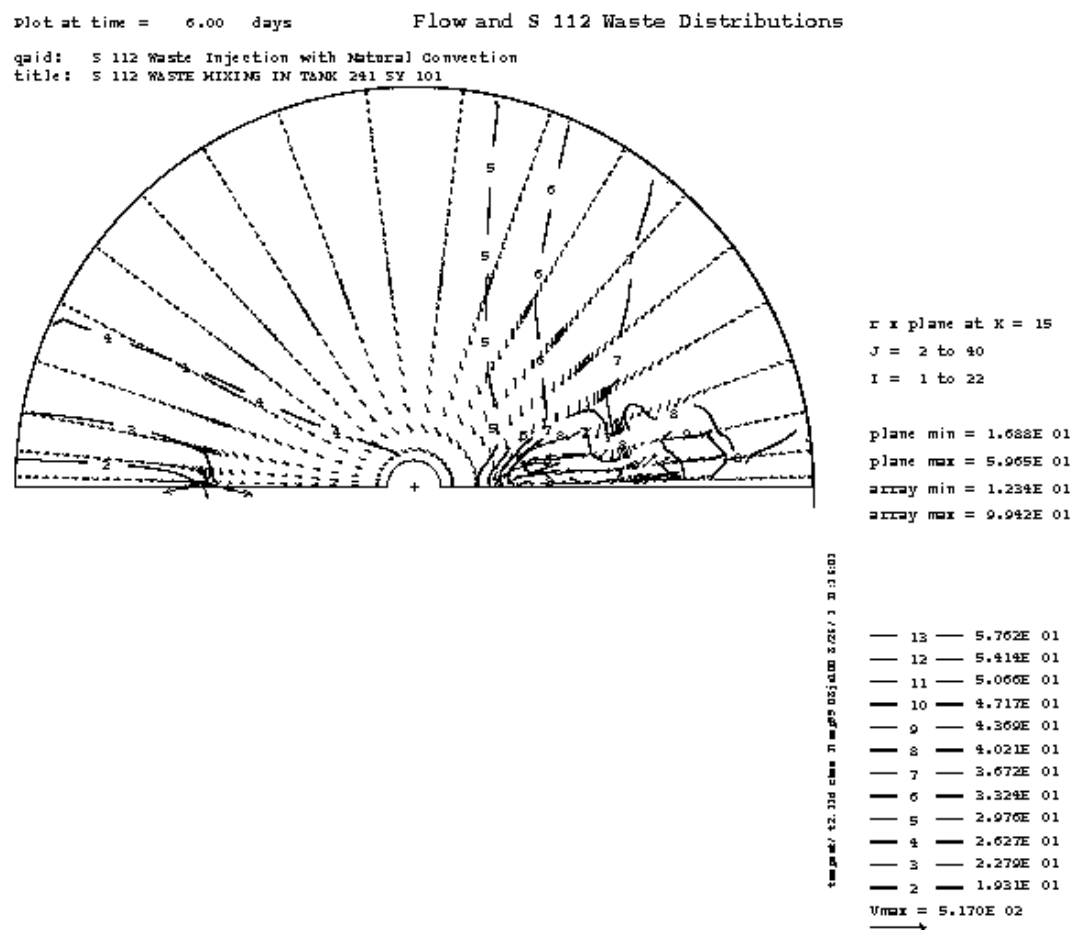

Figure 3.28. Predicted Horizontal Distributions of Flow and Concentration at SY-101 Transfer Pump Inlet Elevation (102 in. above tank bottom) at One Simulation Day for Injection of $1.35-\mathrm{g} / \mathrm{mL} \mathrm{S}-112$ Waste 


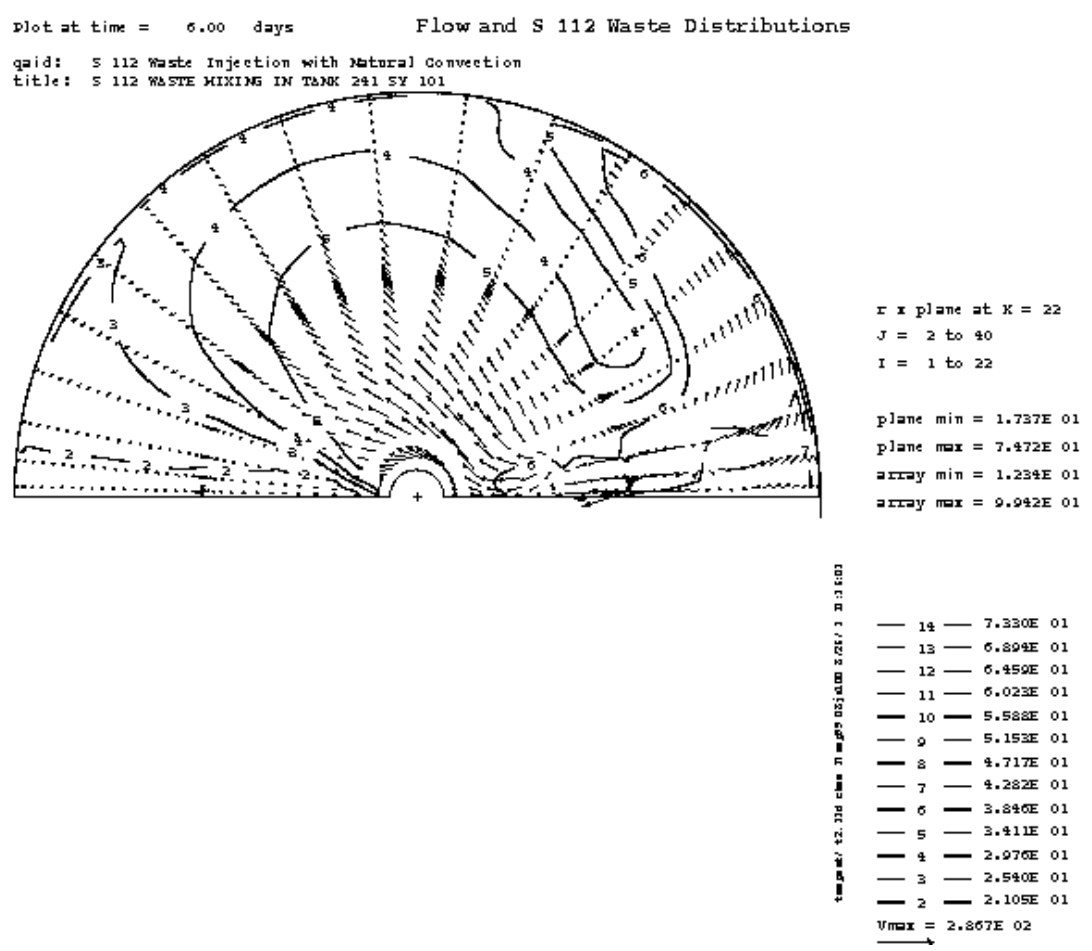

Figure 3.29. Predicted Horizontal Distributions of Flow and Concentration at the Mid-Depth of SY-101 Liquid Waste at One Simulation Day for Injection of $1.35-\mathrm{g} / \mathrm{mL} \mathrm{S}-112$ Waste

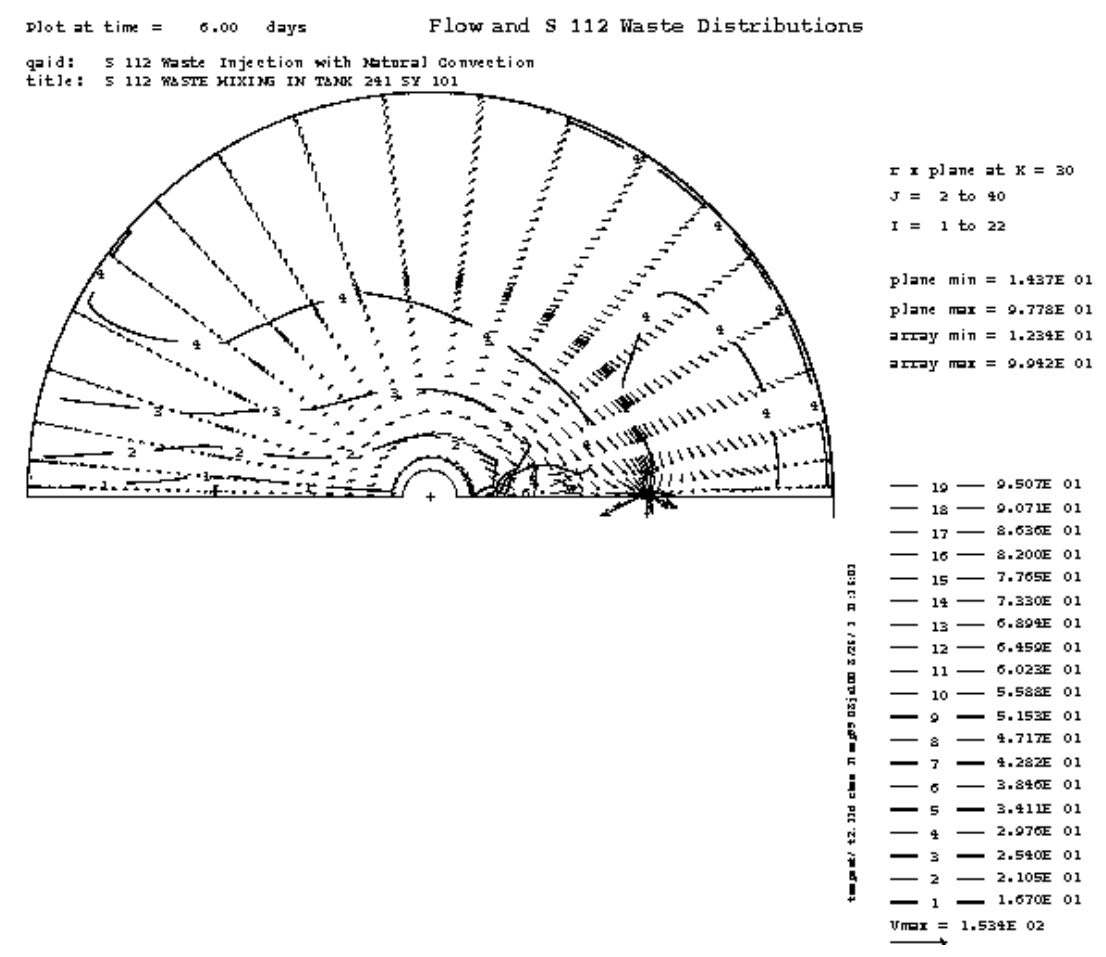

Figure 3.30. Predicted Horizontal Distributions of Flow and Concentration Just Below the Liquid Waste Surface at One Simulation Day for Injection of $1.35-\mathrm{g} / \mathrm{mL} \mathrm{S}-112$ Waste 


\subsection{Mixing S-112 and SY-101 Wastes of Unequal-Densities (Step 4)}

We conducted two additional cases where the S-112 waste had a different density than the SY-101 density of $1.35 \mathrm{~g} / \mathrm{mL}$. One of the two cases evaluated here had an S-112 waste temperature $1^{\circ} \mathrm{F}$ higher than the SY-101 liquid waste. This translates to an S-112 waste density of $1.349 \mathrm{~g} / \mathrm{mL}$, which is $0.001 \mathrm{~g} / \mathrm{mL}$ less than that of SY-101 waste. Thus, the evaluation results for this case are equally applicable to other cases as long as the $\mathrm{S}-112$ density is $1.349 \mathrm{~g} / \mathrm{mL}$. The second case assessed here is Case 2, as shown in Section 2. This case has an S-112 waste density of $1.25 \mathrm{~g} / \mathrm{mL}$, while SY-101 waste has a density of $1.35 \mathrm{~g} / \mathrm{mL}$. As discussed below, Case 2 with lighter S-112 waste significantly limits waste mixing. Thus Case 3 with the S-112 density of $1.10 \mathrm{~g} / \mathrm{mL}$ was not assessed.

\subsubsection{Slightly Warmer S-112 Waste}

S-112 waste whose temperature is $1^{\circ} \mathrm{F}$ above the SY-101 waste has a density of $1.349 \mathrm{~g} / \mathrm{mL}$. We assumed that this slightly lighter waste was injected into Tank SY-101 at a rate of $80 \mathrm{gpm}$. All other conditions are the same of those of the equal density case presented in Section 3.4. Similar to the equal density case, this simulation began with the simulation results at the end of the fifth day of natural convection modeling (see Figures 3.7 and 3.8) as the starting condition.

Because the incoming S-112 waste is very slightly lighter than the receiving SY-101 liquid waste, the S-112 waste jet did not reach the SY-101 sludge surface, as shown in Figure 3.31. This figure shows the flow and S-112 concentration in the vertical plane containing the S-112 injection point at the 3 o'clock position after 12 hours of S-112 waste transfer. At that time, 57,600 gallons of S-112 waste have been transferred into Tank SY-101. On the sludge surface, the S-112 waste concentration was $11 \%$ compared with $50 \%$ in the equal waste density case discussed in Section 3.4 (see Figure 3.13).

Predicted flow and S-112 concentrations at the 12 o'clock and 9 o'clock positions at 12 simulation hours are shown in Figures 3.32 and 3.33, respectively. The predicted horizontal distributions at mid-liquid depth are shown in Figure 3.34. Although the S-112 waste jet would not reach the sludge surface, jet induced flow and natural convection mix the S-112 and SY-101 wastes to about the same extent as in the equal density case. However, unlike the equal density case, the minimum S-112 waste concentration occurs just below mid-liquid depth.

The minimum S-112 concentration after 12 hours of waste transfer was predicted to be $2 \%$, compared with $1 \%$ in the equal waste density case. Using the conversion in Table 3.3 , this waste mixture contains $\mathrm{NO}_{2}{ }^{-}, \mathrm{NO}_{3}{ }^{-}$, and $\mathrm{OH}^{-}$concentrations of $50,000,136,000$, and $16,800 \mu \mathrm{g} / \mathrm{mL}$, respectively. Similarly, the waste being withdrawn by the transfer pump has a concentration of $7 \%$, compared with $6 \%$ in the equal density case. Thus, it contains $\mathrm{NO}_{2}^{-}, \mathrm{NO}_{3}^{-}$, and $\mathrm{OH}^{-}$ concentrations of $48,400,140,000$, and $16,600 \mu \mathrm{g} / \mathrm{mL}$, respectively. 


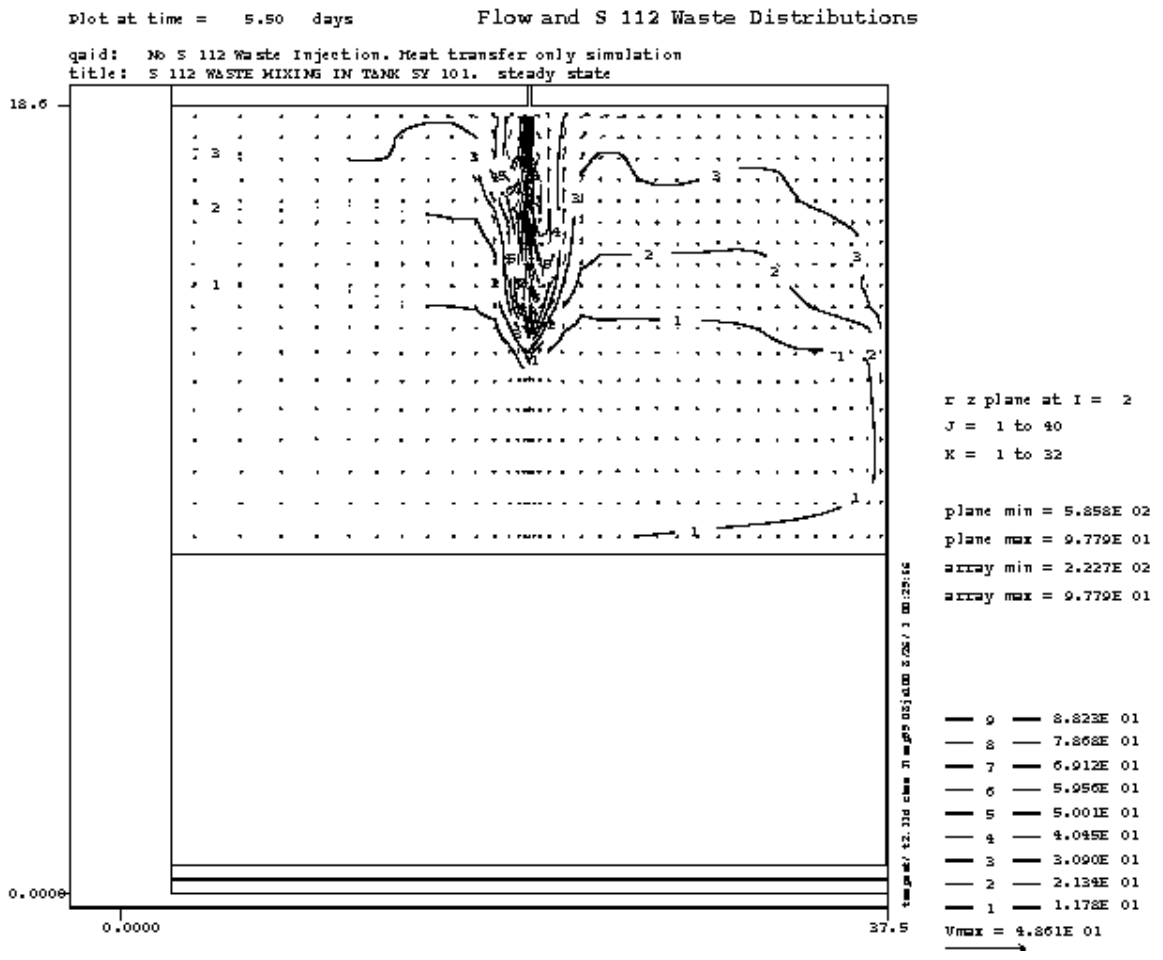

Figure 3.31. Predicted Vertical Distributions of Flow and Concentration Along 3 O'clock Position at 12 Simulation hr for Slightly Lighter S-112 Waste Injection

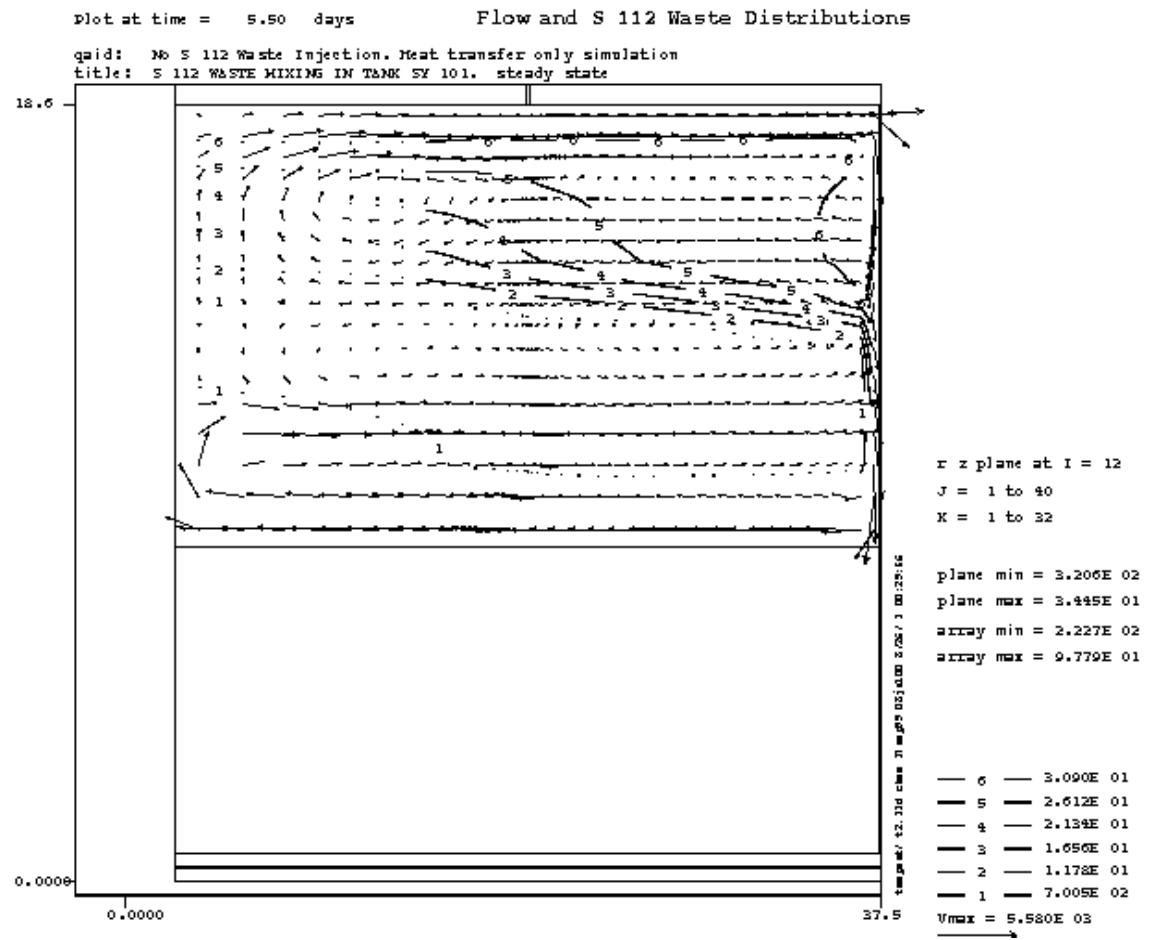

Figure 3.32. Predicted Vertical Distributions of Flow and Concentration Along the 12 O'clock Position at 12 Simulation hr for Slightly Lighter S-112 Waste Injection 


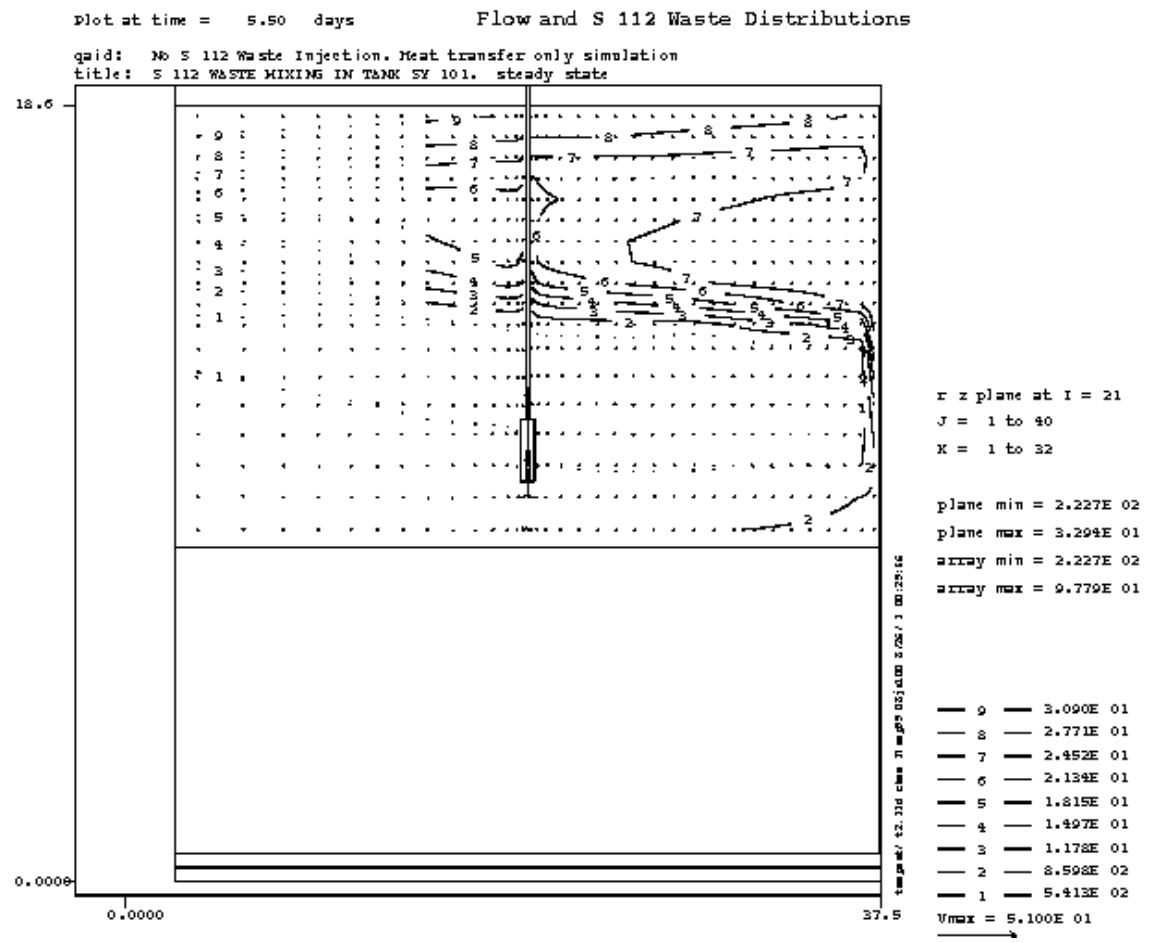

Figure 3.33. Predicted Vertical Distributions of Flow and Concentration Along the 9 O'clock Position at 12 Simulation hr for Slightly Lighter S-112 Waste Injection

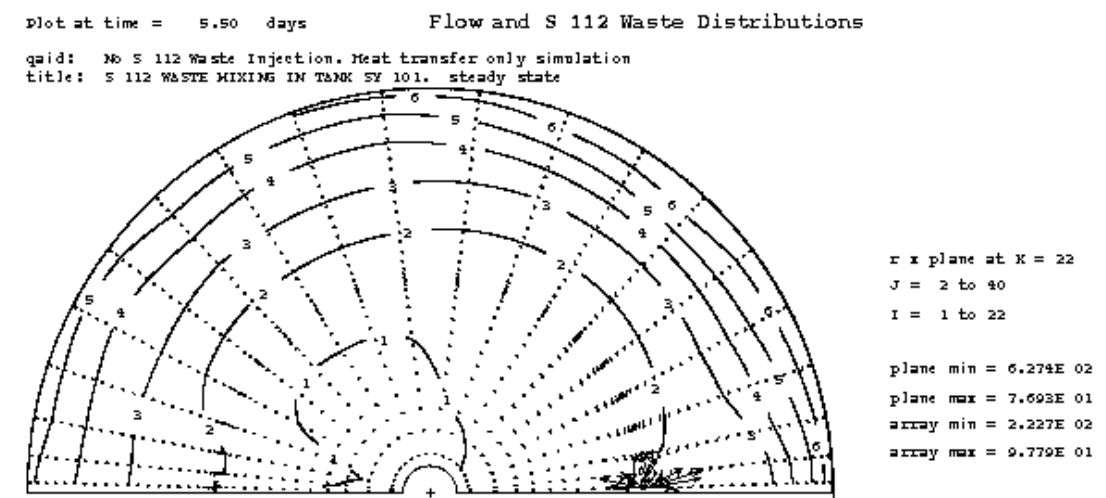

Figure 3.34. Predicted Horizontal Distributions of Flow and Concentration at the Mid-Depth of SY-101 Liquid Waste at 12 Simulation hr for Slightly Lighter S-112 Waste Injection 
After one day of waste transfer, predicted flow and S-112 waste distribution are shown in Figures 3.35 though 3.38. At that time, 115,200 gallons of S-112 waste have been introduced into the tank. Compared with S-112 concentration distributions at 12 simulation hours, the S112 waste at one simulation day is more uniformly distributed, as expected.

For example, the S-112 waste concentration on the sludge surface directly below the waste injection point increased to $35 \%$, compared with $11 \%$ at 12 simulation hours (see Figures 3.31 and 3.35). The minimum S-112 concentration after one day is expected to be $11 \%$, which would be $2 \%$ at the earlier time. The waste withdrawn by the transfer pump contains $22 \% \mathrm{~S}-112$ waste, compared with $7 \%$ at 12 simulation hours.

Even though the injected waste would not reach the sludge surface, the minimum S-112 waste concentration (11\%) within the tank is $11 \%$, compared with $12 \%$ for the equal density case discussed in Section 3.4. The S-112 concentration at the transfer pump inlet is $22 \%$ compared with $20 \%$ for the equal density case.

The waste mixture with $11 \% \mathrm{~S}-112$ waste contains $\mathrm{NO}_{2}{ }^{-}, \mathrm{NO}_{3}{ }^{-}$, and $\mathrm{OH}^{-}$concentrations of $47,000,143,000$, and $16,400 \mu \mathrm{g} / \mathrm{mL}$, respectively. Similarly, the waste being withdrawn by the transfer pump (22\% S-112 waste) has $\mathrm{NO}_{2}{ }^{-}, \mathrm{NO}_{3}{ }^{-}$, and $\mathrm{OH}^{-}$concentrations of 43,400, 153,000, and $16,000 \mu \mathrm{g} / \mathrm{mL}$, respectively.

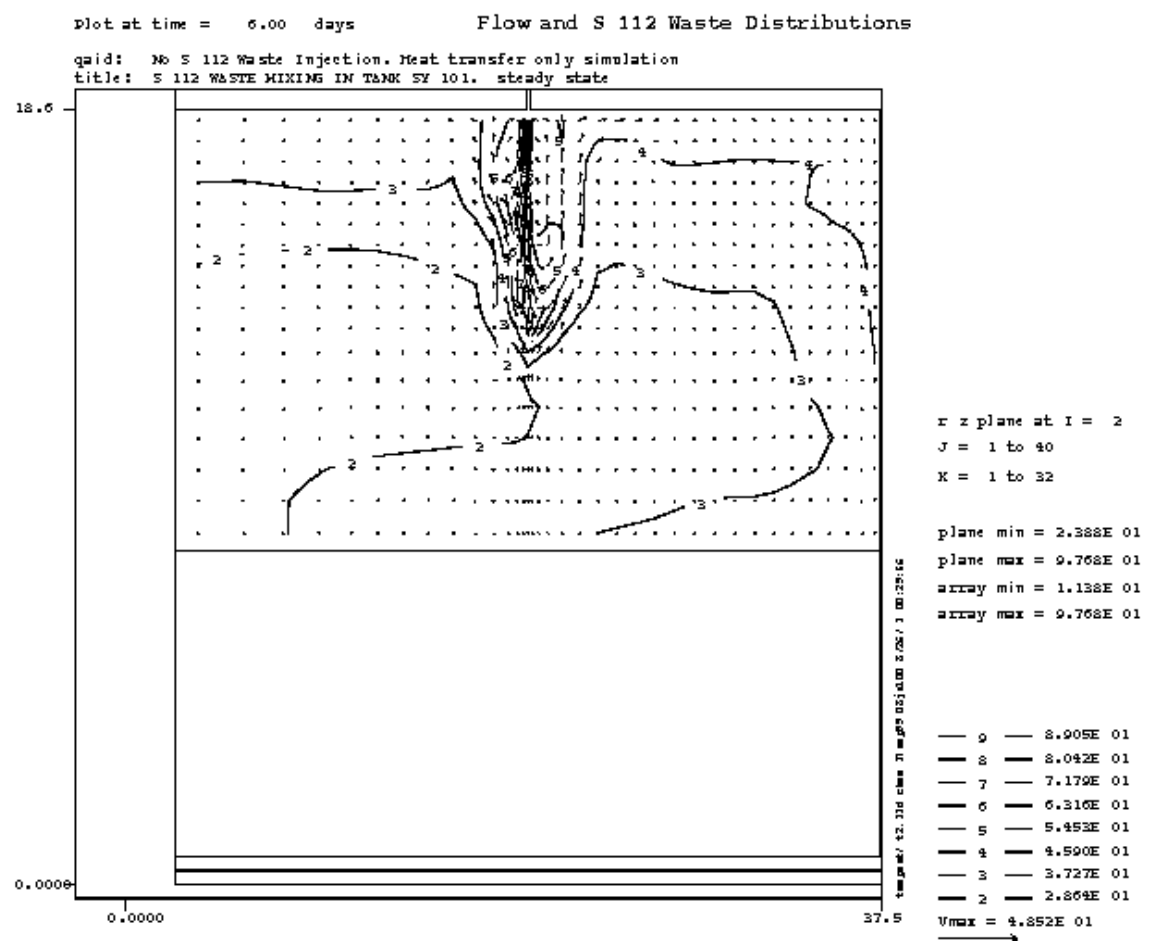

Figure 3.35. Predicted Vertical Distributions of Flow and Concentration Along 3 O'clock Position at One Simulation Day for Slightly Lighter S-112 Waste Injection 


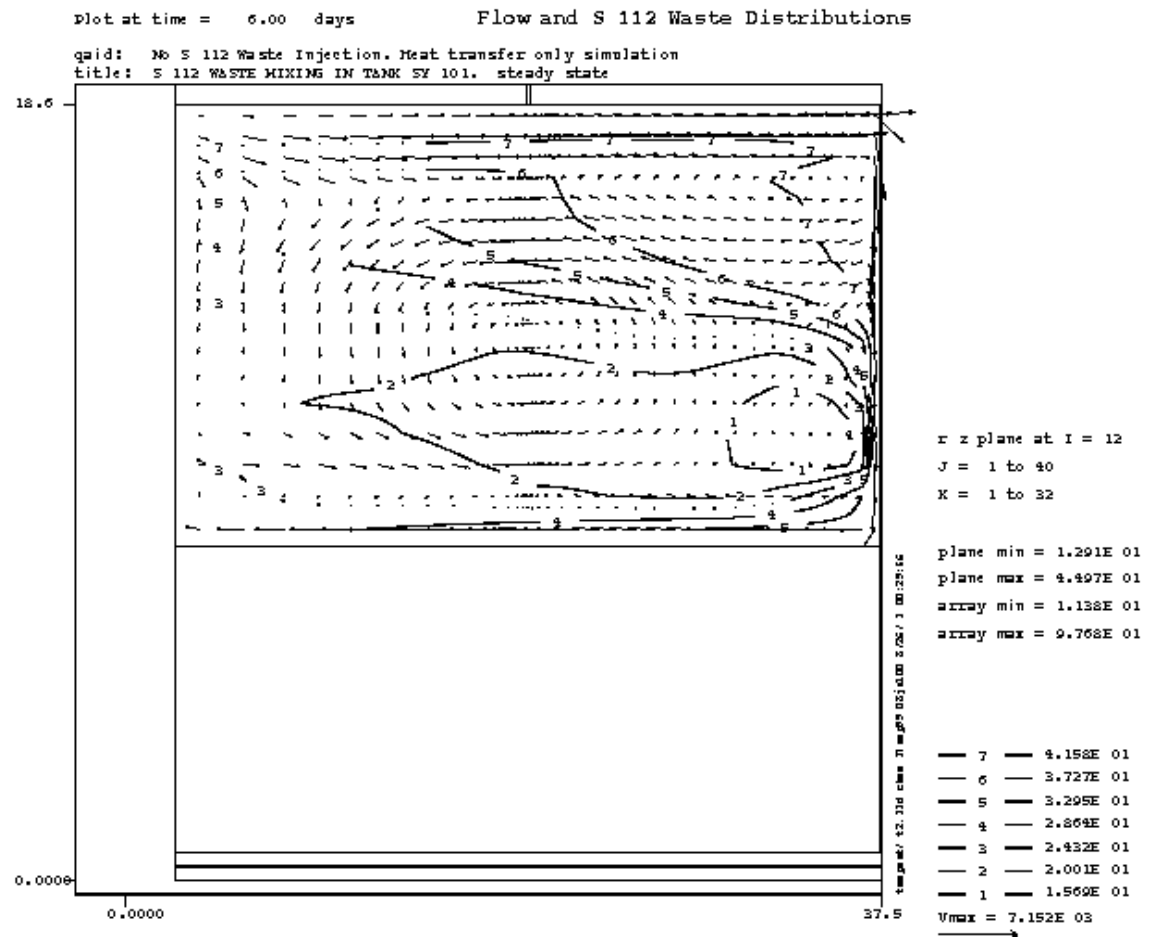

Figure 3.36. Predicted Vertical Distributions of Flow and Concentration Along the 12 O'clock Position at One Simulation Day for Slightly Lighter S-112 Waste Injection

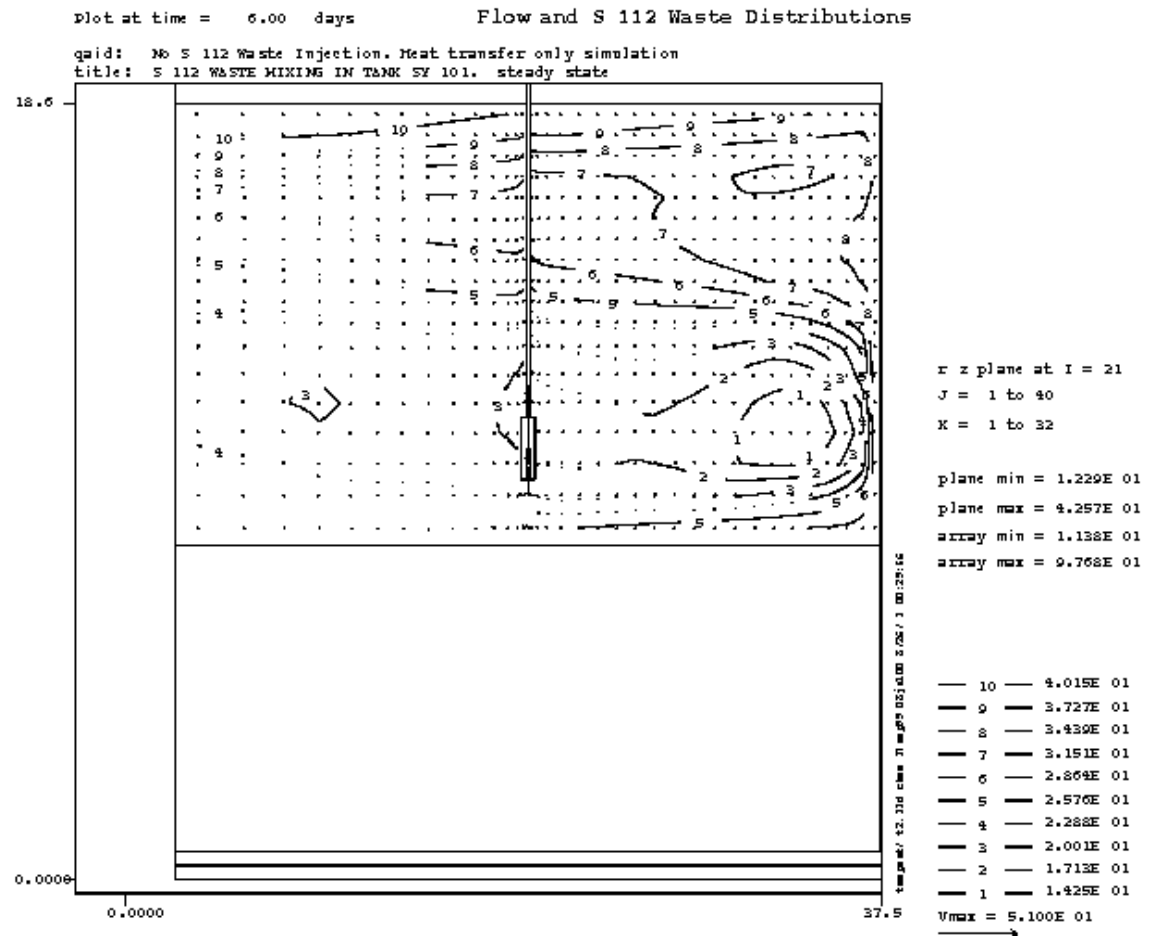

Figure 3.37. Predicted Vertical Distributions of Flow and Concentration Along the 9 O'clock Position at One Simulation Day for Slightly Lighter S-112 Waste Injection 


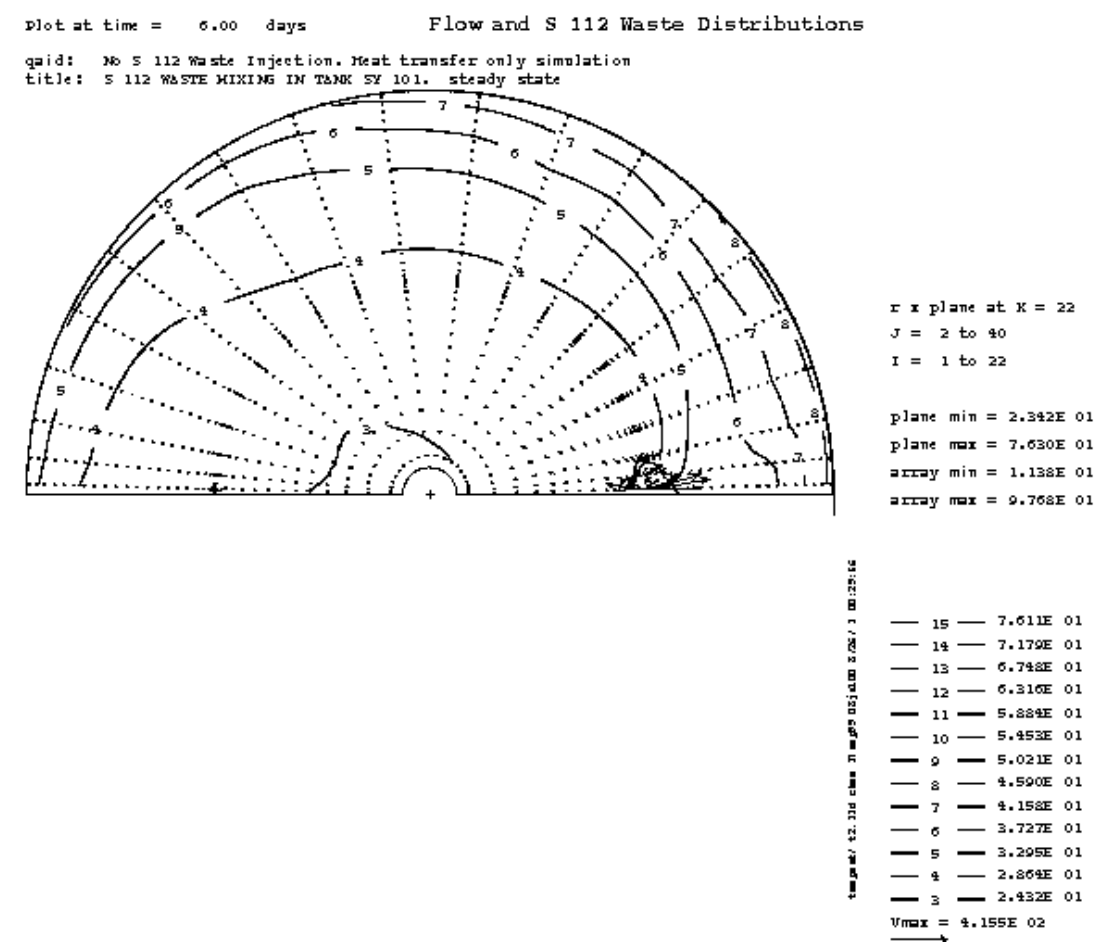

Figure 3.38. Predicted Horizontal Distributions of Flow and Concentration at the Mid-Depth of SY-101 Liquid Waste at One Simulation Day for Slightly Lighter S-112 Waste Injection

\subsubsection{S-112 Waste Density of $1.25 \mathrm{~g} / \mathrm{mL}$}

S-112 waste properties will change as saltwell pumping to retrieve the liquid waste from the tank progresses. The characteristics of waste in receiving Tank SY-101 also may change, reflecting that SY-101 is an active tank that receives and retrieves various wastes. At some stage of saltwell pumping, the S-112 and SY-101 waste properties listed in Table 3.4 are expected to occur (listed as Case 2 in Section 2).

The S-112 liquid density of $1.25 \mathrm{~g} / \mathrm{mL}$ in this case is much smaller than the $1.35 \mathrm{~g} / \mathrm{mL}$ of the receiving SY-101 waste. This much lighter S-112 waste was injected into the tank at $80 \mathrm{gpm}$ in the model. Similar to two previously discussed cases (Sections 3.4 and 3.5.1), this simulation also started with the simulation results at the end of fifth day of natural convection modeling (see Figures 3.7 and 3.8) as the starting condition.

Table 3.4. S-112 and SY-101 Waste Properties for Case 2

\begin{tabular}{|c|c|c|}
\hline & S-112 Waste & SY-101 Waste \\
\hline $\mathrm{NO}_{2}^{-}, \mu \mathrm{g} / \mathrm{mL}$ & 5,520 & 49,000 \\
\hline $\mathrm{NO}_{3}{ }^{-}, \mu \mathrm{g} / \mathrm{mL}$ & 174,000 & 138,500 \\
\hline $\mathrm{OH}^{-}, \mu \mathrm{g} / \mathrm{mL}$ & 3,790 & 22,900 \\
\hline Liquid Density, $\mathrm{g} / \mathrm{mL}$ & 1.25 & 1.35 \\
\hline
\end{tabular}


Because the S-112 waste is much lighter than the SY-101 liquid waste, the S-112 waste jet hardly penetrates into the SY-101 waste, as shown in Figure 3.39. This figure depicts the flow and concentration in the vertical plane (containing the S-112 injection point) at the 3 o'clock position after 12 hours of S-112 waste transfer. On the sludge surface, S-112 waste concentration was only $0.14 \%$, compared with $50 \%$ and $11 \%$ for the previous two cases (see Figures 3.13 and 3.31).

Predicted flow and S-112 concentrations at the 12 o'clock and 9 o'clock positions at 12 simulation hours are shown in Figure 3.40 and 3.41, respectively. Because the S-112 waste cannot move very far downward, it spreads horizontally and thus its lowest concentration occurs on the sludge surface.

The minimum S-112 concentration after 12 hours of waste transfer is predicted to be $0.08 \%$, compared with $1 \%$ in the equal density case. Thus, the waste concentration there is basically the same as the SY-101 waste, having $\mathrm{NO}_{2}{ }^{-}, \mathrm{NO}_{3}{ }^{-}$, and $\mathrm{OH}^{-}$concentrations of 49,000, 138,500, and $22,900 \mu \mathrm{g} / \mathrm{mL}$, respectively. Similarly, the waste withdrawn by the transfer pump has an S-112 concentration of $0.15 \%$, compared with $6 \%$ for the equal density case (Section 3.4 ). Therefore, it also has nearly the same $\mathrm{NO}_{2}{ }^{-}, \mathrm{NO}_{3}{ }^{-}$, and $\mathrm{OH}^{-}$concentrations as $\mathrm{SY}-101$ waste. Its density is also expected to be nearly the same as that of SY-101 waste $(1.35 \mathrm{~g} / \mathrm{mL})$. Table 3.5 converts predicted S-112 waste concentrations to concentrations of $\mathrm{NO}_{2}{ }^{-}, \mathrm{NO}_{3}{ }^{-}$, and $\mathrm{OH}^{-}$.

Table 3.5. Conversion of S- 112 Waste Fraction to $\mathrm{NO}_{2}{ }^{-}, \mathrm{NO}_{3}{ }^{-}$, and $\mathrm{OH}^{-}$Concentrations

\begin{tabular}{|c|c|c|c|}
\hline \multirow{2}{*}{$\begin{array}{c}\text { Fraction of } \\
\text { Predicted S-112 } \\
\text { Waste Concentration }\end{array}$} & \multicolumn{3}{|c|}{$\begin{array}{c}\text { Concentration of Waste Mixture } \\
\mu \mathrm{g} / \mathrm{mL}\end{array}$} \\
\hline & $\mathrm{NO}_{2}^{-}$ & $\mathrm{NO}_{3}^{-}$ & $\mathrm{OH}^{-}$ \\
\hline 0 & 49,000 & 138,500 & 22,900 \\
\hline 0.1 & 44,700 & 142,000 & 21,000 \\
\hline 0.2 & 40,300 & 145,600 & 19,100 \\
\hline 0.3 & 35,700 & 149,100 & 17,200 \\
\hline 0.4 & 31,600 & 152,700 & 15,300 \\
\hline 0.5 & 27,300 & 156,300 & 13.300 \\
\hline 0.6 & 22,900 & 159,800 & 11,400 \\
\hline 0.7 & 18,600 & 163,400 & 9,520 \\
\hline 0.8 & 14,200 & 166,900 & 7,610 \\
\hline 0.9 & 9870 & 170,500 & 5,700 \\
\hline 1.0 & 5,520 & 174,000 & 3,790 \\
\hline
\end{tabular}




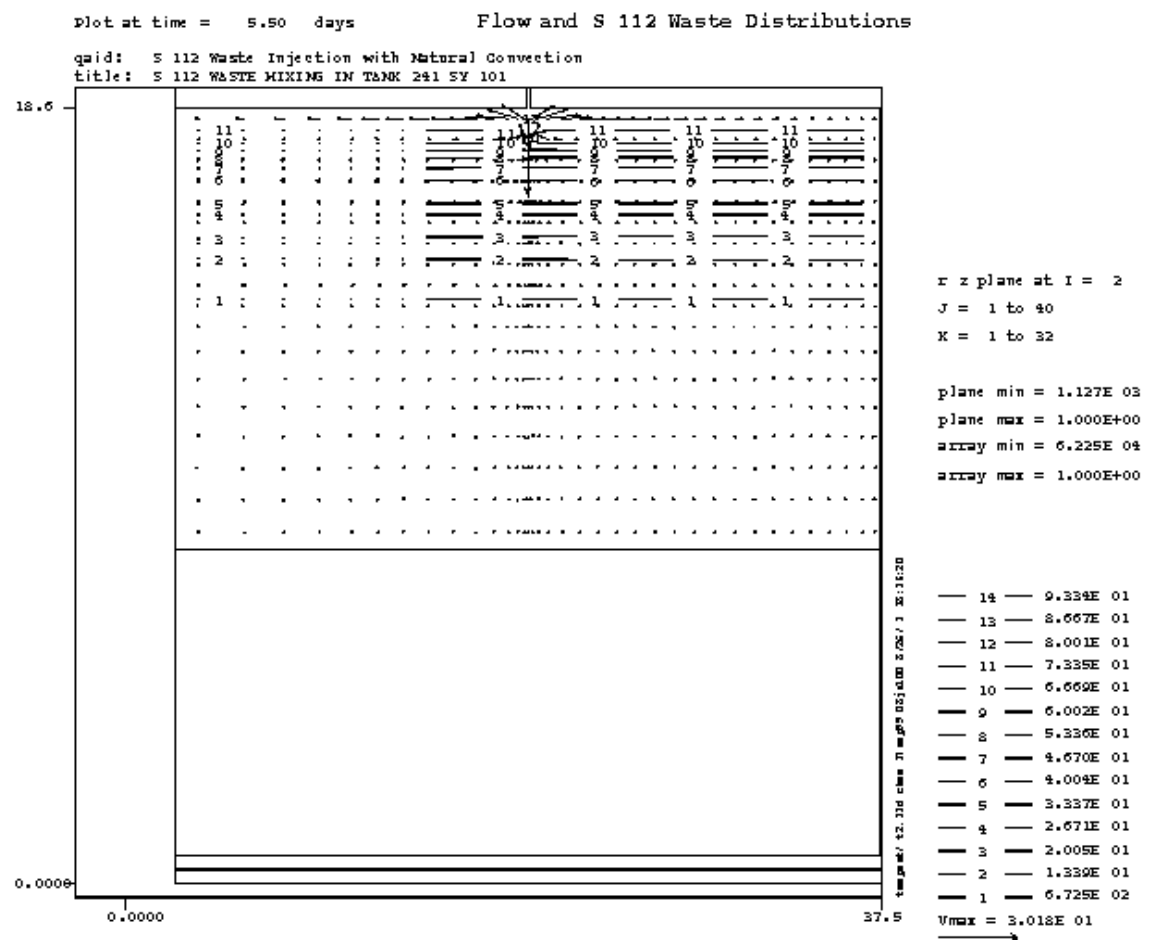

Figure 3.39. Predicted Vertical Distributions of Flow and Concentration Along 3 O'clock Position at 12 Simulation $\mathrm{hr}$ for Injection of $1.25-\mathrm{g} / \mathrm{mL} \mathrm{S}-112$ Waste

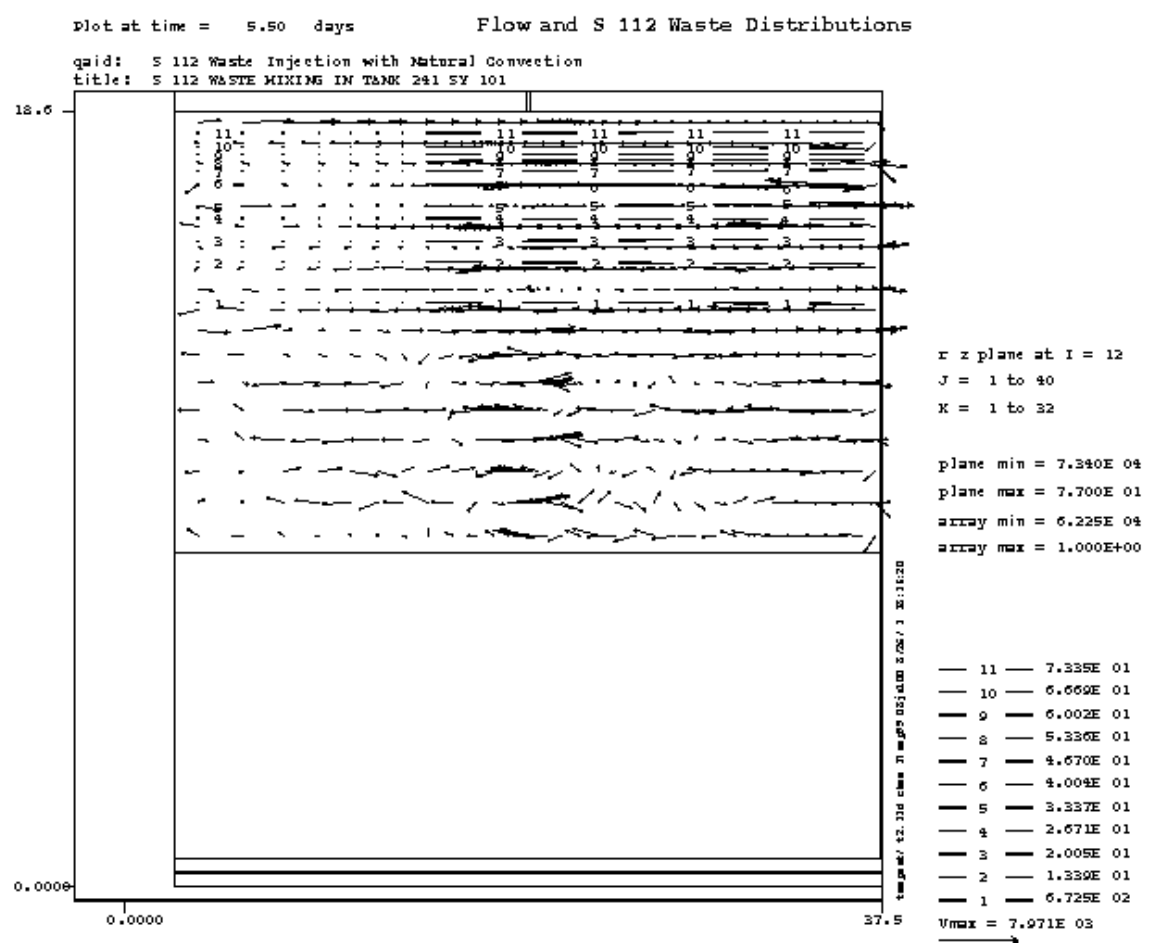

Figure 3.40. Predicted Vertical Distributions of Flow and Concentration Along the 12 O'clock Position at 12 Simulation hr for Injection of $1.25-\mathrm{g} / \mathrm{mL} \mathrm{S}-112$ Waste 


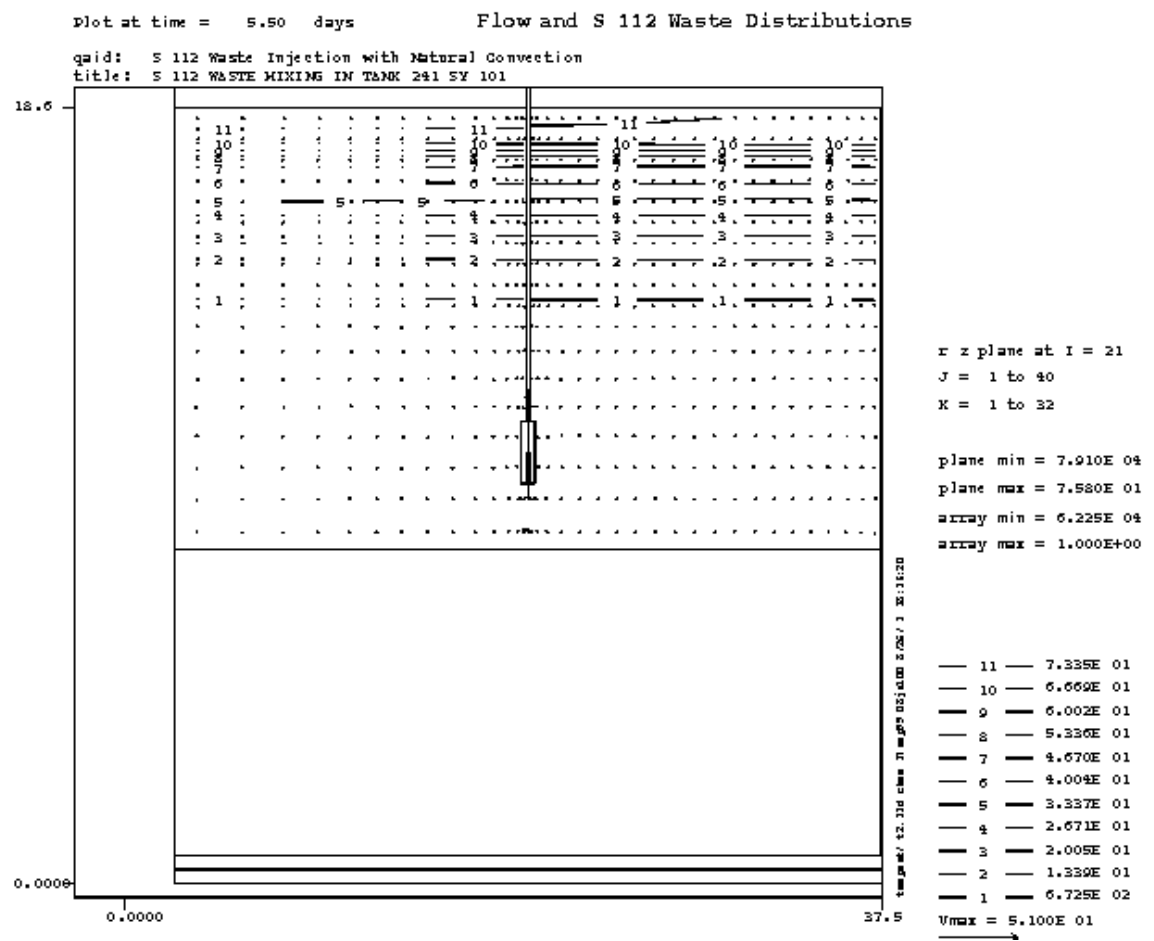

Figure 3.41. Predicted Vertical Distributions of Flow and Concentration Along the 9 O'clock Position at 12 Simulation hr for Injection of $1.25-\mathrm{g} / \mathrm{mL} \mathrm{S}-112$ Waste

Even after one day of waste transfer, the very nonuniform distribution of S-112 waste has not changed much, as shown in Figures 3.42 though 3.44. At that time, 115,200 gallons of S-112 waste have been introduced into Tank SY-101. For example, the S-112 waste concentrations on the sludge surface directly below the injection point increased to only $3 \%$ (see Figure 3.42 ). The minimum S-112 concentration after one day is expected to be $2.9 \%$. The waste withdrawn by the transfer pump contains only $3.3 \% \mathrm{~S}-112$ waste. This mixture contains $\mathrm{NO}_{2}{ }^{-}, \mathrm{NO}_{3}{ }^{-}$, and $\mathrm{OH}^{-}$ concentrations of $47,700,140,000$, and $22,300 \mu \mathrm{g} / \mathrm{mL}$, respectively. Its density is also expected to be $1.347 \mathrm{~g} / \mathrm{mL}$, almost the same as SY-101 waste.

Thus, when the injected S-112 waste has a much lower density, its mixing in the tank is very limited. S-112 waste with density less than $1.25 \mathrm{~g} / \mathrm{mL}$ would further stratify the S-112 waste from the SY-101 waste, resulting in less mixing.

Given the previous results, the mixing evaluation for $\mathrm{S}-112$ waste with a $1.1-\mathrm{g} / \mathrm{mL}$ density was not performed. 


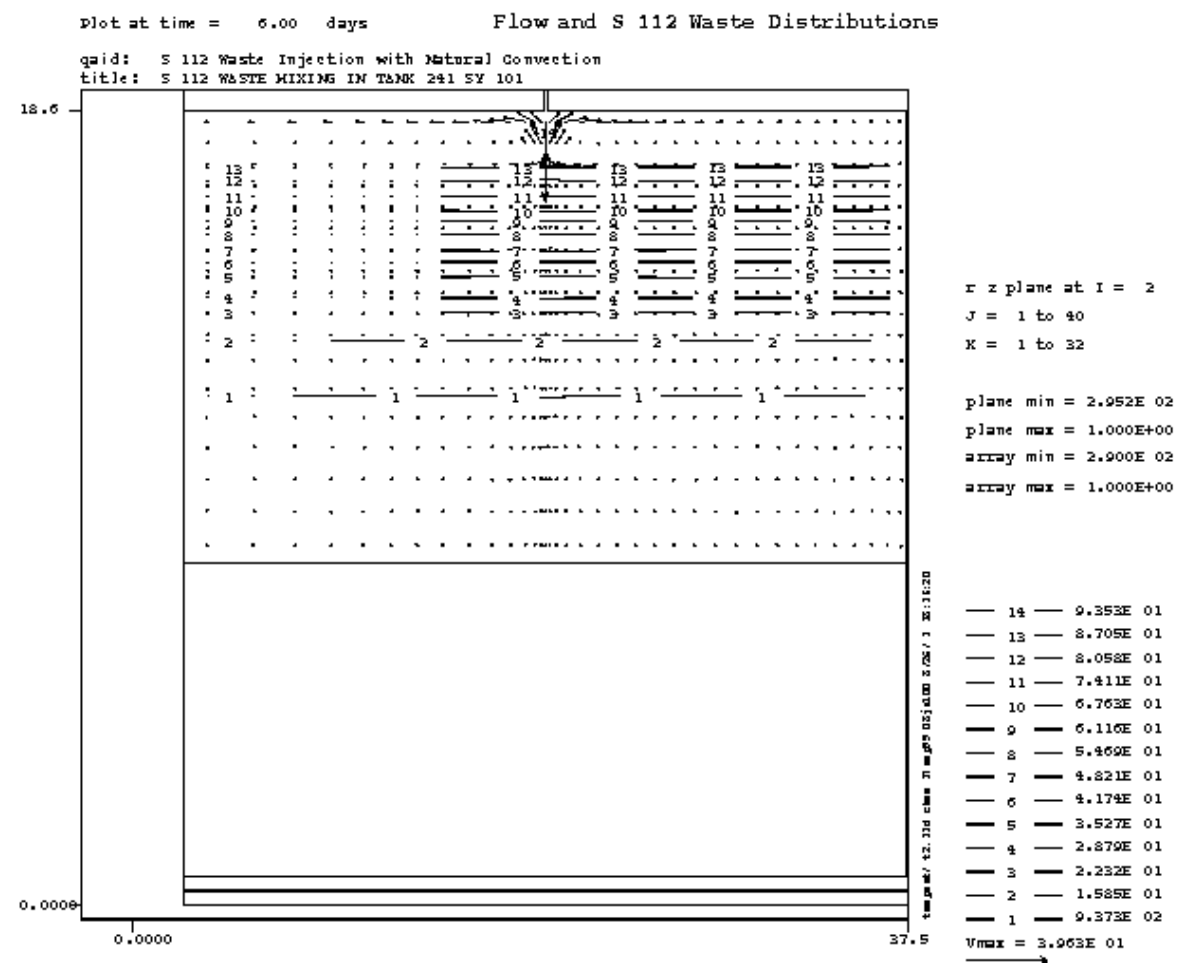

Figure 3.42. Predicted Vertical Distributions of Flow and Concentration Along 3 O'clock Position at One Simulation Day for Injection of $1.25-\mathrm{g} / \mathrm{mL} \mathrm{S}-112$ Waste

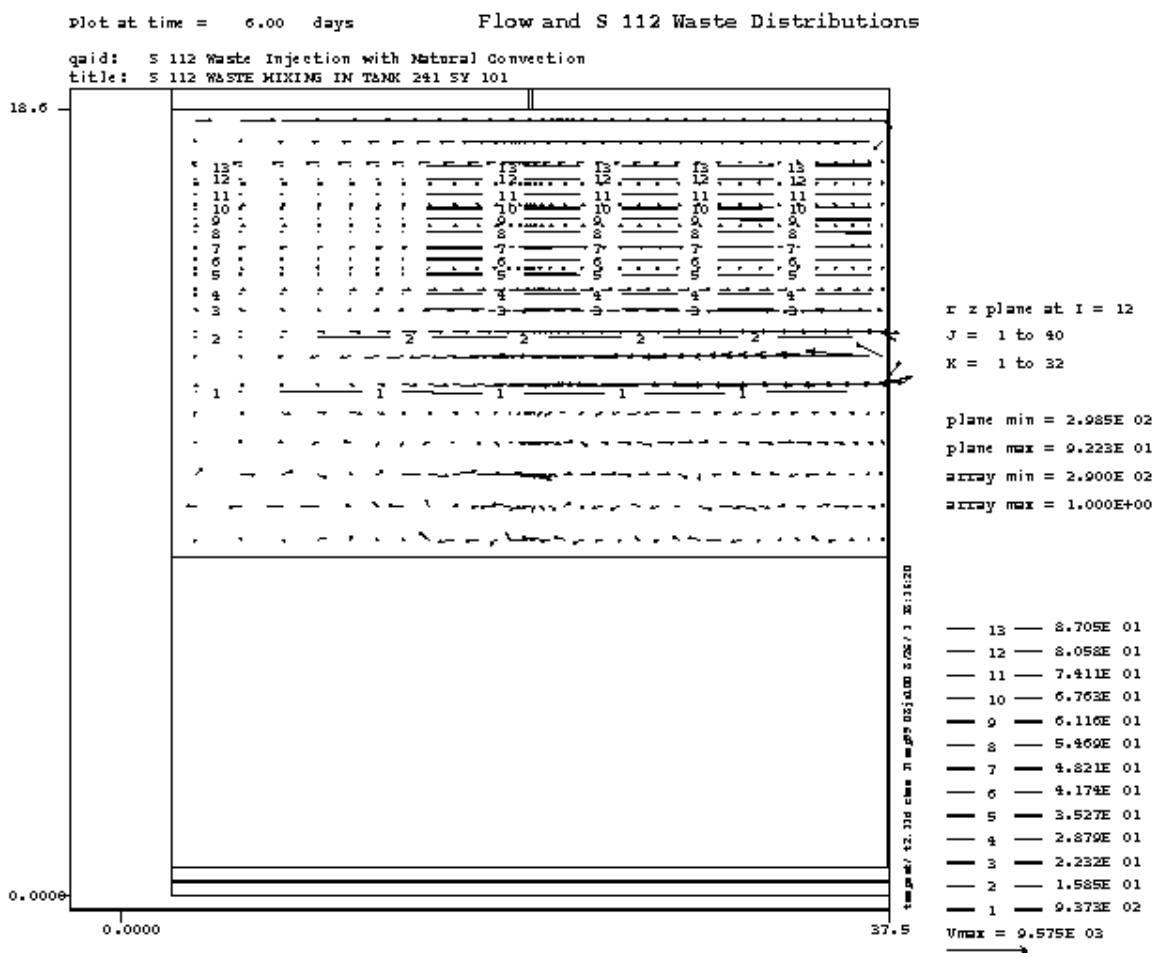

Figure 3.43. Predicted Vertical Distributions of Flow and Concentration Along the 12 O'clock Position at One Simulation Day for Injection of $1.25-\mathrm{g} / \mathrm{mL} \mathrm{S}-112$ Waste 


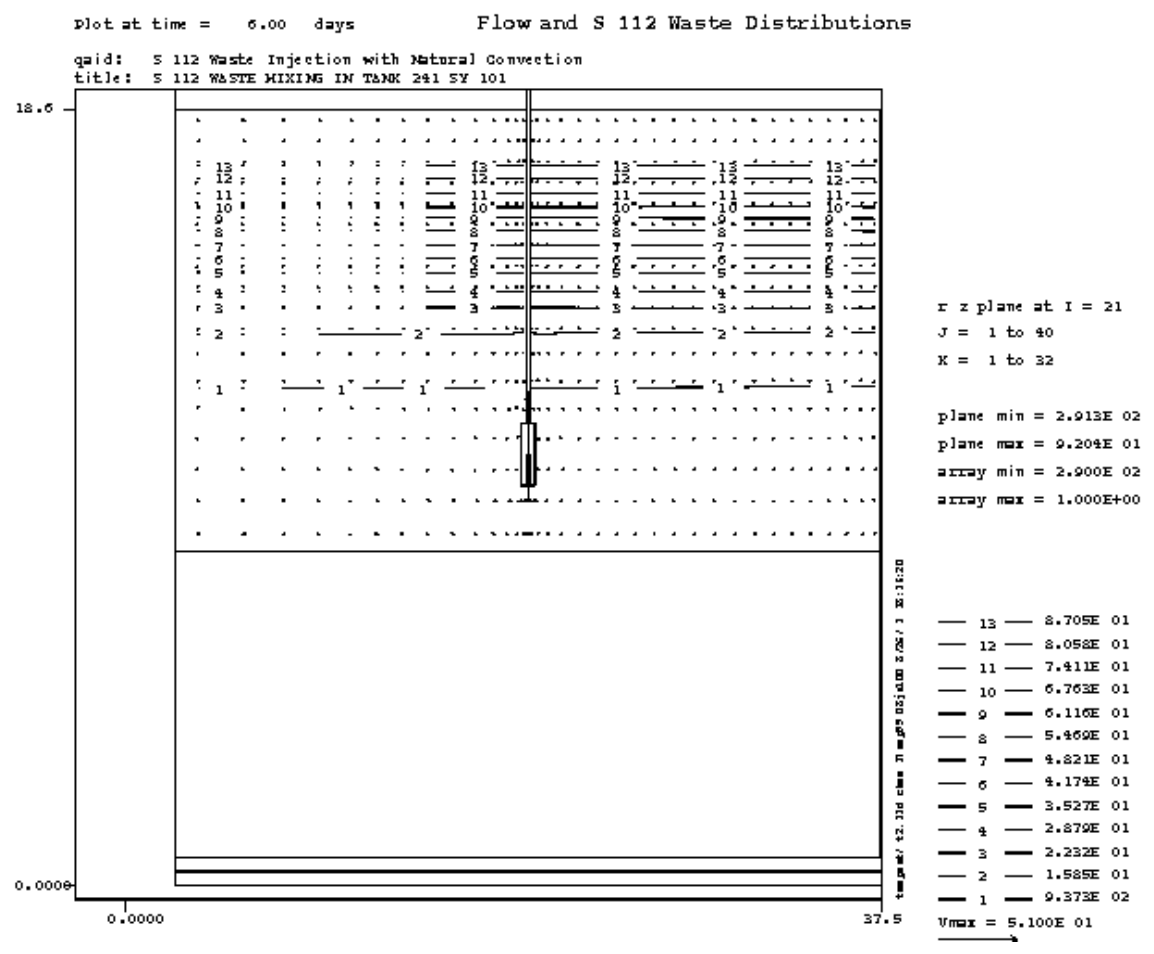

Figure 3.44. Predicted Vertical Distributions of Flow and Concentration Along the 9 O'clock Position at One Simulation Day for Injection of $1.25-\mathrm{g} / \mathrm{mL} \mathrm{S}-112$ Waste 


\subsection{Summary and Conclusions}

This study evaluated the mixing of S-112 liquid waste with SY-101 waste in Tank SY-101 and determined the resulting waste properties. This assessment was performed to avoid potential double-shell tank corrosion and pipeline plugging. We applied the time-varying, threedimensional computer code, TEMPEST (Onishi and Trent 1999) to Tank SY-101 receiving the S-112 liquid waste. We selected the S-112 and SY-101 liquid waste characteristics shown in Table 4.1.

Table 4.1. S-112 and SY-101 Liquid Waste Characteristics

\begin{tabular}{|l|c|c|c|c|}
\hline \multirow{2}{*}{$\begin{array}{c}\text { Waste } \\
\text { Characteristic }\end{array}$} & \multicolumn{2}{c|}{ Case 1 } & \multicolumn{2}{c|}{ Case 2 } \\
\cline { 2 - 5 } & S-112 Waste & SY-101 Waste & S-112 Waste & SY-101 Waste \\
\hline $\mathrm{NO}_{2}^{-}, \mu \mathrm{g} / \mathrm{mL}$ & 17,400 & 50,700 & 5,520 & 49,000 \\
\hline $\mathrm{NO}_{3}^{-}, \mu \mathrm{g} / \mathrm{mL}$ & 218,000 & 134,000 & 174,000 & 138,500 \\
\hline $\mathrm{OH}^{-}, \mu \mathrm{g} / \mathrm{mL}$ & 12,800 & 16,900 & 3,790 & 22,900 \\
\hline Liquid Density, g/mL & 1.35 & 1.35 & 1.25 & 1.35 \\
\hline
\end{tabular}

In addition to these two cases, we assessed a case in which S-112 waste was $1^{\circ} \mathrm{F}$ warmer than SY-101 waste because the modeling revealed that mixing is very sensitive to density. We conducted the assessment in the following modeling sequence:

- Predict current SY-101 temperature distributions mainly affected by decay heat generation in the convective and nonconvective layer wastes, ventilation air in annular and dome spaces, and heat loss/gain from the surrounding soil.

- Predict a natural convection flow pattern in SY-101 without S-112 waste.

- Predict mixture of S-112 and SY-101 waste in SY-101 tank.

Predicted three-dimensional temperature distributions indicate the occurrence of the coolest temperature along the tank wall, while the hottest temperature was predicted around the mid depth of the solid layers, away from the tank wall. Predicted maximum temperature of the SY-101 sludge is $80.4^{\circ} \mathrm{F}$, while the liquid layer has almost a uniform temperature, varying within a fraction of $1^{\circ} \mathrm{F}$. These values are close to those measured in July 2003, although there is considerable scatter and uncertainty in the measured temperatures.

The Tank SY-101 model predicted that temperature variation in the tank generates a natural convection having the following general flow pattern:

- moving from the tank center to tank wall near the waste surface

- moving down along the steel tank wall

- moving from the tank wall toward the tank center just above the sludge layer 
- moving upward near the tank center

- moving from the tank center toward the tank wall at around the $1 / 3$ liquid depth, producing a clockwise circulation

- moving upward above this circulation area.

The predicted natural convection flow is very slow; the maximum velocity of $0.013 \mathrm{ft} / \mathrm{sec}$ ( $50 \mathrm{ft} / \mathrm{hr}$ ) occurs along the tank wall. In most other areas of the convective layer the velocity varies from approximately $7 \times 10^{-5}$ to $1 \times 10^{-3} \mathrm{ft} / \mathrm{sec}(0.3 \sim 4 \mathrm{ft} / \mathrm{hr})$. Thus, the natural convection flow would eventually mix the liquid waste in SY-101, but it would be very slow to achieve near complete mixing.

While the S-112 waste was injected at a rate of $80 \mathrm{gpm}$, the mixture was removed through the transfer pump simulated in the Tank SY-101 model. Except for areas of direct passage of the S-112 waste jet, the velocity induced by the waste injection and natural convection is very small in most areas, about $1 \times 10^{-4} \mathrm{ft} / \mathrm{sec}(0.4 \mathrm{ft} / \mathrm{hr})$ to $2 \times 10^{-3} \mathrm{ft} / \mathrm{sec}(7 \mathrm{ft} / \mathrm{hr})$, so mixing is very slow.

After injecting 57,600 gallons (12 hours at $80 \mathrm{gpm}$ ) of S-112 waste having a density of 1.35 or $1.349 \mathrm{~g} / \mathrm{mL}$, a considerable variation in S-112 concentration existed within the tank. The predicted minimum S-112 concentration was 1 to $2 \%$ of the original waste concentration. Computed $\mathrm{NO}_{2}{ }^{-}, \mathrm{NO}_{3}{ }^{-}$, and $\mathrm{OH}^{-}$concentrations were 50,000 50,400, 135,000 136,000, and $16,800 \sim 16,900 \mu \mathrm{g} / \mathrm{mL}$, respectively. The waste being withdrawn by the transfer pump has an S-112 concentration of $6 \sim 7 \% 12$ hours after the waste injection began. At that time the $\mathrm{NO}_{2}{ }^{-}$, $\mathrm{NO}_{3}{ }^{-}$, and $\mathrm{OH}^{-}$concentrations in this mixed waste were 48,400 48,700, 139,000 140,000, and $16,600 \sim 16,700 \mu \mathrm{g} / \mathrm{mL}$, respectively.

After transfer of 115,200 gallons (one day at 80 gpm) of S-112 waste to Tank SY-101, the minimum S-112 concentration is expected to be only 11 to $12 \%$ of the original waste concentration. These concentrations correspond to $\mathrm{NO}_{2}{ }^{-}, \mathrm{NO}_{3}{ }^{-}$, and $\mathrm{OH}^{-}$concentrations of $46,700 \sim 47,000,143,000 \sim 144,000$, and 16,400 16,500 $\mu \mathrm{g} / \mathrm{mL}$, respectively. The waste withdrawn by the SY-101 transfer pump contains $20 \sim 22 \%$ of S-112 waste after one day. This waste would contains $43,400 \sim 44,000,151,000 \sim 153,000$, and 16,000 16,100 $\mu \mathrm{g} / \mathrm{mL}$.

When the much lighter S-112 waste with its density of $1.25 \mathrm{~g} / \mathrm{mL}$ was injected into Tank SY-101 at $80 \mathrm{gpm}$, the model predicted that the waste jet would hardly penetrate the SY-101 waste. Instead, it would spread horizontally on and around the liquid waste surface.

The minimum S-112 concentration after 12 hours of waste injection is predicted to be $0.08 \%$ of the original S-112 concentration. Thus, the waste there is basically the same as SY-101 waste, having $\mathrm{NO}_{2}{ }^{-}, \mathrm{NO}_{3}{ }^{-}$, and $\mathrm{OH}^{-}$concentrations of $49,000,138,500$, and $22,900 \mu \mathrm{g} / \mathrm{mL}$, respectively. Similarly, the waste being withdrawn by the SY-101 transfer pump has an S-112 concentration of $0.15 \%$. Its density is expected to be about the same as SY-101 $(1.35 \mathrm{~g} / \mathrm{mL})$. 
After one day of waste transfer, the strongly nonuniform distribution of S-112 waste has not changed much. For example, the S-112 waste concentration at the sludge surface directly below the injection point is still only $3 \%$. The minimum S-112 concentration after one day is expected to be $2.9 \%$. The waste withdrawn by the transfer pump contains only $3.3 \%$ of S-112 waste. This mixture contains $\mathrm{NO}_{2}{ }^{-}, \mathrm{NO}_{3}{ }^{-}$, and $\mathrm{OH}^{-}$concentrations of $47,700,140,000$, and $22,300 \mu \mathrm{g} / \mathrm{mL}$, respectively. Its density is also expected to be $1.347 \mathrm{~g} / \mathrm{mL}$, almost the same as the SY-101 waste.

If the incoming S-112 waste has a much smaller density than the SY-101 liquid waste, mixing in Tank SY-101 is very limited. A density of S-112 waste lower than $1.25 \mathrm{~g} / \mathrm{mL}$ would further stratify the S-112 waste from the SY-101 waste, resulting in less mixing.

These simulations indicate that the mixing of S-112 and SY-101 wastes in Tank SY-101 is a very slow process, and the greater density difference in the two wastes would further limit mixing. 


\subsection{References}

Enderlin CW, G Terrones, and C Bates. 2002. Final Test Report for S-112 Project Proof-ofPrinciple Tests at Cold Test Facility. RPP-10884 Rev. 0, prepared by Pacific Northwest National Laboratory for CH2M HILL, Richland, WA.

Felmy AR. 1995. "GMIN, A Computerized Chemical Equilibrium Program Using a Constrained Minimization of the Gibbs Energy: Summary Report." Chemical Equilibrium and Reaction Models. Special Publication 42, Soil Science Society of America.

Herting DL and DB Bechtold. 2002. Tank 241-S-112 Saltcake Dissolution Laboratory Test Report. RPP-10984 Rev. 0, Fluor Hanford Company, Richland, WA.

Harvie CE, JP Greenberg, and JH Weare. 1987. "A Chemical Equilibrium Algorithm for Highly Non-Ideal Multiphase Systems: Free Energy Minimization." Geochemica et Cosmochimica Acta, 51, 1045-1057.

Johnson GD, NW Kirch, RE Bauer, JM Conner, CW Stewart, BE Wells, and JM Grigsby. 2000. Evaluation of Hanford High-Level Waste Tank 241-SY-101. RPP-6517 Rev. 0, CH2M HILL Hanford Group, Inc., Richland, WA.

Onishi Y and DS Trent. March 1999. "Mobilization Modeling of Erosion-Resisting Radioactive Tank Waste." Proceedings of the Rheology in the Mineral Industry II, Kahuku, Oahu, Hawaii. United Engineering Foundation, New York, pp. 45-56.

Onishi Y, BE Wells, SA Hartley, and SK Cooley. May 2002. "Validation of the WASP Slurry Pipeline Model and Its Application to Hanford 241-SY-101 Waste Cross-Site Transfer." Proceedings of the DOE Tank Focus Area Technical Meeting on Saltcake Dissolution, Waste Chemistry, and Transport. U.S. Department of Energy, Richland WA.

Onishi Y. 2002. Reactive Transport Modeling Approach and Initial Saltcake Dilution Chemical Modeling. PNNL-14118, Pacific Northwest National Laboratory, Richland, WA.

Reynolds DA. 1992. Tank 101-SY Window C Core Sample Results and Interpretation. WHC-EP-0589, Westinghouse Hanford Company, Richland, WA. 
PNNL-14399

\section{Distribution}

No. of

Copies

Offsite

D. I. McLean

Department of Civil and Environmental Engineering

Washington State University

Pullman, WA 99164

\section{Onsite}

3 DOE Richland Operations Office

JJ Davis

CA Groendyke

DH Irby

H6-60

H6-60

H6-60

31 CH2M HILL Hanford Group, Inc.

WB Barton (6)

RE Bauer (3)

JR Biggs

MH Brown

JR Buchanan

RJ Cash

JW Cammann

PJ Certa

A-MF Choho
R2-11

S7-73

S7-07

S5-07

R4-05

$\mathrm{S} 7-73$

T4-08

R3-73

R3-73
No. of

Copies

JM Conner

R2-11

DW Crass

S7-90

PW Gibbons

K9-91

CE Hanson

S7-70

DL Herting

T6-07

NW Kirch

R2-11

MR Koch

S7-83

DC Lowe

R2-58

TC Oten

S5-07

DA Reynolds

R2-11

RL Schlosser

R1-14

SL Swaney

S7-24

WT Thompson

S7-90

JE Van Beek

R3-47

WF Zuroff

37 Pacific Northwest National Laboratory

SQ Bennett

K7-90

JL Huckaby

K7-15

LA Mahoney (5)

K7-15

TE Michener

K7-15

Y Onishi (20)

K7-15

CW Stewart

K7-15

WC Weimer

K9-09

BE Wells (5)

K7-15

Information Release (2)

K1-06 